\title{
Implementação de um Fragmento TSQL2 para Bancos de Dados de Tempo de Validade
}

Loreley Zavattiero

\author{
Dissertação submetida em cumprimento \\ parcial dos requisitos para obtenção do grau de \\ Mestre em Matemática Aplicada.
}

\author{
Área de Concentração: Ciência da Computação \\ Orientador: Prof. Dr. Marcelo Finger
}

(A autora recebeu apoio financeiro da CAPES durante a elaboração deste trabalho)

Instituto de Matemática e Estatística da USP

- São Paụlo, dezembro de 1998 


\section{Implementação de um Fragmento TSQL2 para Bancos de Dados de Tempo de Validade}

Este exemplar corresponde à versão final da dissertação apresentada por Loreley Zavattiero e aprovada pela comissão julgadora.

São Paulo, dezembro de 1998.

Banca Examinadora:

Prof. Dr. Marcelo Finger (Orientador) IME - USP

Prof. Dr. Mário Nascimento IC - UNICAMP

Prof. Dr. Flávio Soares Corrêa da Silva IME - USP 


\title{
Implementação de um Fragmento TSQL2 para Bancos de Dados de Tempo de Validade
}

\author{
por Loreley Zavattiero
}

\section{Resumo}

Esta tese propõe o projeto de incorporação de tempo de validade a um Banco de Dados não-Temporal através da implementação de uma Camada Temporal sobre o mesmo.

Em projetos semelhantes, encontrados na literatura, não foram utilizados Sistemas de Bancos de Dados Comerciais em conjunto com a linguagem de consenso, TSQL2. Outro diferencial é a utilização de elemento temporal como tipo de marca de tempo, raramente adotado nos outros projetos.

Neste trabalho são identificados os pontos fortes e as fraquezas da TSQL2, dentro do fragmento sełecionado para implementação. Se, por um lado, a linguagem permite a construção de sentenças que manipulem a dimensão tempo de forma intuitiva, por outro, em alguns casos, dificulta a construção de cláusulas que expressem corretamente a semâncica desejada.

Conclui-se que, as decisões feitas durante o desenvolvimento (tipo e representação interna da marca de tempo, estruturas de dados, método de acesso ao banco, etc), podem, ou não, limitar a flexibilidade e a performance da camada temporal, bem como o tipo de aplicação capaz de utilizá-la. 


\title{
A TSQL2 Fragment Implementation for Valid Time Databases
}

by Loreley Zavattiero

\begin{abstract}
This work proposes the construction of valid time support to a Snapshot Relational Database through the implementation of a Temporal Layer between the user and the Database System.

In the literature, we have not found Comercial Databases and also the consensus language, TSQL2, being used all together. Additionally the use of temporal element as a timestamp format was rarely adopted in other related projects.

In this work it is identified the strong and also the weak points of TSQL2 within the selected fragment implemented. Although the language allows the construction of sentences that manipulate the time dimension in an intuitive way, in some occurences it turns this construction very complex and difficult to rightly express the desired semantic.

Besides all, the decisions made during the development phase (timestamp type and internal representation, data structure, database system access method, etc), may, or may not, restrict the flexibility and also the performance of the temporal layer, as well as the kind of applications able to use it.
\end{abstract}


"Dedico este trabalho àqueles que são meus pelo sangue e àqueles que são meus pelo coração."

Autor Anônimo 


\section{AGRADECIMENTOS}

Ao meu orientador e amigo, Prof. Dr. Marcelo Finger, pela dedicação e disposição com que me orientou neste trabalho, e pela amizade com que sempre me considerou.

Ao Flávio Soares e Mário Nascimento pelas críticas e elogios atribuídos ao trabalho.

À minha mãe por todo apoio e doces de incentivo dados a cada instante.

Ao meu pai pelos comentários em castelhano deixados no meio do texto e pelas discussões intermináveis.

Aos meus irmãos, Mariano e Carolina, pela paciência dispendida desde o início do trabalho.

Ao meu namorado, Marcelo, pelas observações, dicas de programação e por ter me agüentado nas crises.

Ao meu amigo Eduardo, pela força, atenção e companheirismo.

À CAPES, pelo apoio financeiro concedido.

A todos os funcionários do IME, que com o seu trabalho contribuíram, direta ou indiretamente, para a realização do meu.

A todos os professores, amigos e colegas de aula e trabalho, pela compreensão dispendida no decorrer desta jornada.

A você, leitor, pelo seu interesse neste trabalho. 
ÍNDICE

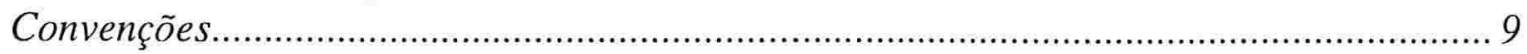

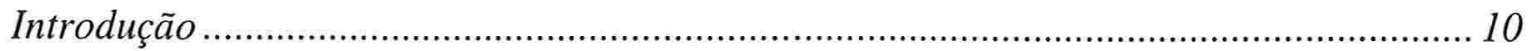

I. Embasamento Teórico.....................................................................................14

I.1. O modelo de Tempo .........................................................................................................................15

I.2. Associando Fatos com o Tempo ........................................................................................17

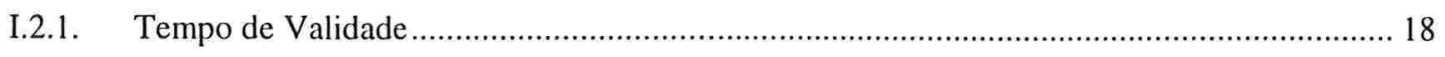

I.2.2. Tempo de Transação ……………………………..................................................... 19

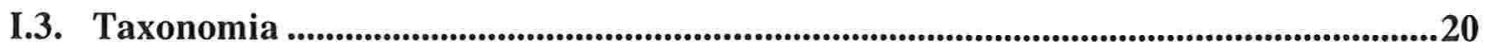

I.3.1. Ilustração para Bancos de Dados Bitemporais .................................................................... 22

I.3.2. Limitações de um Banco de Dados de Tempo de Transação.................................................... 26

I.3.3. Limitações de um Banco de Dados de Tempo de Validade.................................................. 27

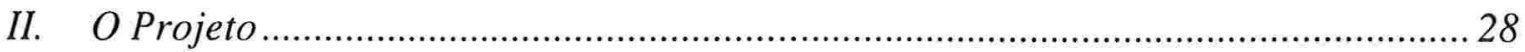

II.1. Outros Projetos .............................................................................................................................30

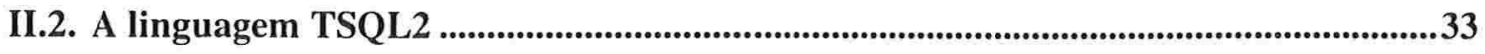

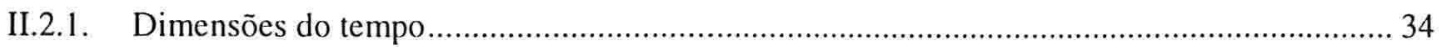

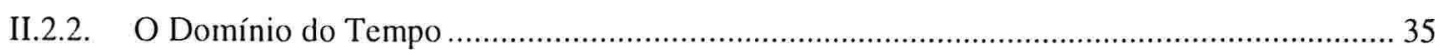

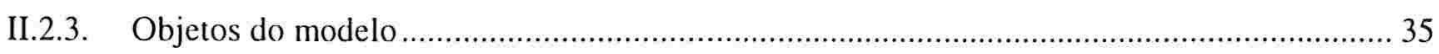

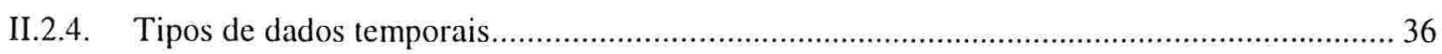

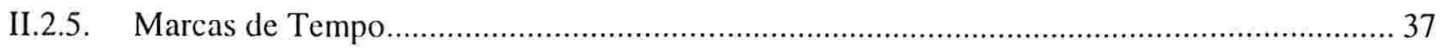

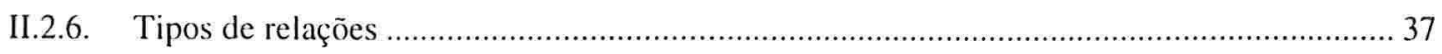

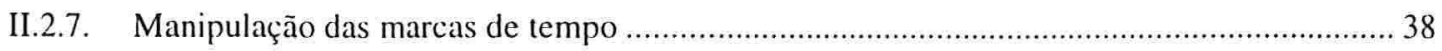

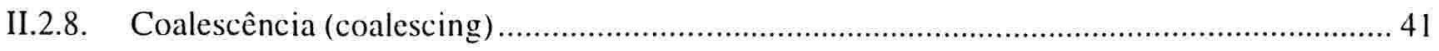




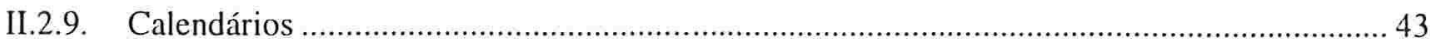

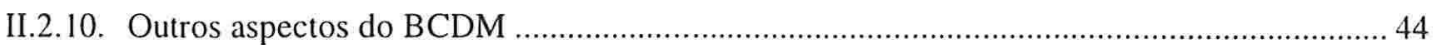

II.2.11. Fragmento TSQL2 selecionado para implementação ................................................ 45

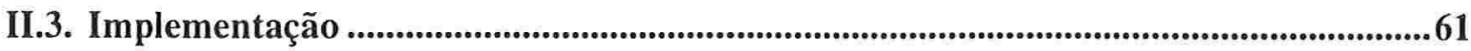

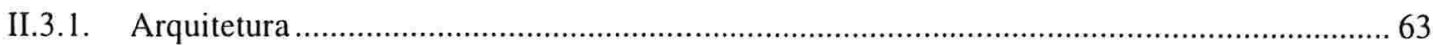

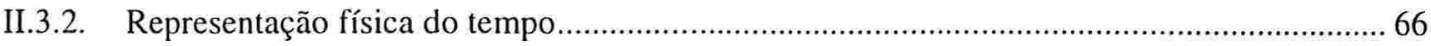

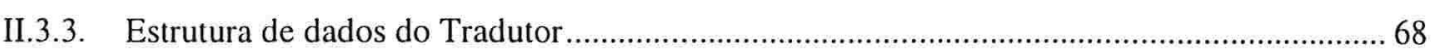

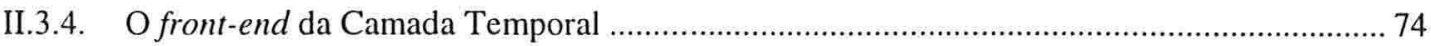

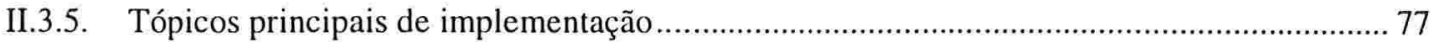

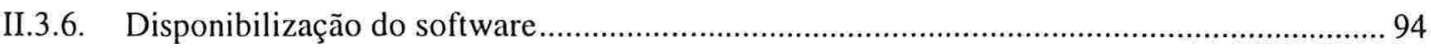

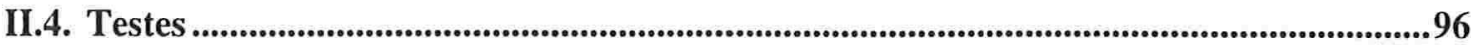

II.4.1. Conclusões dos Testes ............................................................................................... 108

II.5. Conclusões...................................................................................................... 109

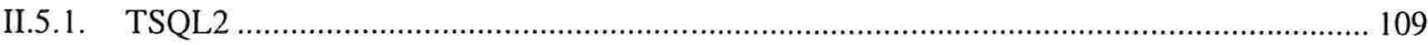

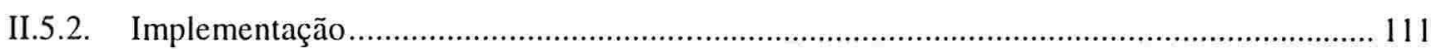

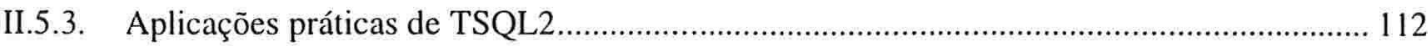

II.5.4. Sugestão de futuros trabalhos .............................................................................. 114

Glossário .................................................................................................. 115

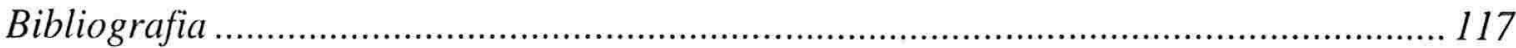

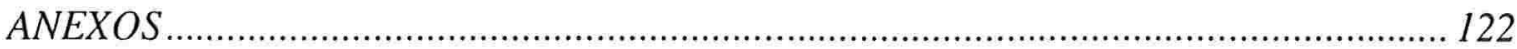

Anexo A. TESTES REALIZADOS SOBRE A CAMADA TEMPORAL ..................... 123

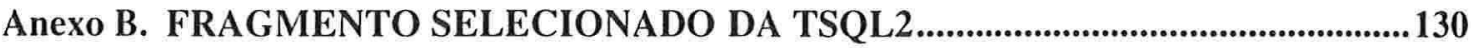




\section{Convenções}

Seguem as convenções utilizadas neste documento:

\begin{tabular}{|l|l|}
\hline \multicolumn{1}{|c|}{ Texto } & \multicolumn{1}{|c|}{ Convenção } \\
\hline Comandos TSQL2 & - Times New Roman \\
& (p.ex. PERIOD) \\
\hline Palavras estrangeiras & - Itálico \\
& (p.ex. scripts) \\
\hline Nomes de tabelas & - COURIER NEW \\
& (p.ex. DEPT) \\
\hline Nomes de colunas & - Courier New \\
& (p.ex. Name) \\
\hline Valores de colunas & - Courier New \\
& (p.ex. Di) \\
\hline Regras & (p.ex. tempo de validade) \\
\hline
\end{tabular}

No caso das palavras estrangeiras estarem referenciando nomes de tabelas, serão escritas com o padrão dado aos nomes de tabelas, ou seja Courier New, Maiúsculas. 


\section{Introdução}

A complexidade das aplicações modernas exige que consultas cada vez mais expressivas sejam respondidas por seus sistemas de software. Um analista financeiro não mais quer saber a rentabilidade de certa área, mas sim um comparativo entre as rentabilidades das áreas da empresa, por exemplo, nos últimos cinco anos. A diferença entre as duas consultas é o número de dimensões. A segunda, ao contrário da primeira, requer que a dimensão rentabilidade da área seja avaliada em função da dimensão tempo.

Uma grande variedade de aplicações, entre elas, contábeis, bancárias, de controle de estoque, de reservas de vôos, de análise de tendências, de apoio à decisão, de sistemas de informação geográfica, de recursos humanos e de manufatura, precisam analisar a evolução das informações em função do tempo [23].

A razão desta necessidade está no fato de que o tempo é um importante foco de interesse. Eventos ocorrem em determinados pontos do tempo, relações entre objetos existem em períodos do tempo, verdades valem por períodos de tempo, podendo tornar-se falsas devido a outros eventos que ocorrem em outros pontos do tempo.

No dia-a-dia usa-se o tempo quase que imperceptivelmente ao marcar reuniões, ao se celebrar o aniversário de namoro, ao se recordar como se pensava nos anos 60. Apesar de ser uma dimensão manipulada muito facilmente pelas pessoas, uma série de complicações surgem quando se tenta tratá-la de forma computacional.

Tanto ferramentas para armazenamento quanto para manipulação de dados temporais são bastante limitadas. Os Bancos de Dados Relacionais [9], repositórios de dados mais comumente usados, são Estáticos, já que modelam apenas versões estáticas (snapshots) da realidade que chamaremos de Universo de Discurso. Tome-se como exemplo uma relação com os atributos NOME e CARGO em que uma das instâncias é João, Trainee. Se João for promovido para Senior, a informação de que João foi Trainee em algum momento no tempo se perde, e a única informação válida é a de que João é Senior. Similarmente, as linguagens de consultas a esses bancos de dados são bastante 
inadequadas quando se quer informações que envolvam o aspecto temporal. Essas linguagens, como o padrão SQL-92 [24], não possuem operadores temporais, forçando a manipulação do tempo de forma explícita e pouco natural, tornando as consultas extremamente complexas. Exemplos de como podem ser complexas consultas temporais feitas por uma linguagem de consulta não temporal estão em II.4. A necessidade da manipulação de dados temporais exige que cada aplicação implemente esse suporte ad hoc. Mecanismos artificiais como arquivos de log, backups e checkpoints são utilizados.

Inerente à modelagem computacional do tempo está a existência intrínsica de duas dimensões temporais. São elas o tempo de validade, correspondente ao tempo em que o dado é verdadeiro no Universo de Discurso, e o tempo de transação, correspondente ao tempo em que o dado estava inserido no Banco de Dados [23]. É interessante notar que essas dimensões são ortogonais já que um mesmo evento pode estar associado a ambas dimensões. De fato, na relação de atributos NOME, CARGO, TEMPO DE VALIDADE, TEMPO DE TRANSAÇÃO, a instância João, Sênior pode ter tempo de validade anterior ao tempo de transação caso a informação tenha sido inserida no Banco de Dados posteriormente a sua ocorrência no Universo de Discurso.

A partir dessas duas dimensões, definem-se quatro tipos de Bancos de Dados [36]: Banco de Dados de Tempo de Validade, que dá suporte apenas ao tempo de validade, Banco de Dados de Tempo de Transação, que só dá suporte ao tempo de transação, Banco de Dados Estático, que não dá suporte a nenhum dos tipos de tempo e o Banco de Dados Bitemporal que dá suporte aos dois tipos.

O primeiro tratamento acadêmico do tempo em Bancos de Dados foi em 1956, onde Frederic Brooks Jr. propôs uma visão tridimensional (tempo, atributos e tuplas) de bancos de dados históricos, como citado em [22]. Em 1979 é definida a primeira linguagem de consulta, a LEGOL 2.0, com suporte à junção temporal, seleção temporal e agregação temporal, como citado em [22]. Na década de 80, muitos trabalhos em modelagem conceitual surgiram, paralelamente à exploração do tempo de transação. Várias linguagens temporais associadas a seus modelos de dados proliferaram. No início da década de 90, continua a dar-se ênfase ao desenho de bancos de dados temporais, linguagens de consulta, aspectos de implementação e otimização de consultas [22]. As 
experiências de quinze anos de um grupo de pesquisadores da área, é consolidada, em 1994, na especificação da TSQL2 [36], baseada na linguagem padrão SQL-92. Esta linguagem é baseada no modelo de dados BCDM (Bitemporal Conceptual Data Model), um modelo de dados bitemporal [36].

O objetivo deste trabalho é a implementação de parte da TSQL2, como linguagem de consulta temporal, extendendo a funcionalidade de um Banco de Dados Estático. Com isto, estaria se incorporando suporte temporal ao Banco de Dados Estático. Devido à amplitude da área, optou-se por focar nosso interesse em Bancos de Dados de Tempo de Validade. O suporte ao tempo de validade é incorporado através desta Camada, que aceita sentenças em TSQL2, traduz para a linguagem do Banco, e processa o resultado. No trabalho serão expostas facilidades e problemas de se manipular dados temporais com a TSQL2, a qual possui uma série de ferramentas intuitivas para lidar com o tempo. Da mesma forma, são apontadas as penalidades impostas pela linguagem às consultas estáticas bem como as dificuldades de se gerar sentenças temporais com a semântica correta. Conclui-se então que, apesar da TSQL2 servir como base para trabalhos na área, não se trata da palavra final. Durante o detalhamento da implementação, são estudados alguns aspectos técnicos como a representação do tempo e seu armazenamento.

No capítulo I é apresentada toda a teoria necessária para contextualizar o projeto detalhado no capítulo II.

Em I.1 é apresentado o modelo do tempo assumido para o tempo de validade. Em I.2 explica-se que a associação do tempo aos fatos resulta na bifurcação do tempo em duas dimensões: os tempos de validade e transação. Finalmente em I.3 descreve-se a taxonomia mais comumente utilizada para Bancos de Dados Temporais e os conceitos abordados são revistos em um exemplo ilustrativos.

Um panorama geral do projetos implementados é apresentada em II.1. Em II.2 parte do modelo de dados em que a linguagem TSQL2 é explorada bem como algumas de suas características principais. Em II.3 é abordada a implementação da Camada Temporal onde são destacados a arquitetura, o tradutor e o front-end. A disponibilização do software se encontra em II.3.6. Em II.4 são elaborados alguns testes ressaltando algumas 
facilidades e deficiências da TSQL2. As conclusões e sugestões de trabalhos futuros estão em II.5.

Em Anexo alguns testes, definidos pelo próprio comitê de criação da TSQL2, que foram aplicados à Camada (Anexo A) e o fragmento implementado (Anexo B).

Este trabalho é produto do estudo de parte de uma área sendo pesquisada há bastante tempo, porém não amplamente aceita pelo mercado. Atualmente não existe nenhum Banco de Dados Temporal Comercial.

A leitura do texto pressupõe familiaridade com conceitos básicos de Sistemas de Bancos de Dados conforme descrito em [9, 13]. 


\section{Embasamento Teórico}

O objetivo desta seção é o de fornecer um panorama da área de Bancos de Dados Temporais, de forma a facilitar a contextualização do projeto. Não é pretensão explorar toda a teoria da área, mas sim, o suficiente para contextualizar o projeto.

A primeira seção tem por foco o modelo de tempo propriamente dito para, em seguida, ser associado aos fatos no capítulo I.2, constituindo a modelagem das informações temporais. Em I.3, a taxonomia adotada neste trabalho é apresentada através de ilustrações dos vários conceitos.

Ao fim desta seção, o leitor terá os conceitos necessários para o entendimento do projeto, detalhado na seção II. 


\section{I.1. O modelo de Tempo}

Antes de iniciar, é preciso definir qual modelo de tempo a ser utilizado, para então relacionar fatos com o tempo e a partir daí abordar a teoria em que está inserido o projeto. Por ontologia, entende-se o estudo da natureza do tempo, ou seja, o estudo dos modelos do fluxo de tempo. A ontologia do tempo é bastante complexa, sendo objeto de estudo da filosofia e da lógica temporal [11]. Não é pretensão deste trabalho explorar esta área mas sim, explicar o modelo de tempo utilizado pela área de Banco de Dados Temporal.

Não há consenso em relação à linha do tempo ser contínua ou discreta, mas há consenso no fato da discreta ser a forma mais adequada para a modelagem computacional e representação do tempo [34]. O modelo de tempo a ser utilizado, portanto, é linear e discreto.

A característica linear garante que o tempo avance do passado para o futuro passo a passo. Uma outra possibilidade pode ser o modelo ramificado o qual é linear do passado até o presente onde se divide em várias linhas do tempo, representando as possíveis sequências de eventos [37]. Aplicações de controle de versão utilizam este modelo.

A natureza do tempo é discreta, o que o torna isomorfo ao conjunto dos números inteiros, implicando que cada ponto no tempo possui um sucessor e antecessor único. No modelo discreto, cada número natural corresponde a uma unidade do tempo indivisível com duração arbitrária, denominada chronon [23]. Um dos motivos em se utilizar o modelo discreto é o fato de que medidas do tempo são imprecisas, ou seja, os instrumentos para a medição do tempo a fazem em termos de chronons e não pontos do tempo.

A Figura 1 mostra que, independentemente da linha do tempo ser contínua, densa ou discreta, será visualizada de forma discreta, ou seja, como uma sequência ordenada de chronons. 
Imagem discreta do tempo

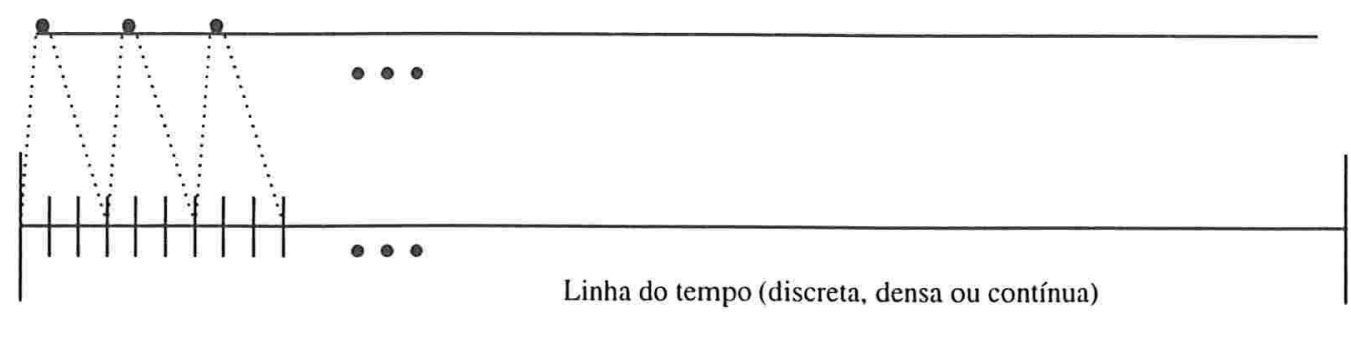

Big Bang

Big Crunch

\section{Figura 1 - Modelo do Tempo}

As caracterizações abordadas neste capítulo, aplicam-se às duas dimensões do tempo apresentadas adiante, a saber a de validade e a de transação. 


\section{I.2. Associando Fatos com o Tempo}

Utilizando o modelo de tempo abordado em I.1, apresentam-se as duas dimensões de tempo que estão associadas a um fato armazenado em um Banco de Dados.

Para ilustrar, tome-se como exemplo a Expansão Marítima que iniciou no ano de 1415 com os Portugueses. O ano 1415 corresponde ao início do tempo de validade da informação, ou seja, o tempo em que o fato (Expansão Marítima) começou a ser verdadeiro no Universo de Discurso.

Suponha-se, agora, que em 1997 é criado um Banco de Dados com todas as informações históricas. O ano 1997 corresponde ao início do tempo de transação, tempo em que a informação (Expansão Marítima) estava no sistema.

Como mostra a Figura 2, o tempo bifurca-se em duas dimensões no exato momento em que a informação é inserida no sistema. Isto porque ao inserirmos os dados no computador, têm-se os fatos "vistos" pela ótica do Universo de Discurso e pela ótica do sistema.

Universo de Discurso

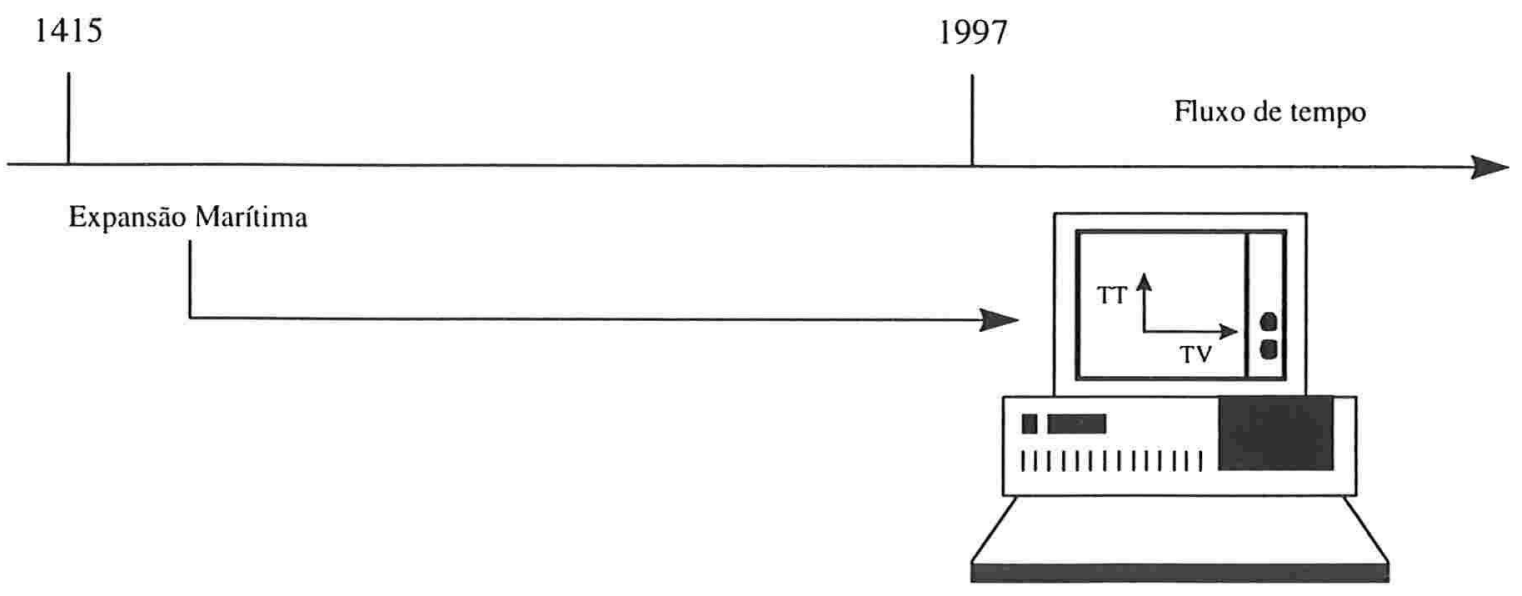

Figura 2 - As duas dimensões do tempo 
Como cada fato pode ser associado aos dois conceitos de tempo, diz-se que são ortogonais. O tempo de validade é uma dimensão manipulada pelo próprio usuário. $\mathrm{O}$ tempo de transação é o tempo em que o fato foi inserido no sistema, independentemente do tempo em que foi válido. É uma dimensão manipulada pelo próprio Banco de Dados.

Confundir as dimensões do tempo associadas a um evento com simples atributos não é difícil. Isto acontece porque as dimensões serão forçosamente representadas como atributos, dada a limitação dos Bancos de Dados Estáticos (apresentados mais adiante). A diferença está na interpretação. Os atributos "normais" possuem uma representação interna e funções de entrada e saída; já os atributos "temporais" são interpretados pelo Banco de Dados, de forma a relacionar o evento modelado pelos atributos "normais" com as dimensões temporais representadas pelos atributos "temporais". Esta diferenciação ficará mais clara quando se detalhe a processamento das consultas TSQL2 (II.3).

\section{I.2.1. Tempo de Validade}

Como já foi mencionado, o tempo de validade corresponde ao tempo durante o qual um dado é verdadeiro no Universo de Discurso e, portanto, precisa ser definido pelo próprio usuário.

Dar suporte a este conceito de tempo não é trivial, pois exige operações complexas para que sua semântica seja manipulada corretamente, como será visto na seção de Implementação.

Tomemos a afirmação: “João ficou no departamento de Finanças de Jan97 até Jan98”. Ao fato "João pertence ao departamento de Finanças" está associado o tempo de validade representado pelo período "Jan97 - Jan98” como mostra a Relação 1.

\begin{tabular}{|l|l|l|}
\hline \multicolumn{1}{|c|}{ Nome } & \multicolumn{1}{|c|}{ Departamento } & \multicolumn{1}{c|}{ Tempo de Validade } \\
\hline João & Finanças & Jan97-Jan98 \\
\hline
\end{tabular}

Relação 1 


\section{I.2.2. Tempo de Transação}

O tempo de transação corresponde ao tempo em que o dado foi inserido e aceito (commit) pelo Banco de Dados. Ao contrário do tempo de validade, sua semântica não está relacionada com o Universo de Discurso, mas com as transações executadas no Banco. Dar suporte a este tipo de tempo é mais simples do que ao tempo de validade.

Utilizando a Relação 1, suponhamos que a informação de que "João pertence ao departamento de Finanças" foi inserida no Banco em "Mar97". O tempo de transação do fato "João pertence ao departamento de Finanças" é "Mar97 - UC" como está explicitado na Relação 2. A sigla UC significa Until Change, e portanto, a informação continua válida no Banco até que alguma alteração seja feita. Sua determinação e manipulação não é nada trivial como é descrito em [36]. Não faz parte do escopo do trabalho entrar em detalhes sobre este assunto.

\begin{tabular}{|l|l|l|l|}
\hline \multicolumn{1}{|c|}{ Nome } & \multicolumn{1}{|c|}{ Departamento } & \multicolumn{1}{c|}{ Tempo de Validade } & \multicolumn{1}{c|}{ Tempo de Validade } \\
\hline João & Finanças & Jan97-Jan98 & Mar97-UC \\
\hline
\end{tabular}

\section{Relação 2}

Na seção a seguir é apresentada a taxonomia gerada pela bi-dimensionalidade do tempo. 


\section{I.3. Taxonomia}

É importante ressaltar que as duas dimensões sempre existem, independentemente do seu armazenamento ou não. A taxonomia apresentada a seguir baseia-se na capacidade de manipular os tempos de validade e transação [15].

\begin{tabular}{|l|l|l|}
\hline & \multicolumn{1}{|c|}{ Tempo de Transação } & \multicolumn{1}{c|}{ Tempo de Validade } \\
\hline BD Estático & & \\
\hline BD de Tempo de Transação & $\mathrm{x}$ & \\
\hline BD de Tempo de Validade & & $\mathrm{x}$ \\
\hline BD Bitemporal & $\mathrm{x}$ & $\mathrm{x}$ \\
\hline
\end{tabular}

Figura 3 - Taxonomia de Bancos de Dados Temporais

Como mostra a Figura 3 temos:

- Banco de Dados Estático: A maioria dos bancos convencionais são estáticos, ou seja, não dão suporte nem ao tempo de validade, nem ao tempo de transação. Cada instância ou estado do banco é representado pelo conjunto de dados corrente, que não necessariamente reflete as informações do mundo real. Toda vez que uma alteração é feita nos dados, um novo estado, refletindo essas alterações, sobrescreve-se ao anterior. O conjunto de dados das relações corresponde a uma fotografia, em dado instante, do Universo de Discurso.

A Relação 3 é uma relação estática e representa o fato de que "João é Trainee".

\begin{tabular}{|l|l|}
\hline \multicolumn{1}{|c|}{ Nome } & \multicolumn{1}{c|}{ Cargo } \\
\hline João & Trainee \\
\hline
\end{tabular}

Relação 3

Se "João é promovido a Senior" após dois anos de serviço, o novo estado da relação correspoderá ao apresentado na Relação 4. 


\begin{tabular}{|l|l|}
\hline \multicolumn{1}{|c|}{ Nome } & \multicolumn{1}{c|}{ Cargo } \\
\hline João & Senior \\
\hline
\end{tabular}

\section{Relação 4}

A informação de que "João foi Junior" se perde.

Como se vê, os Bancos de Dados Estáticos são deficientes no que diz respeito à manipulação de dados que variam com o tempo. Assim, toda vez que for necessário manipular informações dependentes do tempo, fica sob responsabilidade da própria aplicação esta implementação.

- Banco de Dados de Tempo de Transação: uma forma de eliminar a limitação apresentada no item anterior, é armazenando os estados passados indexados pelo tempo. Isso é possível se o Banco der suporte ao tempo de transação, caracterizandose como um Banco de Dados de Tempo de Transação. Desta forma o Banco fica habilitado a "responder perguntas" sobre eventos passados. Cada vez que uma mudança ocorre, a nova informação é concatenada às anteriores, permitindo a manutencão dos estados passados. Em um Banco de Dados de Tempo de Transação, não existe eliminação física de informações e portanto, os dados não podem ser alterados. Esta característica é bastante cabível, pois se está armazenando o histórico das atividades, das transações do banco, e estas aconteceram, independentemente do evento ao qual se referem. O Banco de Dados de Tempo de Transação é incapaz de corrigir erros. De fato, se a promoção de João tivesse sido um erro, a nova informação: "João é na verdade Trainee", seria concatenada, mantendo-se a informação errada de que "João foi Senior".

- Banco de Dados de Tempo de Validade: a deficiência apresentada no item anterior pode ser eliminada se o histórico dos eventos do Universo de Discurso for armazenado. Para isso, é preciso incorporar suporte ao tempo de validade a um Banco de Dados, tornando-o um Banco de Dados de Tempo de Validade. Neste tipo de Banco, correções são efetuadas com a eliminação dos dados falsos. Se a promoção de João tiver sido um erro, a informação de que "João foi Senior" será fisicamente eliminada do Banco. 
- Banco de Dados Bitemporal: os Bancos Bitemporais dão suporte, tanto ao tempo de validade, quanto ao tempo de transação, acumulando desta forma, as vantagens dos Bancos de Dados de Tempo de Transação e de Tempo de Validade.

Bancos de Dados que dão suporte a quaisquer das duas dimensões são chamados de Temporais.

A escolha do tipo de Banco depende do tipo de aplicação a ser implementada. Aplicativos de controle de versão utilizariam Bancos de Dados de Tempo de Transação, enquanto que os que manipulam históricos de funcionários utilizariam Bancos de Dados de Tempo de Validade. Claramente, o Banco Bitemporal seria usado quando houvesse a necessidade de consultas bitemporais.

A seguir, os conceitos aprendidos até aqui são ilustrados através da apresentação das alterações feitas por uma sequência de eventos, sobre um Banco de Dados Bitemporal. Apesar do foco do trabalho ser o tempo de validade, a utilização de um Banco de Dados Bitemporal como exemplo, permite um melhor entendimento do contexto em que está inserido o projeto, bem como suas limitações.

\section{I.3.1. Ilustração para Bancos de Dados Bitemporais}

Nesta seção, são mostradas como as mudanças em uma informação são representadas em um Banco de Dados Bitemporal. Várias alterações nas informações serão propostas com o intuito de fixar os dois conceitos de tempo. Em seguida, são explicitadas as limitações de não se armazenar alguma das dimensões temporais.

As duas dimensões temporais podem ser representadas em um gráfico no qual o eixo $X$ corresponde ao tempo de validade e o eixo $Y$ ao tempo de transação [32] . A bissetriz corresponde ao agora (now) já que é formada pelos pontos em que o tempo de validade é igual ao tempo de transação.

Suponha-se que uma empresa queira armazenar o histórico de seus funcionários e, para isso, utilize um Banco de Dados Bitemporal. Seja João um novo funcionário:

- "João é contratado como Trainee". A Figura 4 mostra como este fato é representado em função dos dois conceitos de tempo. O período entre parênteses (Jan97-Jan98) 
corresponde ao tempo de validade, ou seja, período em que o fato é válido no Universo de Discurso. O período logo abaixo [Jul97 - UC] corresponde ao tempo de transação, ou seja, tempo em que a informação é válida para o sistema. As duas setas mostram que a tupla não foi logicamente deletada e permanece válida UC (until change). A interpretação do gráfico é: A informação de que "João é Trainee" é válida, no Universo de Discurso, de Janeiro de 97 a Janeiro de 98, é "conhecida" pelo sistema a partir de Julho de 97.

Os conceitos e definições irão tornar-se mais claros à medida que novos eventos forem acontecendo.

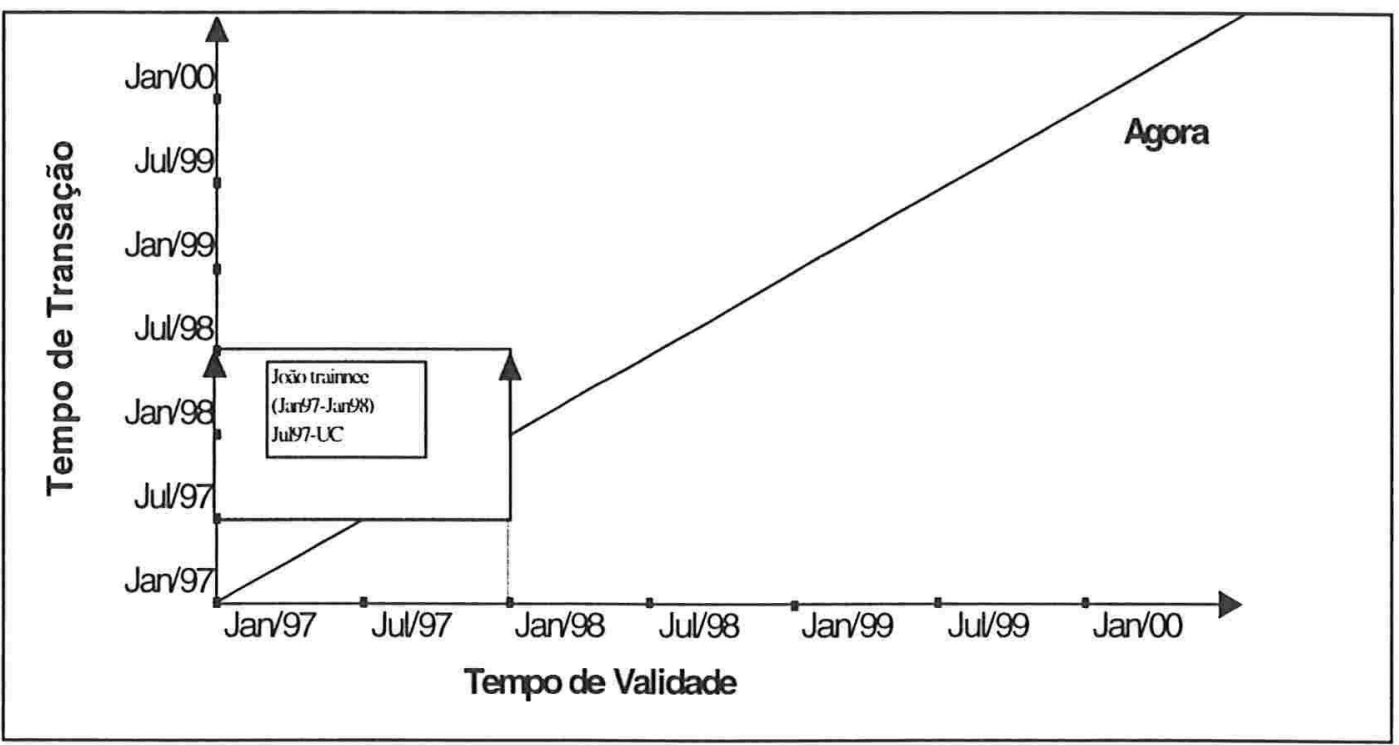

Figura 4 - João é Trainnee

- "João é promovido a Senior". Em Janeiro de 98 João é promovido a Senior, permanecendo na categoria até Janeiro de 99. Essa informação é inserida no Banco em Julho de 98 e permanece válida UC. A informação de que "João é Trainee" é logicamente eliminada, como mostra a Figura 5, já que para o Banco, a informação atualmente correta é a de que "João é Senior". 


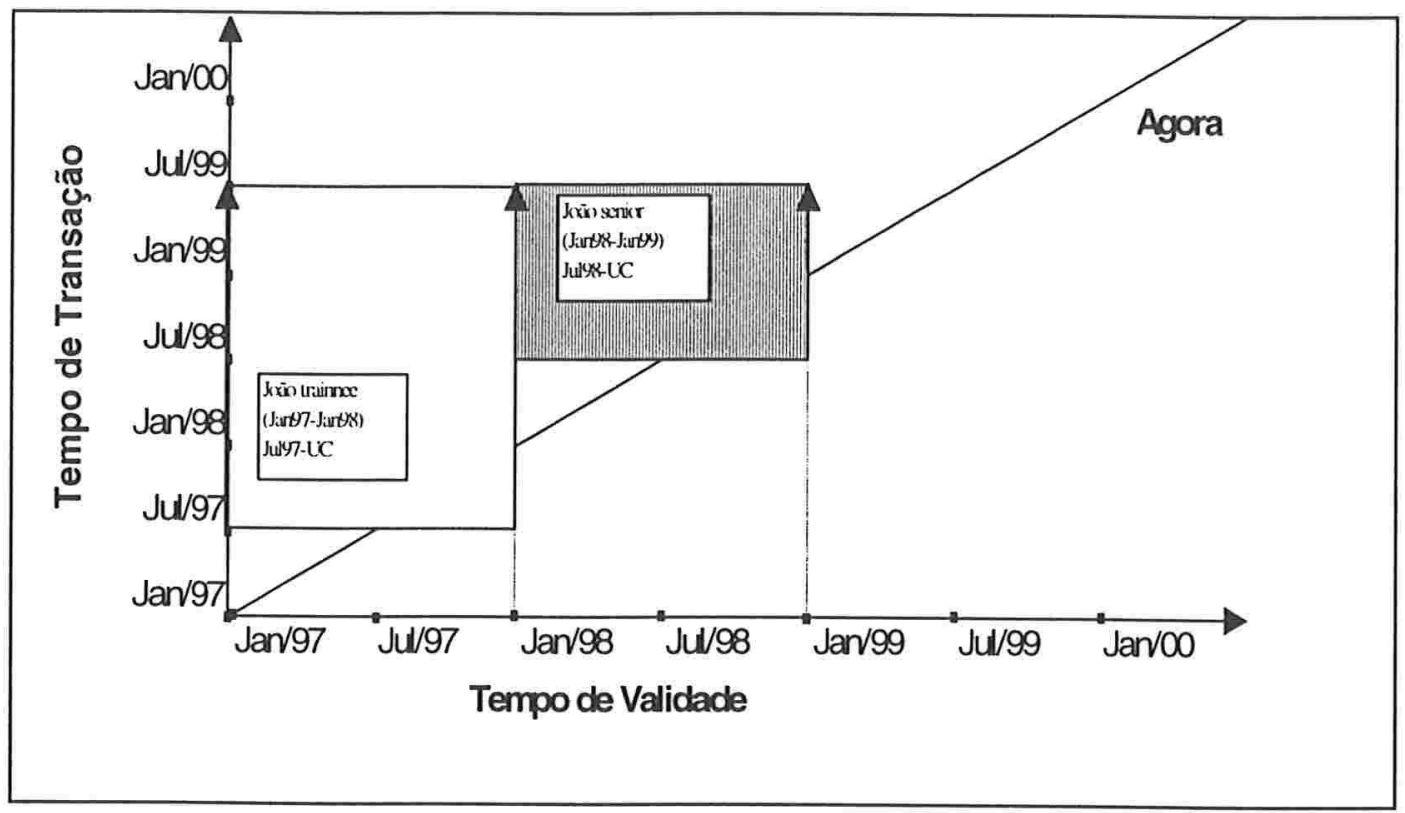

Figura 5 - João é promovido a Senior

- "João deveria ter sido promovido a Junior". Descobre-se um erro: João deveria ter sido promovido a Junior e não a Senior. Em Janeiro de 99, é inserida a informação de que "João é Junior"; esse fato é verdadeiro no Universo de Discurso desde Janeiro de 98 até Janeiro do ano 2000. A informação errada (João é Senior) é eliminada logicamente do Banco como mostra a Figura 6. O retângulo com hachura vertical mostra que a informação de que "João é Senior" foi válida no Banco desde Janeiro de 98 a Janeiro de 99 .

Porque armazenar o erro? Suponha-se que em Janeiro do ano 2000 se queira saber porque João recebeu salário de Senior em Setembro de 98, se ele é Junior. Bastaria "voltar no tempo" para verificar que em Setembro de 98 pensava-se que João era Senior. Esta recuperação de informação só é possível se a eliminação for lógica, ou seja, se o Banco der suporte ao tempo de transação. 


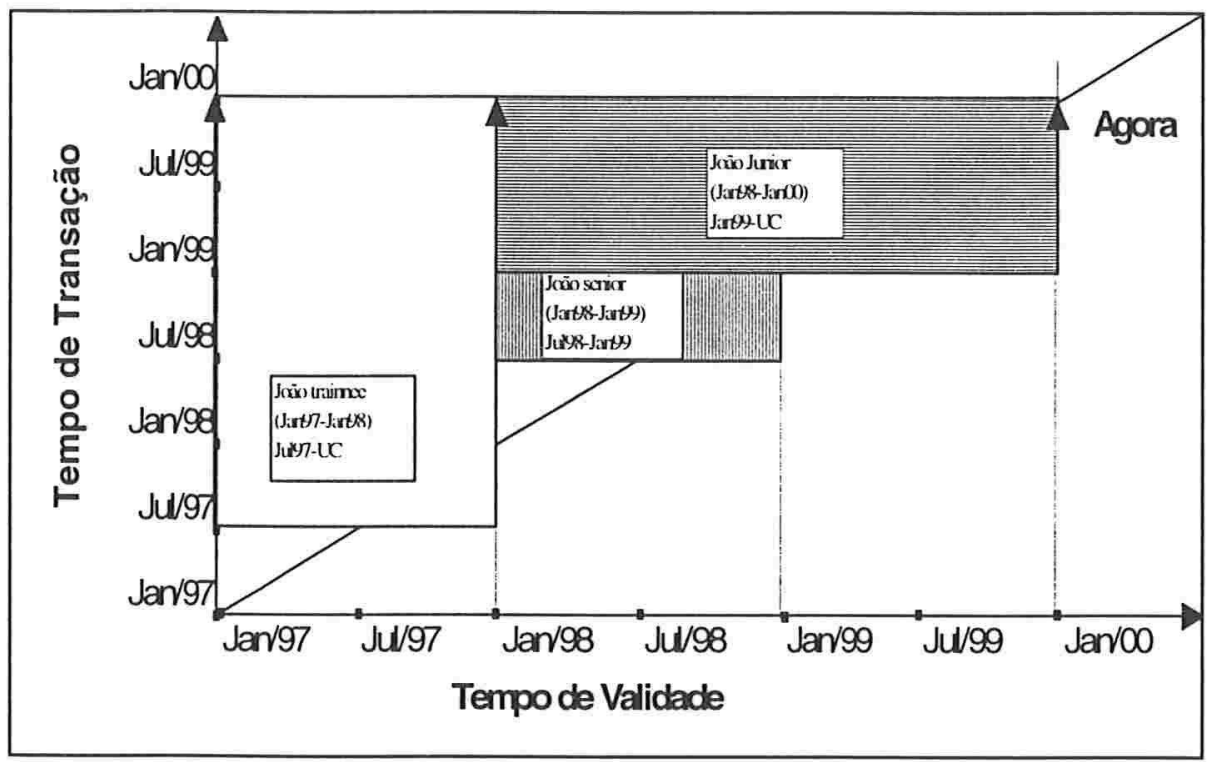

Figura 6 - João deveria ter sido promovido a Junior

- "João recebe promoção retroativa". João é tão bom funcionário que recebe uma promoção ao cargo de Pleno, retroativa a Janeiro de 99. Essa informação é inserida no Banco em Julho de 99. Como a promoção é retroativa, parte do histórico de João deve ser eliminado logicamente como mostra a Figura 7.

Bancos de Dados Bitemporais são bastante poderosos já que permitem deslocamentos nas duas dimensões. Com isso, é possível saber o que se pensava em Julho de 98 sobre um fato que ocorreu em Fevereiro de 98. No caso do exemplo pode-se consultar: "Em Julho de 98, qual pensava-se ter sido o cargo de João em Fevereiro de 98?”. Para encontrar essa resposta bastaria um deslocamento vertical (tempo de transação) até Julho de 98 e depois um deslocamento horizontal (tempo de validade) até Fevereiro de 98 para chegar à resposta Senior.

No entanto, toda essa flexibilidade tem um custo: espaço de armazenamento grande, performance das consultas penalizada e implementação complexa. Por isso é importante avaliar a necessidade de suporte às duas dimensões do tempo, muitas vezes a aplicação requer apenas uma das duas. 


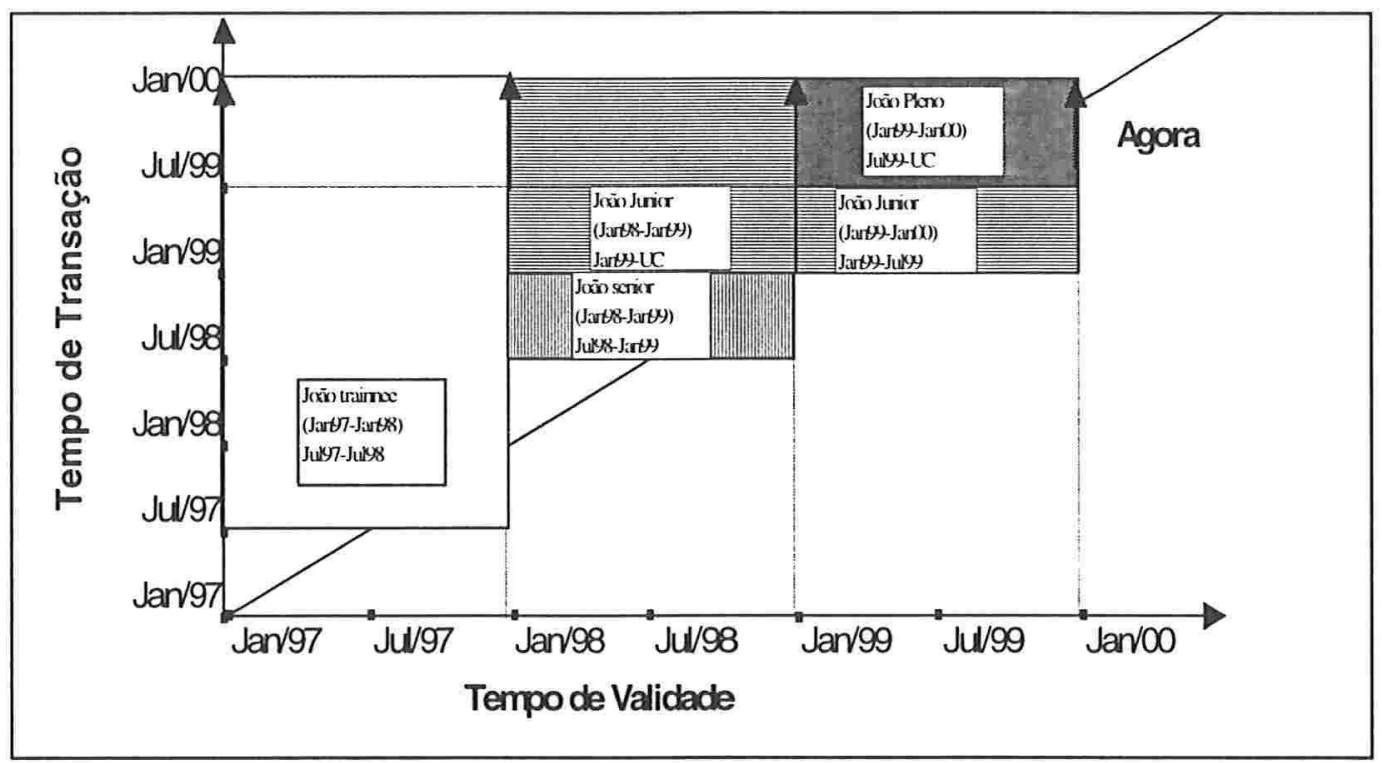

Figura 7 - João recebe uma promoção retroativa

A seguir, são feitas considerações sobre as limitações resultantes de não se armazenar uma das dimensões.

\subsubsection{Limitações de um Banco de Dados de Tempo de Transação}

Ao se armazenar apenas o tempo de transação, perde-se a noção de quando os fatos foram válidos no Universo de Discurso. Com isso, nenhuma consulta, em que o tempo de transação deve ser levado em consideração pode ser feita. No exemplo anterior: "Qual o cargo de João em Fevereiro de 98?”, a resposta de um Banco de Dados de Tempo de Transação seria Junior, quando na verdade João era Senior.

O tempo de transação é manipulado pelo próprio Banco. À medida em que os dados vão sendo inseridos, o sistema os "marca" com o tempo de entrada. Como o domínio dessas marcas são os valores da linha do tempo, cada uma é sempre maior que todas as anteriormente usadas. Como consequência não se pode "voltar no tempo", o que impede a eliminação física dos dados. A Relação 5 corresponde à relação de tempo de transação da Figura 7. Como se pode perceber, a relação corresponde à sequência dos fatos sob a "ótica" do sistema. 


\begin{tabular}{|l|l|l|}
\hline \multicolumn{1}{|c|}{ Nome } & \multicolumn{1}{|c|}{ Cargo } & \multicolumn{1}{c|}{ Tempo de Transação } \\
\hline João & Trainee & Jul97-Jul98 \\
\hline João & Senior & Jul98-Jan99 \\
\hline João & Junior & Jan99-Jul99 \\
\hline João & Pleno & Jul99-Jan00 \\
\hline
\end{tabular}

Relação 5

\section{I.3.3. Limitações de um Banco de Dados de Tempo de Validade}

Armazenando apenas o tempo de validade, perde-se o tempo em que as informações foram inseridas no Banco. Consultas do tipo "o que se pensava em..." não são possíveis. O tempo de validade é manipulado pelo próprio usuário e portanto, ao contrário do tempo de transação, permite referências a tempos passados e futuros. Erros, em Bancos de Dados de Tempo de Validade, são eliminados fisicamente.

Este tipo de Banco guarda apenas as informações conhecidas como válidas no Universo de Discurso. A Relação 6 mostra como seria a relação caso o Banco fosse de Tempo de Validade.

\begin{tabular}{|l|l|l|}
\hline \multicolumn{1}{|c|}{ Nome } & \multicolumn{1}{c|}{ Cargo } & \multicolumn{1}{c|}{ Tempo de Validade } \\
\hline João & Trainee & Jan97-Jan98 \\
\hline João & Junior & Jan98-Jan99 \\
\hline João & Pleno & Jan99-Jan00 \\
\hline
\end{tabular}

\section{Relação 6}

Como se pode notar, o fato "João foi Senior " não aparece na relação, pois se trata de uma informação errada.

Todas as informações até o momento apresentadas servem de base teórica para uma melhor compreensão do projeto, detalhado na próxima seção. Sugere-se a leitura de [37] e [36], caso se queira explorar mais alguns dos conceitos. 


\section{O Projeto}

O projeto tem por objetivo a incorporação de suporte ao tempo de validade a um Banco de Dados Estático de forma que:

1. as conclusões sobre as dificuldades e vantagens possam servir como parâmetro às aplicações interessadas nesse tipo de solução.

2. haja uma preocupação em se utilizar padrões, permitindo uma continuidade do trabalho e colaborando para a convergência da área.

3. seja levado em conta a existência de diversos bancos de dados com dificuldades em recuperar informações temporais.

Neste projeto será utilizada a linguagem TSQL2, baseada no padrão SQL-92, e o Banco de Dados Oracle, amplamente utilizado em aplicações comerciais. Com isso, os ítens 1. e 2. são atendidos.

A opção do tempo de validade deve-se a:

- apesar de um Banco de Dados Bitemporal ser mais interessante de ser implementado, do ponto de vista da complexidade de consultas que podem ser realizadas, é um projeto bastante complicado para ser integralmente concluído em um trabalho de Mestrado.

- o tempo de validade, por ser manipulado pelo próprio usuário, é mais atraente do ponto de vista de implementação, já que é manipulado pelo pelo próprio usuário, ao contrário do tempo de transação, manipulado exlusivamente pelo Banco de Dados.

Existem duas formas de se incorporar suporte ao tempo de validade em um Banco de Dados[19,28,31]. Uma delas consiste em modificar a estrutura interna do Banco de forma que o processamento e otimização de consultas, a indexação e o armazenamento físico levem em conta a dimensão tempo. Esta solução, no entanto, vai além do escopo de um trabalho de mestrado, requerendo um esforço em equipe grande, além de exigir a disponibilidade do código do fonte do Banco de Dados. 
A segunda forma consiste na implementação de uma camada temporal entre o usuário e o Banco de Dados Estático, como mostrado na Figura 22. Essa Camada receberia sentenças TSQL2 que seriam traduzidas para sentenças em linguagem nativa do Banco Estático. Esta estratégia atende ao item3, pois sendo a TSQL2 um superconjunto da SQL-92, todas as sentenças não temporais seriam possíveis. Desta forma, os sistemas legados continuariam a funcionar normalmente, juntamente com as novas aplicações que seriam desenvolvidas utilizando as facilidades temporais que a TSQL2 oferece.

Esta seção está dividida em quatro capítulos. Em II.1, são abordadas de forma suscinta as implementações da área. Em II.2, a linguagem e seu modelo de dados são apresentados, bem como o fragmento da linguagem a ser implementado. A Arquitetura do projeto, o tradutor e outros detalhes da implementação encontram-se em II.3. Testes são detalhados em II.4, em que se detectam facilidades e problemas na utilização da TSQL2. Finalmente em II.5 são sumariadas as conclusões extraídas ao longo do trabalho e apontadas oportunidades para trabalhos futuros. 


\section{II.1. Outros Projetos}

Apesar de pesquisas na área de sistemas de Bancos de Dados Temporais tenham surgido há mais de 20 anos, implementações começaram a surgir na década de 90 . Esta é uma das razões porque os bancos de dados comerciais atuais dão suporte limitado às funcionalidades temporais.

Em 1995, Michael Böhlen, realizou uma pesquisa sobre o estado da arte das implementações de sistemas de bancos de dados temporais [31]. Treze implementações foram analisadas de acordo com critérios bem conhecidos, como o volume de dados, suporte à negação temporal, tipo de marcas de tempo e suporte a diversos calendários. Segue um resumo dos resultados apresentados em [31].

Entre as propriedades pouco implementadas estão:

- Testes usando Bancos de Dados com grande volume de informações

- Suporte ao tempo de transação

- Suporte à negação temporal

- Suporte a múltiplos calendários

- Utilização de marcas de tempo por atributo

- Utilização de marcas de tempo do tipo elemento temporal

- Suporte à projeção temporal

Entre as propriedades bastante implementadas estão:

- Marcas de tempo por tupla

- Marcas de tempo do tipo período

- Suporte à seleção temporal e junção temporal

- Suporte a diferentes granularidades

- Suporte ao tempo de validade 
Das treze implementações, apenas dois incorporaram suporte a múltiplos calendários, entre eles, MultiCal [25]. MultiCal é um protótipo que dá suporte a diferentes noções do tempo através da possibilidade de definição de diversos calendários e sistemas de calendários (calendric systems). Para as consultas, foi modificada a SQL-92, retirando as funcionalidades temporais e adicionando funcionalidades próprias. Calendários e Sistemas de Calendários podem ser definidos e parametrizados pelo usuário. Foram acrescentados os tipos de dados evento, período e intervalo. Para a manipulação e conversão de dados foram adicionadas nove funções temporais, entre elas, Begin e First. Os operadores aritméticos $(+,-, *, /)$ foram extendidos para eventos, períodos e intervalos. Operadores de comparação como overlaps e precedes foram acrescentados. A arquitetura de MultiCal prevê o processamento do tempo em dois módulos: o Time-stamp Abstract Data Type (TADT), responsável por todas as operações temporais que não requerem interpretações de calendários, e o Uniform Calendric Support (UCS), interface que gerencia o acesso dos serviços fornecidos pelos calendários [25].

Tiger [30], é uma camada desenvolvida sobre o banco de dados comercial Oracle . A camada é bitemporal e o tipo de dados da marca de tempo é período. A linguagem implementada é a ATSQL [30], extensão temporal da SQL. Este projeto enfatizou a integração do tempo em sistemas legados. No nível físico, são acrescentados quatro atributos: tempos de transação inicial e final e os tempos de validade inicial e final.

No caso do projeto desta tese, em relação às questões pouco implementadas, dá-se suporte às duas últimas. O tipo elemento temporal para marcas de tempo, analisado mais adiante, é utilizado e a projeção temporal, detalhada mais adiante, é suportada pela Camada Temporal. Devido ao tempo para o término do programa de Mestrado, o escopo não comporta as outras características.

Das propriedades mais implementadas, não foi dado suporte, neste projeto, a diferentes granularidades e não foi utilizado o tipo de dados período para as marcas de tempo.

Poucas implementações usaram Bancos Comerciais, entre elas Tiger [31]. Nenhum combinou o Banco Oracle com a TSQL2 que, respectivamente, correspondem ao Banco mais comumente usado por aplicações comerciais [1] e à linguagem temporal de consenso [36]. 
Nas seções subsequentes são abordados alguns dos aspectos da implementação. Não há pretensão de explorar todos os tópicos relacionados com suporte temporal, como otimização de consultas temporais, indexação, armazenamento [31], ficando como sugestões para trabalhos futuros. 


\section{II.2. A linguagem TSQL2}

Muitas linguagens de consulta temporais foram propostas (35) desde que Bancos de Dados Temporais tornou-se área de pesquisa, há pelo menos quinze anos. A Tabela 1 mostra algumas delas. Essa variedade de linguagens está associada a diferentes modelos de dados $[10,17,18,21,27,36]$. Cada modelo de dados definiu um conjunto de objetos com uma estrutura específica, um conjunto de restrições e de operações sobre esses objetos. Como consequência, mesmos problemas foram tratados isoladamente [36].

\begin{tabular}{|l|l|}
\hline \multicolumn{1}{|c|}{ Nome } & \multicolumn{1}{c|}{ Baseada Em } \\
\hline HQL & DEAL \\
\hline Hquel & Quel \\
\hline HSQL & SQL \\
\hline HTQuel & Quel \\
\hline TDM & SQL \\
\hline Tquel & Quel \\
\hline TemSQL & SQL \\
\hline TSQL & SQL \\
\hline
\end{tabular}

Tabela 1 - Extensões temporais

Era imperativa a definição de uma linguagem temporal padrão. Em 1992, Richard Snodgrass, propôs que a comunidade de pesquisa em Bancos de Dados Temporais produzisse uma extensão da linguagem padrão SQL-92. Em 1993, discussões no "ARPA/NSF International workshop on an Infrastructure for Temporal Databases" indicaram um grande interesse nessa extensão. Mais de 12 pesquisadores da área iniciaram a definição do que seria a Linguagem de Consulta Estruturada Temporal (Temporal Structured Query Language): TSQL2 [28]. A especificação completa foi apresentada em Setembro de 1994. 
A TSQL2 é o resultado da maturação da área de Banco de Dados Temporais ao integrar o padrão SQL-92 com a experiência adquirida das várias extensões acima mencionadas.

A TSQL2 é baseada no Bitemporal Conceptual Data Model (BCDM) [36].

A maioria dos modelos temporais visa à satisfação simultânea de várias metas: captar a semântica das relações temporais de forma a permitir uma modelagem clara e concisa, ser consistente, ser uma extensão mínima de um modelo de dados existente, ser fácil de implementar e ter boa performance. A experiência de 15 anos e de 40 modelos de dados existentes, mostra que a obtenção de todos esse objetivos é provavelmente impossível [37].

O $B C D M$ não almeja cumprir todos os objetivos acima mencionados. Trata-se de um modelo que mantém a simplicidade do modelo relacional e tenta captar a semântica das relações temporais. Para a implementação são utilizados modelos de dados representacionais, próprios para isso. [37]

Apesar deste modelo conceitual dar suporte ao tempos de validade e de transação, tendo em vista o escopo do projeto, não serão abordados aspectos relativos ao tempo de transação.

Seguem algumas das características do BCDM.

\section{II.2.1. Dimensões do tempo}

O tempo é multi-dimensional [16]. Como já descrito, o tempo de validade corresponde ao tempo em que o dado é verdadeiro no Universo de Discurso e o tempo de transação ao tempo em que o evento foi inserido no Banco de Dados.

A cada evento podem ser associadas duas dimensões, sendo por isso caracterizadas como ortogonais entre si.

O Modelo de Dados que não dá suporte a nenhuma das dimensões é chamado de modelo estático. O que dá suporte apenas ao tempo de validade é chamado de modelo de tempo de validade. O que dá suporte apenas ao tempo de transação é chamado de modelo de tempo de transação. Aquele que dá suporte a ambos é chamado de modelo bitemporal. 
Genericamente, modelos que dão suporte a alguma das dimensões do tempo são chamados de temporais [27]. O BCDM é um modelo de dados bitemporal.

Para um melhor entendimento de todas as explicações que seguem, é importante ter claro as seguintes propriedades da dimensão de tempo de validade:

- A cada informação do Banco de Dados de Tempo de Validade está associado o tempo em que foi verdadeiro no Universo de Discurso.

- O tempo de validade é inserido pelo próprio usuário.

- Erros são eliminados fisicamente.

- Afirmações sobre passado e futuro são possíveis.

\section{II.2.2. O Domínio do Tempo}

O BCDM não é uma exceção quanto ao modelo de tempo que usa e, como explicitado em I.1, assume um modelo de tempo linear e discreto para o tempo de validade.

A linha do tempo, limitada nas duas pontas, é particionada em segmentos indivisíveis de tempo de igual duração chamados chronons. Conjuntos consecutivos de chronons podem ser agrupados em grânulos, em que diferentes agrupamentos representam diferentes granularidades.

A SQL-92 dá suporte às seguintes granularidades: dia, mês, ano, hora, minuto, segundo e frações de segundo.

No caso da TSQL2 as granularidades podem ser criadas pelo próprio usuário, de acordo com a necessidade da aplicação. Por exemplo, no caso de empresas de publicidade, cada estação do ano pode ser uma granularidade.

\section{II.2.3. Objetos do modelo}

Uma relação de tempo de validade consiste em um número arbitrário de atributos explícitos e de um atributo implícito de marca de tempo. Uma tupla, em uma instância de uma relação de tempo de validade, consiste em um conjunto de valores de atributos associados, ao conjunto de chronons em que o evento é verdadeiro no Universo de Discurso. 
A relação que não possui suas tuplas associadas à uma marca de tempo é chamada de estática (snapshot).

\section{II.2.4. Tipos de dados temporais}

A SQL-92 possui dois tipos de dados temporais: datetimes e intervals.

Datetimes são pontos isolados no tempo de certa granularidade. Um datetime $i$, ocorre no tempo $t$ se $i$ ocorre em qualquer tempo durante o grânulo representado por $t$. TIME, DATE e TIMESTAMP são tipos de dados datetimes. Eles são delimitados por aspas simples “" ". TIMESTAMP '10:00 Terça' e 'Meia-Noite 31 Dezembro' são exemplos de datetimes no calendário Gregoriano.

Intervals descrevem durações no tempo sem referência no tempo, por exemplo, um intervalo de uma semana refere-se a um intervalo de tempo de sete dias, mas pode se referir a quaisquer sete dias consecutivos no calendário. INTERVAL ' 1 semana' e INTERVAL '2 anos' são exemplos de intervals no calendário Gregoriano.

Além dos tipos acima, a TSQL2 inclui o tipo de dados temporal period. Periods descrevem períodos de tempo com referência temporal dependente do calendário utilizado, ou seja, possuem datetimes de início e fim. PERIOD 'Julho 1973' e PERIOD ' $19 / 07 / 73$ - 28/05/98' são exemplos de periods no calendário Gregoriano.

A Figura 8 ilustra a diferença semântica de cada um dos tipos de dados mencionados.

\begin{tabular}{|l|l|}
\hline \multicolumn{1}{|c|}{ Tipo de Dados } & \multicolumn{1}{c|}{ Exemplo de consulta } \\
\hline Datetime & Quando Getúlio Vargas nasceu? \\
\hline Interval & Quanto tempo durou seu primero governo? \\
\hline Period & $\begin{array}{l}\text { Em que períodos de tempo contínuos Getúlio Vargas esteve } \\
\text { no governo? }\end{array}$ \\
\hline
\end{tabular}

Figura 8 - Tipos de dados 
Apesar dos datetimes e periods estarem relacionados (dois datetimes determinam unicamente um period), devido à frequente utilização do tipo period, optou-se por definílo como um tipo de dados nativo da linguagem [36].

\section{II.2.5. Marcas de Tempo}

O BCDM associa marca de tempo de validade a cada tupla.

Existem três tipos de marcas de tempo: evento, período ou elemento temporal. O evento corresponde à marca de tempo em que cada tupla está associada a um único chronon. $\mathrm{O}$ período é uma marca de tempo composto por um evento delimitando início e outro o fim, caracterizando um intervalo associado de tempo. Um elemento temporal é um conjunto de eventos ou períodos maximais. Períodos maximais são aqueles que possuem intersecção vazia com os outros períodos do elemento temporal.

As marcas de tempo do BCDM são elementos temporais. É importante notar que o modelo é conceitual e portanto, a escolha do tipo da marca de tempo não afeta a representação física da mesma. No caso do projeto, optou-se por representar a marca de tempo como elemento temporal, como será visto em II.3.2.

\section{II.2.6. Tipos de relações}

É o tipo de aplicação que determina o tipo de relação temporal que será necessária para modelar o Universo de Discurso. Existem aplicações, como as geográficas, que necessitam guardar, por exemplo, a profundidade, latitude, longitude e a temperatura, em determinado instante. Neste caso, uma relação de eventos modelaria o Universo de Discurso corretamente, já que se estaria associando uma tupla a um instante no tempo. Por outro lado, pode-se querer armazenar em que intervalo a temperatura manteve-se constante em determinada profundidade, latitude e longitude. Neste caso, devería-se utilizar uma relação de estado, já que se quer associar um período de tempo a cada tupla.

Uma relação de evento pode ser representada como uma relação de estado em que, para cada período, associado a uma tupla, o instante inicial é igual ao final. Por este motivo, no projeto serão utilizadas apenas relações de estado. 
Existe ainda a possibilidade de se associar uma marca de tempo a conjuntos de atributos da tupla. Além de poucas aplicações requerem uma marca de tempo para cada atributo, este tipo de solução representa um custo muito alto em termos de espaço e tempo de processamento [36].

\section{II.2.7. Manipulação das marcas de tempo}

Uma das maiores deficiências das linguagens estáticas está na manipulação da componente tempo das tuplas. As aplicações que lidam com informações temporais acrescentam, em suas relações, atributos armazenadores da dimensão temporal. Para a construção de sentenças que façam referência ao tempo, é preciso a manipulação explícita desses atributos, tornando a consulta complexa e pouco natural.

No caso da TSQL2, é totalmente transparente para o usuário a representação física utilizada para o suporte ao tempo de validade. Referências às marcas de tempo são feitas através do comando VALID(<correlation name $>$ ) em que <correlation name $>$ é a regra que pode corresponder ao nome de uma tabela ou alias.

Allen definiu relações entre períodos como explicado em [36]. Para a TSQL2 foram definidos, de forma análoga, um conjunto de operadores para os tipos de dados datatime, período e intervalo [36].

Existem três categorias de operadores que manipulam marcas de tempo: extração, construção e comparação. A Figura 9 contém os operadores desses grupos.

Os extratores de evento, BEGIN e END, retornam o primeiro e o último eventos, respectivamente, de um evento, um período, ou um elemento temporal. Os extratores de período, FIRST e LAST, podem ser aplicados a marcas de tempo do tipo período ou elemento e retornam o primeiro e último períodos dos argumentos, respectivamente.

Os construtores de evento, FIRST e LAST, recebem dois eventos e retornam, respectivamente, o menor (ocorreu mais cedo na linha do tempo) evento e o maior (ocorreu mais tarde na linha do tempo) evento. O construtor de períodos e elementos INTERSECT, recebe como argumentos, dois períodos ou dois elementos e retorna, 
respectivamente, um período e um elemento que corresponde à intersecção dos argumentos.

Observe-se que, para eventos, os operadores $=$, OVERLAPS e CONTAINS são equivalentes.

A semântica dos operadores de comparação apresentados na Figura 9, encontra-se na Figura 10. Como o período é um caso especial de elemento temporal, períodos podem ocorrer como argumentos onde elementos são permitidos. Similarmente, eventos podem ocorrer onde períodos são permitidos.

Maiores detalhes sobre os operadores podem ser encontrados em [36]. 


\begin{tabular}{|c|c|}
\hline Tipo de operação & Operador \\
\hline Referência & VALID $(<$ correlation name $>)$ \\
\hline Extração de evento & $\begin{array}{l}\text { BEGIN(evento) BEGIN(período) BEGIN(elemento) } \\
\text { END(evento) END(período) END(elemento) }\end{array}$ \\
\hline Extração de período & $\begin{array}{l}\text { FIRST(período) FIRST(elemento) } \\
\text { LAST(período) LAST(elemento) }\end{array}$ \\
\hline Construtores de evento & $\begin{array}{l}\text { FIRST(evento,evento) } \\
\text { LAST(evento,evento) }\end{array}$ \\
\hline Construtores de período & $\begin{array}{l}\text { PERIOD(evento, evento) } \\
\text { INTERSECT(período, período) }\end{array}$ \\
\hline Construtores de elemento & $\begin{array}{l}\text { INTERSECT(elemento,elemento) } \\
\text { Elemento + Elemento } \\
\text { Elemento - Elemento } \\
\text { Pode ser aplicado para Períodos e Eventos }\end{array}$ \\
\hline Comparação de elementos & $\begin{array}{l}\text { Elemento PRECEDES Elemento } \\
\text { Elemento = Elemento } \\
\text { Elemento OVERLAPS Elemento } \\
\text { Elemento CONTAINS Elemento }\end{array}$ \\
\hline Comparação de períodos & $\begin{array}{l}\text { Período PRECEDES Período } \\
\text { Período = Período } \\
\text { Período OVERLAPS Período } \\
\text { Período MEETS Período } \\
\text { Período CONTAINS Período }\end{array}$ \\
\hline Comparação de eventos & Evento PRECEDES Evento \\
\hline
\end{tabular}




\begin{tabular}{|l|l|}
\hline & Evento = Evento \\
Evento OVERLAPS Evento \\
Evento MEETS Evento \\
Evento CONTAINS Evento
\end{tabular}

Figura 9 - Operadores da TSQL2

\begin{tabular}{|l|l|}
\hline \multicolumn{1}{|c|}{ Operador } & \multicolumn{1}{c|}{ Definição } \\
\hline E1 PRECEDES E2 & END(E1) é menor do que BEGIN(E2) \\
\hline E1 = E2 & E1 e E2 são idênticos \\
\hline E1 OVERLAPS E2 & A intersecção entre E1 e E2 é não vazia \\
\hline E1 CONTAINS E2 & Cada evento ou período em E1 está contido em E2 \\
\hline P1 MEETS P2 & $\begin{array}{l}\text { END(P1) PRECEDES BEGIN(P2) e não há eventos entre } \\
\text { END(P1) e BEGIN(P2) }\end{array}$ \\
\hline
\end{tabular}

Figura 10 - Semântica dos operadores de Comparação

\section{II.2.8. Coalescência (coalescing)}

A Relação 7 corresponde a uma instância da relação que armazena a informação dos presidentes do Brasil. A primeira tupla contém a informação de que Getúlio Vargas foi Presidente de 1930 a 1937. A segunda tupla mostra que Getúlio foi presidente novamente no período 1937-1945.

Quando uma relação possui essa duplicidade de atributos explícitos é chamada de não coalesçada [33].

Como o BCDM não permite tuplas com atributos explícitos idênticos [36], é preciso transformar as relações não coalesçadas em coalesçadas. Isto é feito através do processo de coalescência (coalescing), similar à eliminação de tuplas idênticas em relações estáticas, com o adicional de que as marcas de tempo devem ser coalesçadas, caso haja intersecção ou meets dos períodos de cada tupla sendo coalesçada. 
Apesar da semelhança, o processo de coalescência exige mais processamento que o da simples eliminação de tuplas idênticas em Bancos Estáticos, e portanto torna-se necessária a utilização de algoritmos eficientes em conjunto com as melhores representações físicas das marcas de tempo. Maiores detalhes sobre performance e coalescência encontram-se em [33].

O projeto implementa a coalescência mas não objetiva conseguir a melhor performance.

A Relação 8 mostra o resultado da coalescência da Relação 7, composta por apenas uma tupla indicando que Getúlio foi Presidente de 1930 a 1945. Em geral, duas tuplas são candidatas à coalescência se possuirem atributos explícitos idênticos e suas marcas de tempo forem adjacentes ou se sobrepuserem.

O BCDM assume que as relações estão coalesçadas e portanto, o processo de coalescência é executado implicitamente toda vez que a relação resultar não coalesçada. Alguns modelos de dados não assumem tal asserção [33]. O fato de se assumir as relações, como coalesçadas ou não, afeta a semântica das consultas. Se a Relação 7 e a Relação 8 fossem consultadas sobre as pessoas que permaneceram como presidente por mais de 10 anos, as respostas seriam, respectivamente, ninguém e Getúlio Vargas. Isto porque na Relação 7 nenhum dos dois períodos possuem dez anos de intervalo.

Algumas consultas requerem o particionamento da relação em períodos maximais, podendo resultar em uma relação não coalesçadas. Por exemplo, a consulta "Quais presidentes exerceram o cargo por mais de 10 anos consecutivos", requer que cada tupla seja particionada em períodos maximais. Para isso usa-se a palavra reservada PERIOD, vista mais adiante.

Manter as relações coalesçadas pode resultar em queda de performance. Para que o processo de coalescência não aconteça desnecessariamente, precisam ser identificadas operações que destroem ou a mantém [33]. Operações como projeção temporal e inserção podem tornar uma relação coalesçada em outra não coalesçada. Operações como a junção e a seleção temporal realizadas sobre relações coalesçadas resultam em relações coalesçadas.

A implementação da coalescência é detalhada em II.3. 


\begin{tabular}{|c|c|c|}
\hline Nome & Título & Tempo de Validade \\
\hline Getúlio & Presidente & $1930-1937$ \\
\hline Getúlio & Presidente & $1937-1945$ \\
\hline
\end{tabular}

Relação 7

\begin{tabular}{|c|c|c|}
\hline Nome & Título & Tempo de Validade \\
\hline Getúlio & Presidente & {$[1930-1945]$} \\
\hline
\end{tabular}

Relação 8

\section{II.2.9. Calendários}

A SQL-92 foi desenvolvida para dar suporte apenas ao calendário Gregoriano, não sendo possível generalizar para outros calendários.

A TSQL2 foi desenvolvida de forma a permitir a utilização de outros calendários, ou melhor, de outros sistemas de calendários (calendric system). Um sistema de calendário é um conjunto de calendários em que cada calendário é definido sobre períodos do tempo que não se interseccionam. É possível a existência de períodos na linha do tempo não cobertos por nenhum calendário. O sistema de calendário padrão para a TSQL2 é o SQL92_calendric_system, formado por um único calendário (Gregoriano) e válido desde $1 \mathrm{AD}$ até $10000 \mathrm{AD}$. Se for necessário utilizar outro sistema, basta especificar através da sentença:

DECLARE CALENDRIC SYSTEM AS <nome do sistema de calendários>.

Cada Calendário define suas granularidades. Um dia civil começa ao meio-dia, já o Gregoriano começa à meia-noite. Um calendário contábil define que o mês possui 30 dias, enquanto que o calendário acadêmico define granularidades de períodos letivos e semestres. A TSQL2 permite a definição de um calendário, com uma particular 
hierarquia de granularidades. Em [36] está detalhado como é possível a definição de novos sistemas de calendários, assim como as operações com DateTimes, e a flexibilidade na representação do "agora" (now) e do "para sempre" (forever).

No projeto foi utilizado o sistema padrão (SQL2_calendric_system) da TSQL2, ficando para trabalhos futuros a implementação do suporte a outros calendários.

\section{II.2.10. Outros aspectos do BCDM}

Segue um resumo de outros aspectos aos quais o BCDM dá suporte. Apesar de não pertencerem ao escopo de implementação, são importantes para que se tenha uma visão mais ampla da flexibilidade da TSQL2. Maiores detalhes estão em [36].

As características da TSQL2 abaixo citadas não são suportadas pela SQL-92.

- Suporte a múltiplas granularidades. A SQL-92 dá suporte apenas às granularidades básicas SEGUNDO, MINUTO, HORA, DIA, MÊS e ANO. No entanto, para aplicações bancárias uma granularidade de SEMANA poderia ser mais interessante, enquanto que para aplicações de reservas de hotéis uma granularidade de ESTAÇÕES seria muito útil. A TSQL2 permite que os usuários especifiquem outras granularidades.

- Suporte a múltiplas representações. A SQL-92 possui uma estrutura fixa de representação para marcas de tempo: ano-mês-dia hora-minuto-segundo. A TSQL2 permite ao usuário definir seus próprios formatos, por exemplo, 1997 semana 10 .

- Suporte a vários idiomas. Aplicativos são usados em diferentes países, portanto, dar suporte a várias linguagens e a vários formatos torna-se cada vez mais relevante.

- Suporte à indeterminação do tempo. Em aplicações científicas é importante que se armazene a imprecisão. Aplicações que lidam com planejamentos futuros precisam guardar informações do tipo "Eu não sei quando" ou "Eu não sei exatamente quando". A TSQL2 permite manipulação de tempos indeterminados.

- Suporte a vários limites do fluxo do tempo. Neste caso o usuário pode definir os limites de seu fluxo do tempo. Esses limites variam de acordo com as necessidades, 
por exemplo, um arqueólogo precisa de limites e granularidades grandes, ao contrário de um cientista químico que lida com eventos de duração inferior a microsegundos.

Vale ressaltar que a TSQL2 é uma extensão da SQL-92 e portanto, qualquer sentença em SQL-92 pode ser escrita em TSQL2, não se perdendo expressividade.

\section{II.2.11. Fragmento TSQL2 selecionado para implementação}

Não é ambição deste projeto implementar todas as extensões que a TSQL2 fez na SQL92, mas sim selecionar um subconjunto delas, de forma que:

- permita evidenciar as facilidades ou dificuldades de se utilizar a TSQL2.

- seja viável no tempo disponível para o programa de Mestrado.

- tenha em vista aspectos da linguagem envolvidos em quaisquer aplicações temporais, muito embora a linguagem providencie construções que são de aplicação a domínios limitados.

A seguir, no entanto, são comentadas algumas das extensões temporais feitas à SQL-92, explicitadas em negrito. Uma linha tracejada envolve as especificações que foram implementadas no projeto.

No Anexo B encontram-se todas as partes das regras da TSQL2 que foram implementadas.

\section{Create table}

A fim de relacionar eventos com seu tempo de validade é preciso criar as entidades que irão armazená-los, ou seja as tabelas de tempo de validade. O grafo da regra de criação de tabelas temporais está na Figura 12 na qual as extensões feitas na TSQL2 são evidenciadas em negrito. Para indicar que a tabela a ser criada é uma tabela de estado basta acrescentarmos AS VALID STATE no final de sua definição.

A regra <vacuuming definition> permite a deleção física de dados obsoletos. Maiores detalhes do fragmento não implementado podem ser obtidos em [36]. 
A Figura 11 mostra um exemplo de criação de uma tabela de tempo de validade em TSQL2. A sentença corresponde à criação da tabela de estado de tempo de validade DEPT com as colunas Name, Budget e MgrID.

Assume-se como padrão para <timestamp precision> a granularidade Dia com zero casas de precisão.

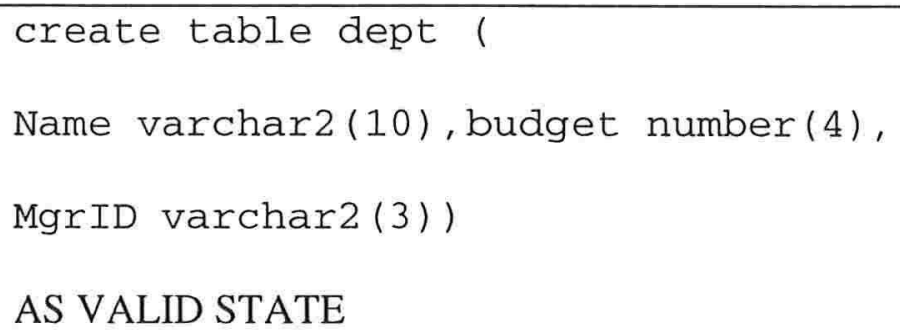

Figura 11 - Exemplo de criação de tabela temporal

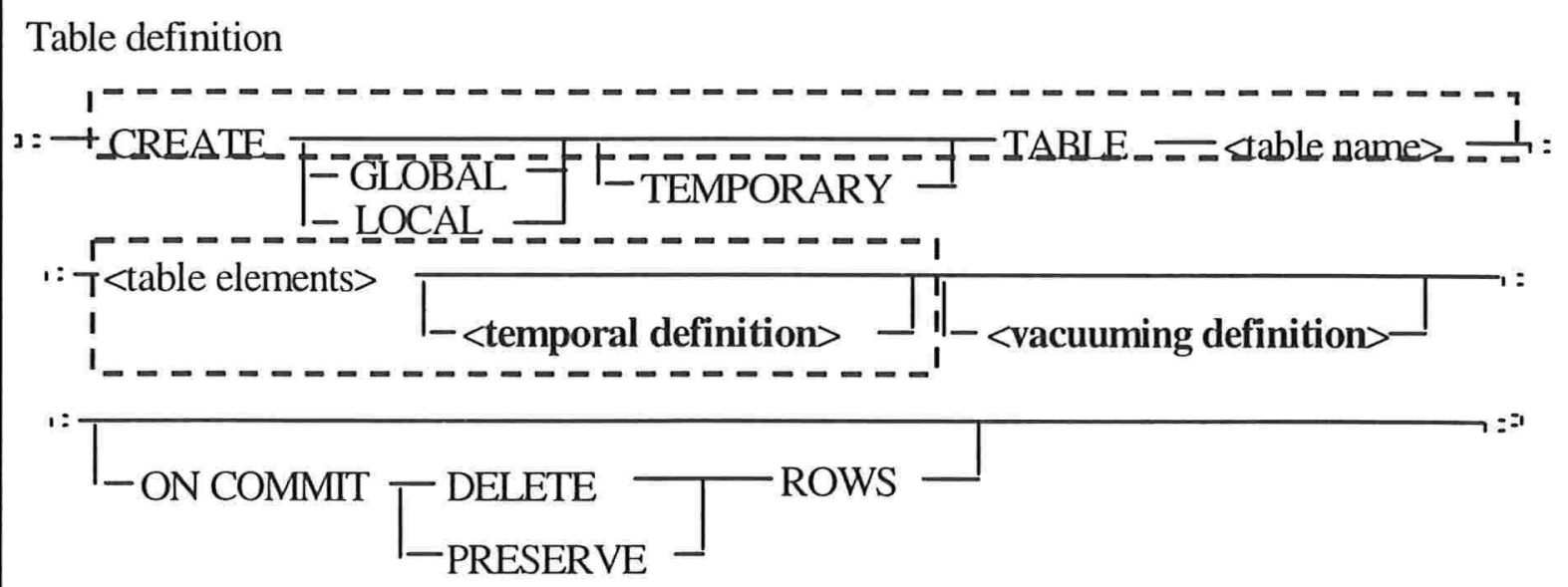

Temporal definition

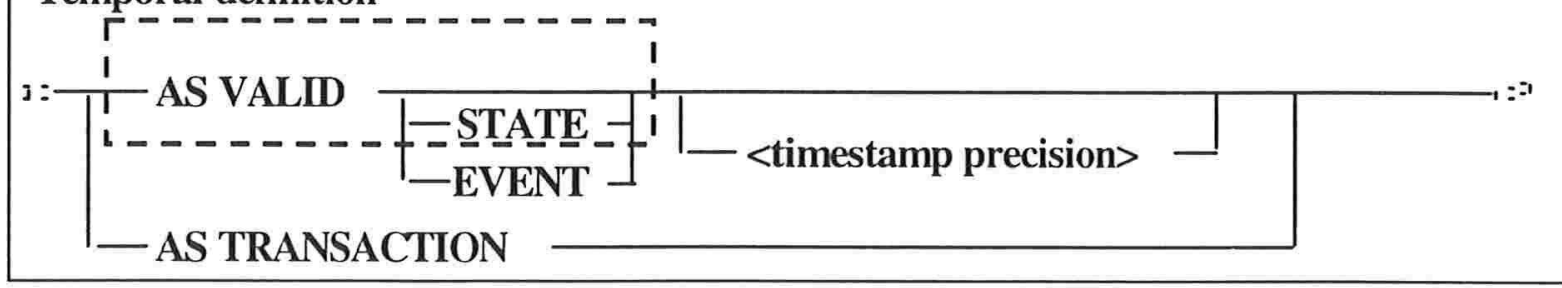

Figura 12 - Regras de definição de tabelas

$\underline{\text { Insert }}$

Após a geração das tabelas de tempo de validade é preciso implementar a sentença que irá inserir informações temporais. Como o escopo é a implementação de partes 
significativas de consultas, o mínimo necessário para que se possa incluir informação de tempo de validade nas tabelas foi desenvolvido. Não foi dado suporte à inserção através da regra <query expression>, ou seja, através de dados de outras tabelas.

Foi dado suporte apenas ao estritamente necessário para que a informação possa ter seu tempo de validade associado. Esta associação é feita através da <valid clause> (Figura 14), que será explicada quando seja descrita a projeção temporal, mais adiante. Um exemplo de inserção de um dado de tempo de validade é descrita na Figura 13. A senteça insere na tabela de estado de tempo de validade DEPT, a informação de que a gerente Di do departamento Toy possuia um orçamento de $\$ 150$ no período de '01/01/1982 31/07/1984'.

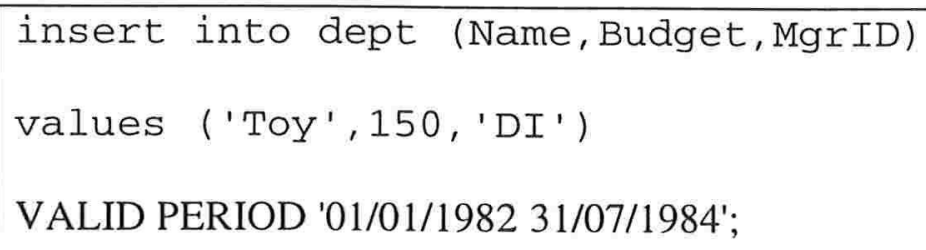

Figura 13 - Exemplo de inserção de dados temporais

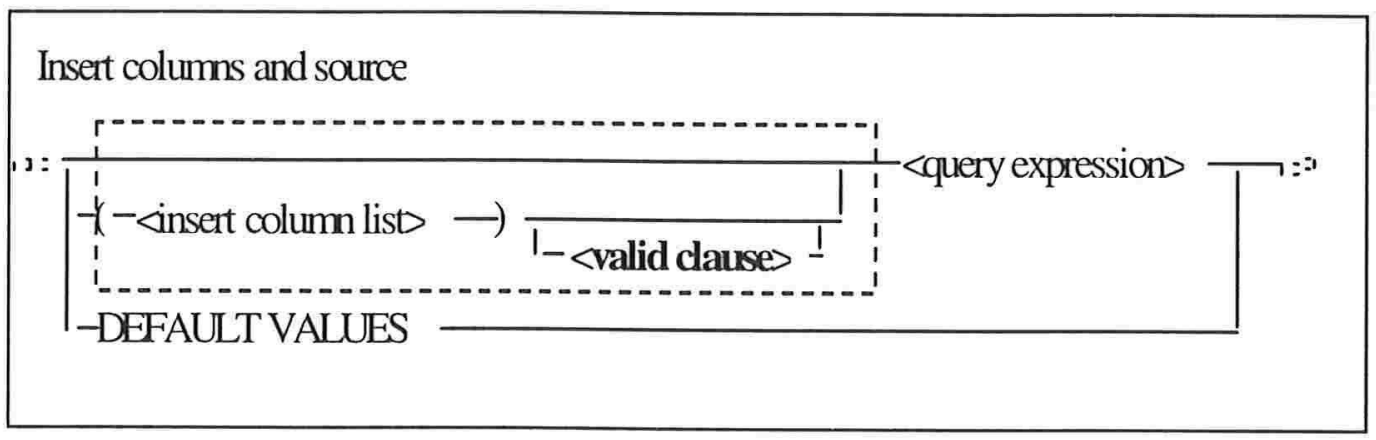

Figura 14 - Regras de inserção de dados

\section{$\underline{\text { A cláusula From }}$}

Recuperação de informação é o objetivo das linguagens de consulta de Bancos de Dados. A regra <from clause> é um importante componente da sentença de consulta já que define as tabelas das quais as informações serão obtidas [9].

A Figura 15 mostra o grafo da $<$ from clause $>$ da TSQL2. As extensões feitas na SQL-92 estão em negrito. 
Uma das extensões temporais mais simples feitas na $<$ from clause $>$ é a possibilidade de se associar vários alias a cada regra <table source> (nome de uma tabela ou outro alias) e $<$ derived table $>$ (regra geradora de uma tabela através de uma consulta), tornando a linguagem mais concisa e compreensível. Assim, em vez de se escrever

FROM Empregados E1, Empregados E2,

pode-se usar a forma mais curta

FROM Empregados E1,E2.

A implementação desta caracaterística é bastante trabalhosa, dada a estrutura de dados escolhida no projeto (detalhada mais adiante), e como não se trata de uma extensão crucial na demonstração da flexibilidade da linguagem, optou-se por não implementá-la.

Uma das principais extensões na regra $<$ from clause $>$ está em $<$ correlation modifier $>$.

Esta regra permite que, de forma bastante intuitiva e expressiva, altere-se a organização das colunas e/ou da marca de tempo de uma tabela ou alias. Pode-se agrupar as tuplas em conjuntos arbitrários de colunas determinadas na regra <coalescing columns>. Por exemplo, na sentença

\section{FROM Empregados(Nome) E,}

a variável E corresponde à projeção da tabela Empregados sobre a coluna Nome. As colunas Cargo e Salário não são acessíveis a partir de E. Se a tabela Empregados for de tempo de validade, as tuplas de E sofrerão o processo de coalescência descrito em II.2.8. A Relação 9 mostra uma instância da tabela Empregados. A variável E é apresentada na Relação 10 na qual a única instância da coluna Nome é 'Diana' e o valor da marca de tempo corresponde à união de todos os períodos em que Diana foi funcionária, independentemente de cargo e salário. 


\begin{tabular}{|l|l|l|l|}
\hline \multicolumn{1}{|c|}{ Nome } & \multicolumn{1}{|c|}{ Salário } & \multicolumn{1}{c|}{ Cargo } & Tempo de Validade \\
\hline Diana & 20 & Analista Junior & $1 / 1 / 95-1 / 1 / 96$ \\
\hline Diana & 30 & Analista Pleno & $2 / 1 / 96-1 / 1 / 97$ \\
\hline Diana & 40 & Analista Pleno & $10 / 07 / 97-1 / 1 / 98$ \\
\hline
\end{tabular}

Relação 9

\begin{tabular}{|l|c|}
\hline \multicolumn{1}{|c|}{ Nome } & Tempo de Validade \\
\hline Diana & $1 / 1 / 95-1 / 1 / 9710 / 07 / 97-1 / 1 / 98$ \\
\hline
\end{tabular}

Relação 10

Na verdade, a regra <coalescing columns $>$ é syntactic sugar já que

FROM Empregados (Nome) E,

é equivalente a

FROM (SELECT Nome FROM Empregados) E.

No entanto, a primeira construção é muito mais concisa e intuitiva. Caso nehuma coluna de coalescência seja explicitada, o padrão é ' *', indicando que todas as colunas devem ser consideradas. 


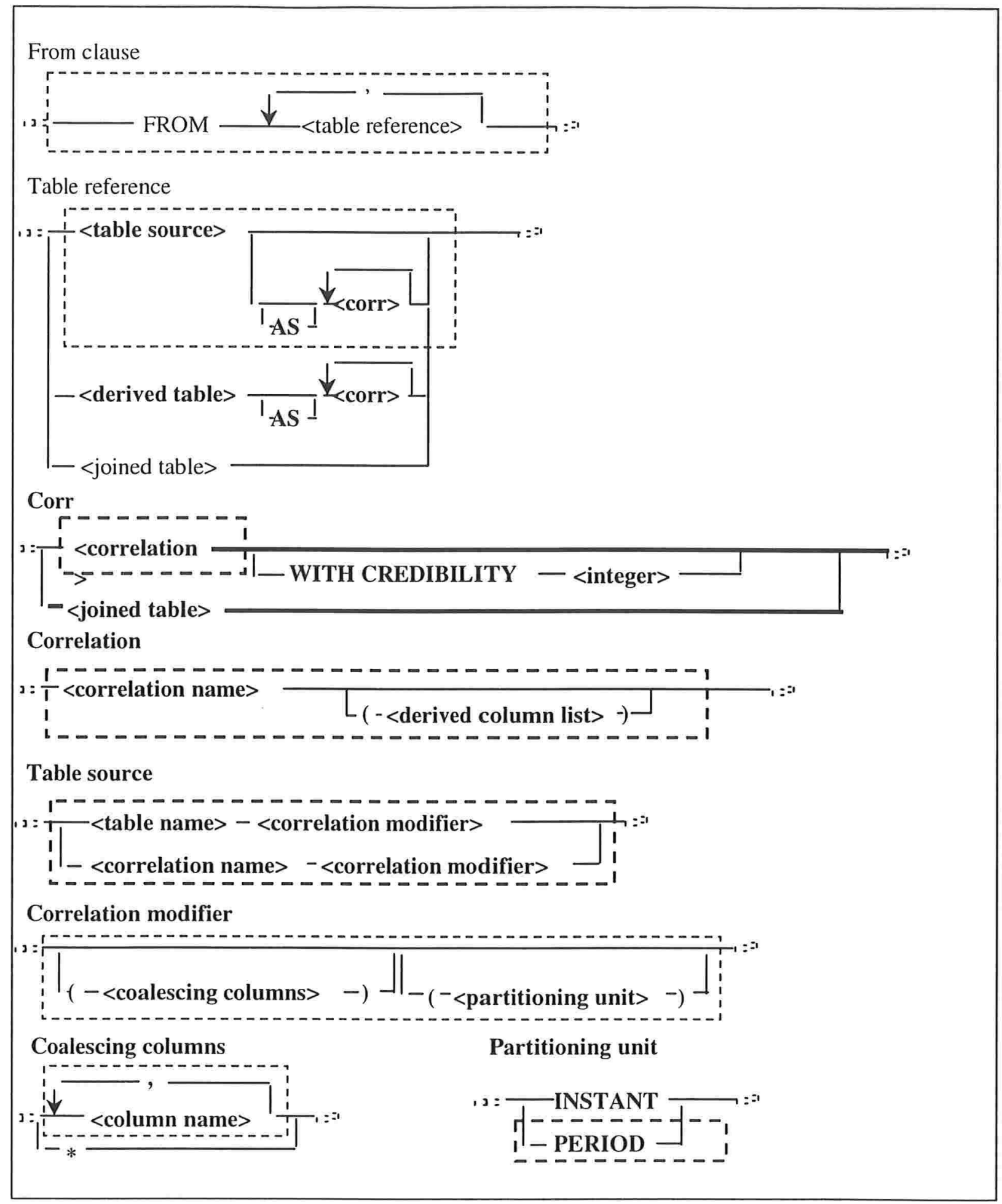

Figura 15 - Regras da cláusula from

A TSQL2 permite ainda construções para associações de tuplas mais complexas. A sentença

FROM Empregados(Nome) E, E(Salário) F, 
especifica que F é uma variável de tupla com dois atributos em que um deles (Nome) está sincronizado com E. Desta forma, E agrupará EMPREGADOS sobre Nome, e F agrupará EMPREGADOS sobre Nome e Salário em que o valor do atributo Nome será, ao mesmo tempo, o mesmo, para E e F. Se para um E particular, não existir um $F$ que satisfaça a regra <where clause>, então considera-se que $\mathrm{E}$ não satisfaz a $<$ where clause $>$. A sentença

FROM Empregados(Nome) E, E(Salário) F

é equivalente a

$$
\begin{aligned}
& \text { FROM Empregados (Nome) E, E(Nome, Salário) F } \\
& \text { WHERE E. Nome = F.Nome, Valid(E) OVERLAPS Valid(F). }
\end{aligned}
$$

Apesar de parecer que há um ganho em expressividade, a primeira construção é pouco intuitiva. A primeira <table reference>, Empregados (Nome) E, é semanticamente distinta da segunda, E (Salário) F . Na primeira <table reference> há uma projeção da coluna Nome sobre a tabela EMPREGADOS, enquanto que na segunda, a coluna Salário não é projetada sobre E mas sim, adicionada a E. Como a utilização dessa construção é pouco intuitiva, optou-se por não implementá-la.

A extensão feita através da regra <partitioning unit> é imprescindível quando se quer responder perguntas como "Quem foi o funcionário que trabalhou continuamente por mais tempo?". Perguntas como esta requerem a manipulação de períodos maximais de tempo. Em TSQL2 são facilmente escritas através do uso das palavras reservadas PERIOD e EVENT. Na sentença

FROM Empregados (Nome) (Period) E, 
primeiro coalesçam-se os elementos temporais da coluna Nome, resultando na Relação 10, e em seguida, particionam-se os elementos temporais em períodos maximais. Este processo gerará tuplas com atributos explícitos idênticos associados a um único período maximal, como mostra a Relação 11. A utilização de EVENT dá-se quando se quer particionar em eventos. Como no projeto só se dá suporte a tabelas de estado, apenas o PERIOD foi implementado.

\begin{tabular}{|l|l|}
\hline \multicolumn{1}{|c|}{ Nome } & Tempo de Validade \\
\hline Diana & $1 / 1 / 95-1 / 1 / 97$ \\
\hline Diana & $10 / 07 / 97-1 / 1 / 98$ \\
\hline
\end{tabular}

\section{Relação 11}

Este é o único caso em que há duplicação de atributos explícitos.

Existem outras extensões como aquelas para dar suporte à indeterminação temporal que não foram implementadas e são descritas em [36].

\section{$\underline{\text { Seleção }}$}

Bancos de Dados Temporais devem oferecer meios de recuperar informação segundo diversos critérios temporais. A seleção de tuplas de acordo com seus tempos de validade é chamada de seleção de tempo de validade. As regras da seleção temporal estão descritas na Figura 16, Figura 17 e Figura 18.

A extensão mais importante na seleção foi realizada na regra $<$ predicate $>$, à qual foram acrescentados quatro predicados para manipulação de expressões temporais incluindo marcas de tempo. Os operandos implementados para esses operadores são os determinados pela regra <value expression > que foi extendida para que fossem possíveis manipulações de expressões com períodos, eventos e elementos temporais. No caso particular do projeto foi dado suporte a período e elemento temporal. Foram 
implementadas algumas das funções temporais para manipulação de elementos temporais, (INTERSECT, FIRST, LAST) explicadas em II.2.

Ao contrário da SQL-92, a TSQL2 permite que a marca de tempo de uma tabela de tempo de validade seja referenciada sem que seja necessário o conhecimento do seu armazenamento físico. A função VALID(<correlation name>) recebe como parâmetro o nome de uma tabela ou alias de tabela de tempo de validade, e retorna a marca de tempo associada com a tupla em questão. A utilização desta função também diferencia a marca de tempo de um atributo normal, evidenciando o fato de que se trata de uma dimensão temporal. 


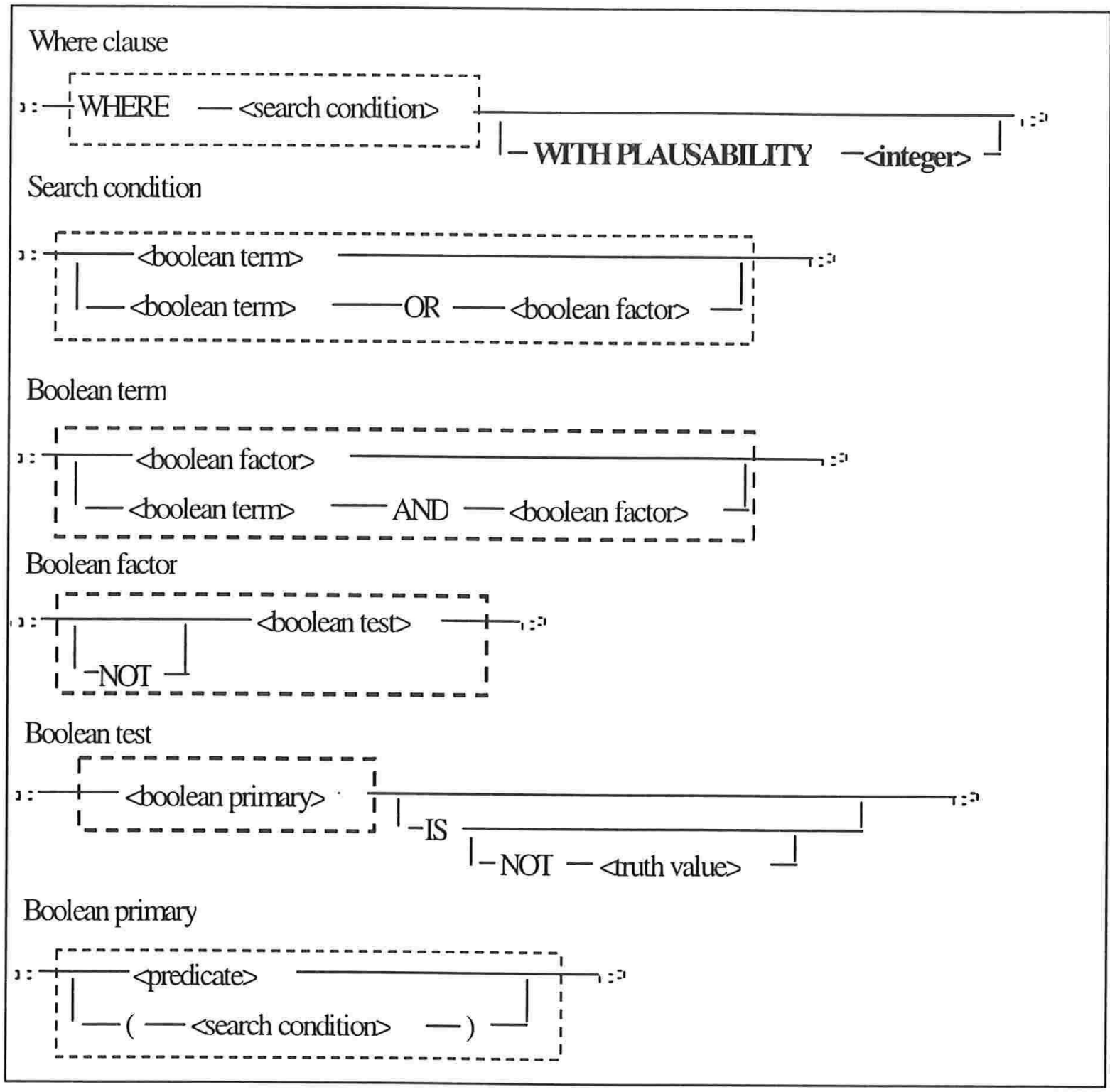

Figura 16 - Regras de Seleção Temporal 


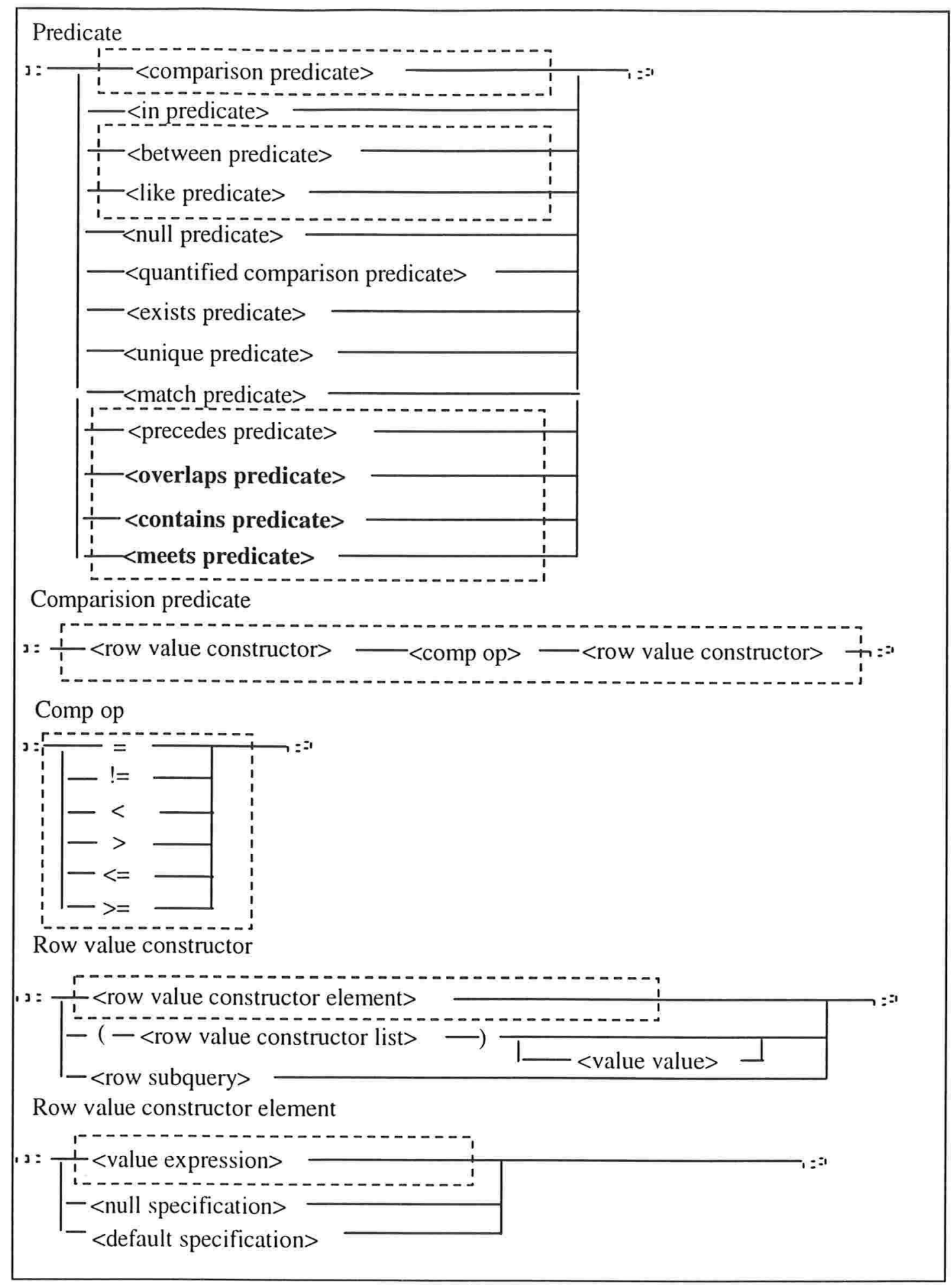

Figura 17 - Regras de Seleção Temporal 


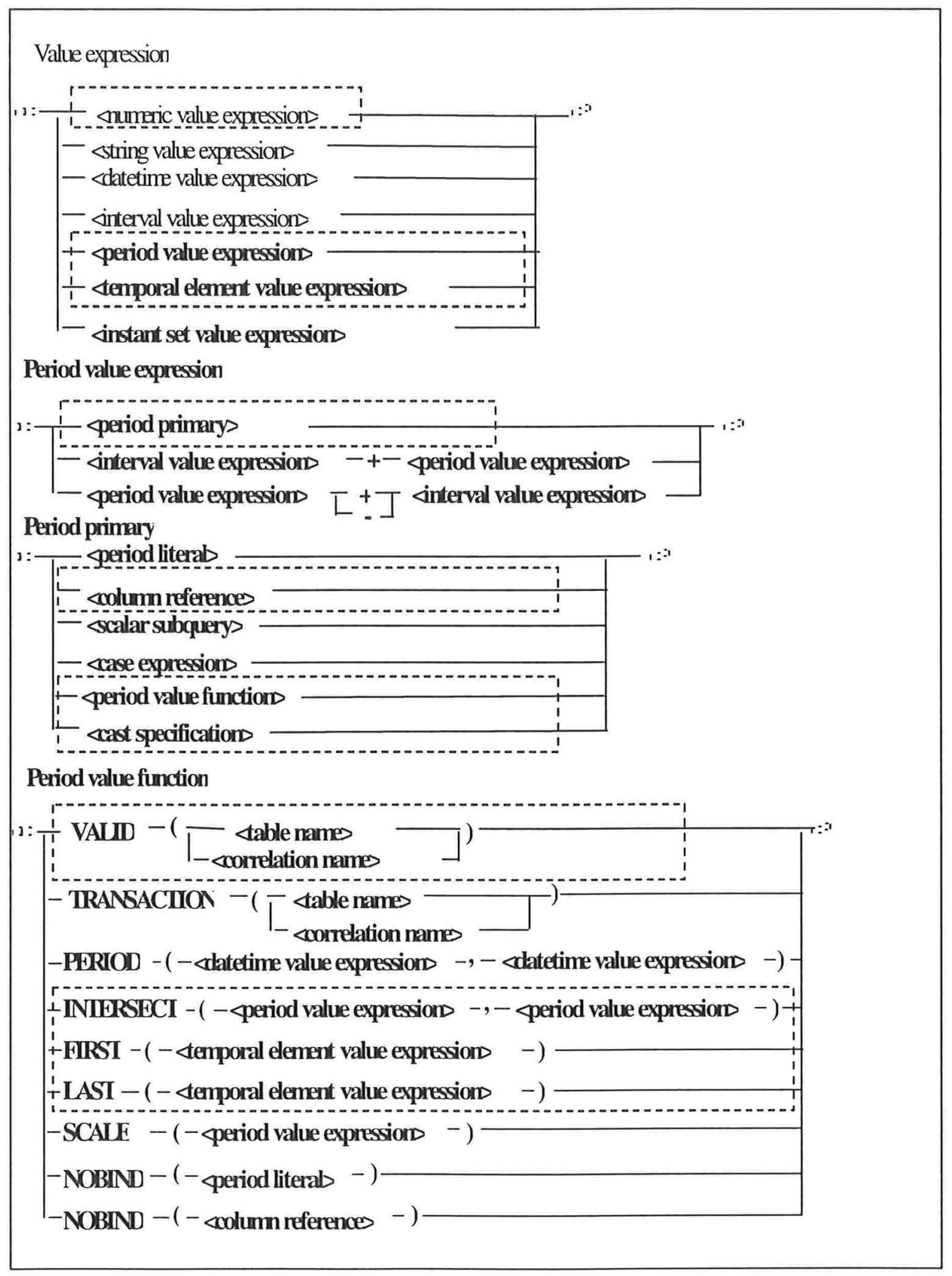

Figura 18 - Regras de Seleção Temporal 
A função CAST, cuja regra encontra-se no Anexo B, foi extendida de forma que inclua tipos de dados temporais. No projeto é possível ter construções como

\section{CAST (VALID(Empregados) AS INTERVAL DAY).}

A função CAST, nesta última expressão, converte o tipo de dados das marcas de tempo de cada tupla da tabela EMPREGADOS no tipo de dados intervalo com granularidade de um dia. Se a marca de tempo for um elemento temporal, então CAST retornará a somatória de todos os intervalos dos períodos que compõem esse elemento temporal. A $<$ cast specification > pode ser utilizado também para truncar a <cast operand $>$ quando utilizado com a <time granularity>, como por exemplo, CAST (DATE '1998-06-01' AS YEAR) = '1994'. O projeto não contempla este último tipo de expressão.

\section{Projeção}

Da mesma forma que se escolhem as tabelas das quais serão retirados os dados e as tuplas que farão parte do resultado através das regras que definem a $<$ from clause $>$ e a $<$ where clause $>$, também podem-se definir as colunas integrantes da tabela resposta. A definição dessas colunas é realizada através da projeção. A projeção permite que se escolham colunas provenientes das tabelas ou alias da $<$ from clause $>$ ou que sejam geradas novas colunas, baseadas ou não, em colunas das tabelas da $<$ from clause $>$.

No caso de tabelas de tempo de validade, torna-se necessário que sejam definidas as marcas de tempo das tuplas da tabela resultante de uma consulta. Esta definição é feita através da projeção temporal, com a regra $\langle$ valid clause $\rangle$, definida imediatamente antes da <table expression $>$. O exemplo:

\section{SELECT *}

FROM Empregados

WHERE VALID(Empregados) CONTAINS PERIOD('1 Jan 1990 - 1 Jan $\left.1992^{\prime}\right)$,

seleciona todos os funcionários que trabalharam no período determinado na <where clause $>$. A marca de tempo das tuplas da tabela resultante é a mesma da tabela 
EMPREGADOS, pois o padrão é a intersecção entre as marcas de tempo das tabelas da $<$ from clause $>$, como só existe uma, o resultado é a própria marca. Já no exemplo:

\section{SELECT *}

VALID INTERSECT PERIOD ('1 Jan 1990 - 1 Jan 1992')

\section{FROM Empregados,}

além de serem selecionados os funcionários que trabalharam no período especificado pela $<$ valid clause>, as marcas de tempo das tuplas resultantes serão atualizadas para a intersecção das marcas com o período ' 1 Jan 1990 - 1 Jan 1992'. Se algum funcionário não trabalhou nesse período, a intersecção é vazia e portanto, essa tupla não pertence ao resultado.

A projeção temporal está separada porque a projeção estática define os atributos explícitos da tabela resultante, e como a marca de tempo está relacionada com a tupla, diferenciando-se de um atributo normal, é natural separar as duas projeções [36].

A projeção temporal em TSQL2 é bastante complexa e depende de uma série de fatores. A seguir explica-se como são determinadas as marcas de tempo da tabela resultante e quais os elementos influenciadores dessa determinação.

O padrão da <valid clause > é VALID INTERSECT 'todo o tempo', significando que a marca de tempo resultante é a intersecção de todas as marcas de tempo resultantes. O processamento de uma consulta temporal será apresentado em detalhes, inclusive com as tabelas intermediárias, mais adiante.

A Figura 19 contém um quadro explicativo de como o tipo das tabelas da <from clause $>$, a palavra SNAPHOT, a < valid clause $>$ e os padrões influenciam o resultado da consulta. Se pelo menos uma das tabelas da <from clause> for estática, o padrão será SNAPSHOT, podendo ser anulado com a existência de uma <valid clause $>$ explicitando a marca de tempo resultante das tuplas. Por outro lado, se todas as tabelas da $<$ from clause $>$ forem temporais, então, o padrão será a <valid clause $>$ : VALID INTERSECT PERIOD 'todo o tempo', explicada acima. Como SNAPSHOT anula a definição de marcas de tempo para as tuplas resultantes e a $<$ valid clause $>$ as defini, a presença explícita das duas gera um erro de sintaxe. 


\begin{tabular}{|l|c|c|c|c|}
\hline \multicolumn{1}{|c|}{ Tabelas } & SNAPSHOT & $<$ Valid clause $>$ & Padrão & RESULTADO \\
\hline 1 Estática & $\mathrm{x}$ & - & - & Estático \\
\hline 1 Estática & - & $\mathrm{x}$ & - & Temporal \\
\hline 1 Estática & $\mathrm{x}$ & $\mathrm{x}$ & - & ERRO \\
\hline 1 Estática & - & - & SNAPSHOT & Estática \\
\hline Todas Temporais & $\mathrm{x}$ & - & - & Estática \\
\hline Todas Temporais & - & $\mathrm{x}$ & $\mathrm{x}$ & Temporal \\
\hline Todas Temporais & $\mathrm{x}$ & $\mathrm{x}$ & $\mathrm{x}$ & ERRO \\
\hline Todas Temporais & - & - & $<$ valid clause $>$ & Temporal \\
\hline
\end{tabular}

Figura 19 - Determinação do resultado da consulta

A projeção temporal em TSQL2 é bastante complexa e requer cuidados especiais durante a geração de consultas. Ao se construir uma consulta é preciso prestar atenção no mecanismo de padrãos explicitados na Figura 19. A explicação de como é determinado o resultado de uma consulta TSQL2 em [36] é obscura. A descrição apresentada nesta seção foi baseada em estudo minucioso do texto e em mensagens eletrônicas trocadas com Richard Snodgrass e Mike Soo, dois dos mentores da linguagem [36].

A Figura 20 mostra o grafo da projeção temporal definida pela <valid clause $>$. 


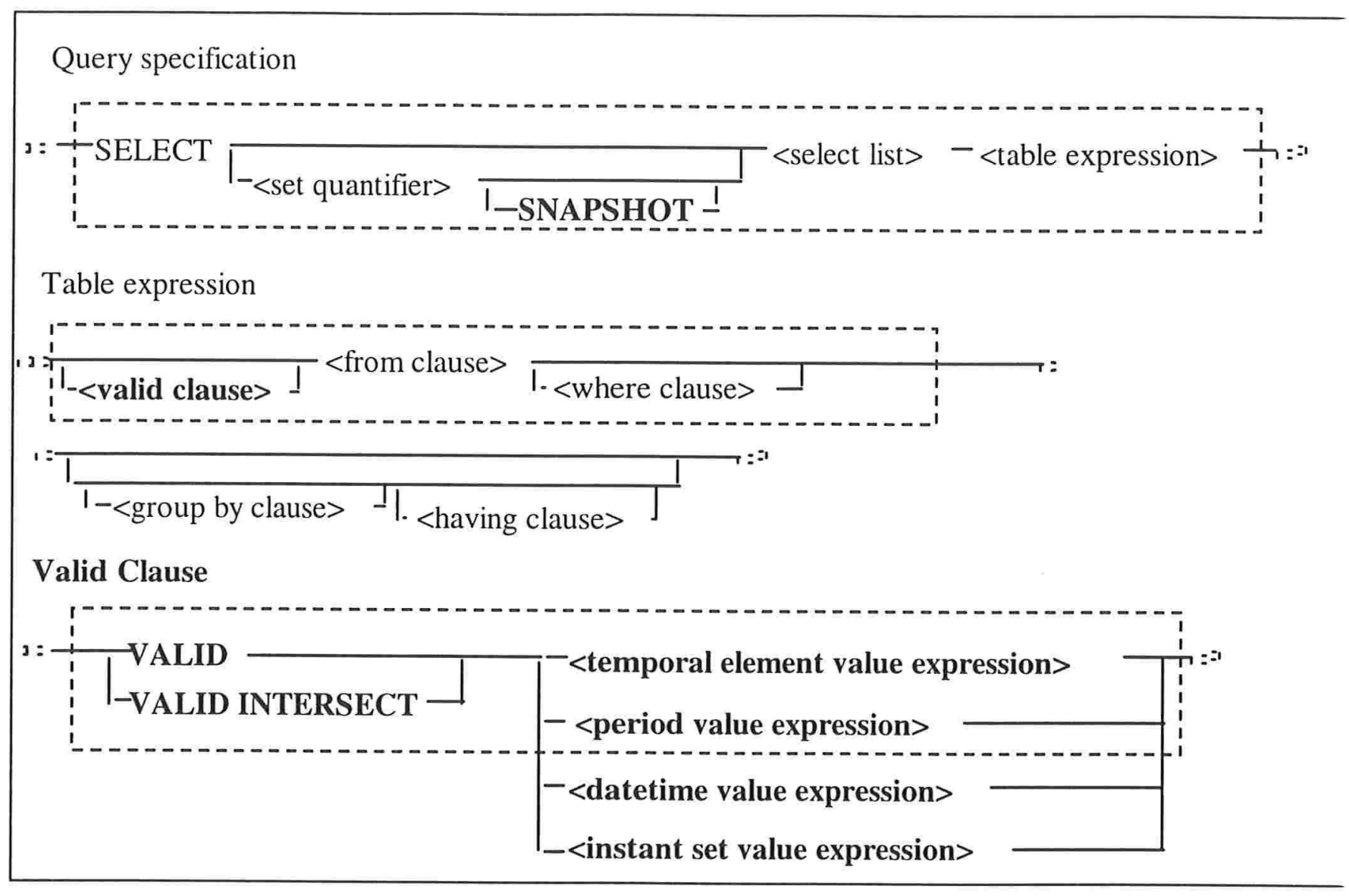

Figura 20 - Regras de Projeção Temporal 


\section{II.3. Implementação}

Neste capítulo será detalhada a implementação da Camada Temporal.

A incorporação de suporte a tempo de validade ao Banco de Dados Oracle [2] foi feita através de desenvolvimento de uma camada temporal mono-usário cujo front-end foi feita em Delphi. Esta camada foi desenvolvida com o intuito de promover e aprofundar os conhecimentos de Bancos de Dados de Tempo de Validade.

No nível físico foi adicionada uma coluna a cada tabela, correspondente à marca de tempo de tempo de validade. Esta marca de tempo é do tipo elemento temporal, ou seja, o conjunto de todos os instantes em que o evento, determinado pelo conjunto de atributos explícitos, foi verdadeiro no Universo de Discurso. O elemento temporal é formado por um conjunto finito de períodos, definindo assim tabelas de estado.

Nas seções a seguir são detalhados: o fragmento da linguagem que foi implementado, a arquitetura do sistema, a estrutura do compilador e um conjunto de testes.

Durante o decorrer do texto, vários exemplos são dados de forma a ilustrar os conceitos apresentados. As relações que seguem, serviram como base para os exemplos, e foram copiadas verbatim de [29].

São três relações de tempo de validade: EMP, que armazena o período em cada funcionário pertenceu a algum departamento da empresa, DEPT, que armazena os períodos que cada gerente gerenciou determinado departamento, bem como o orçamento daquele período e SKILLS, que armazena as habilidades de cada funcionário no decorrer do tempo. O modelo Entidade Relacionamento [9] está descrito na Figura 21. 


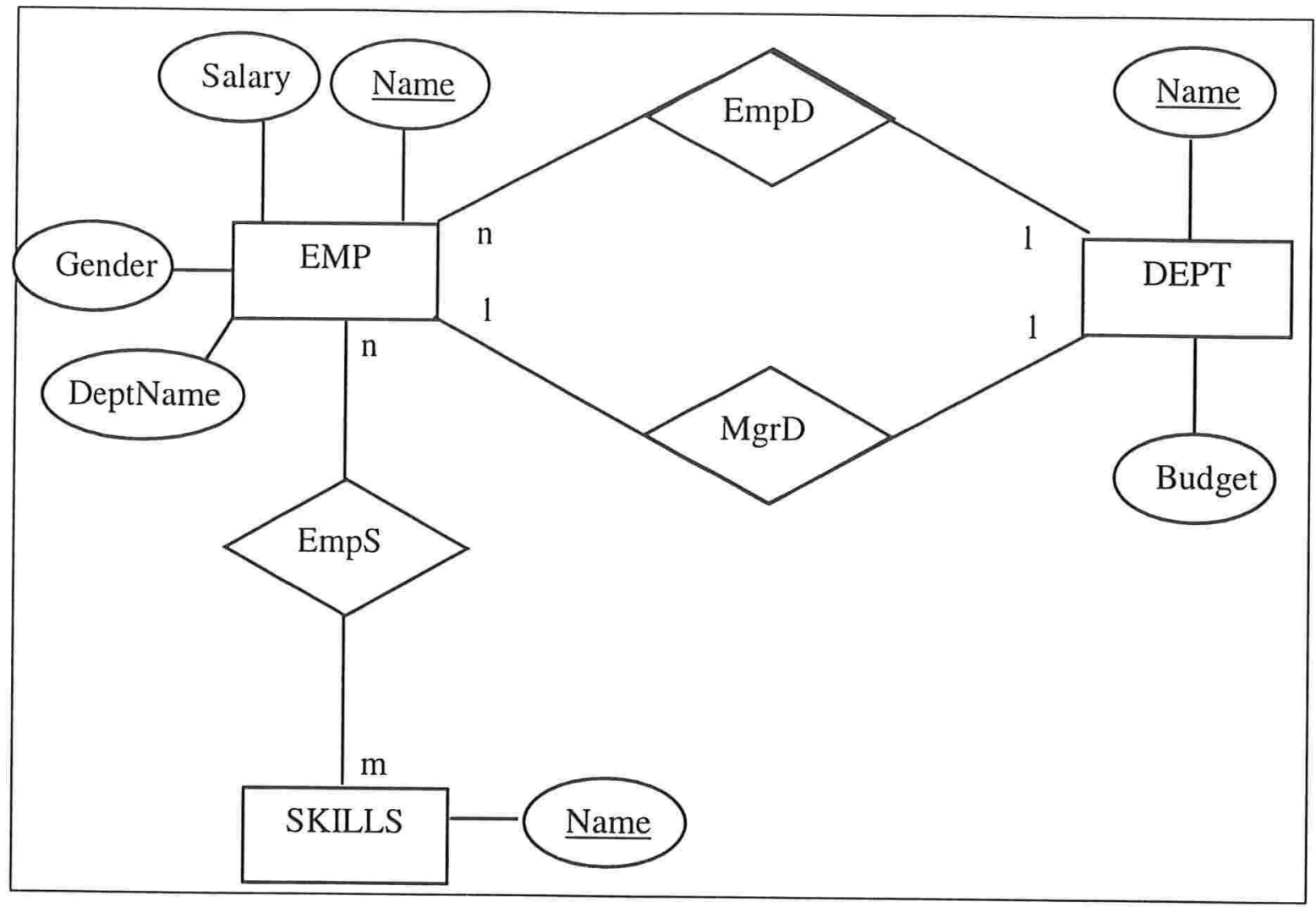

Figura 21 - Modelo Entidade Relacionamento das tabelas utilizadas

Fisicamente essas relações correspondem às tabelas EMP, DEPT e SKILLS. No texto serão utilizadas as seguintes instâncias dessas tabelas:

\section{EMP}

\begin{tabular}{|l|l|l|l|l|l|}
\hline \multicolumn{1}{|c|}{ ID } & Name & \multicolumn{1}{c|}{ Salary } & \multicolumn{1}{c|}{ Gender } & \multicolumn{1}{c|}{ DeptName } & \multicolumn{1}{c|}{ TIMESTAMP } \\
\hline ED & Ed & 20 & $\mathrm{M}$ & Toy & $01 / 02 / 8231 / 05 / 82$ \\
\hline ED & Ed & 30 & $\mathrm{M}$ & Toy & $01 / 06 / 8231 / 01 / 85$ \\
\hline ED & Ed & 40 & $\mathrm{M}$ & Toy & $01 / 02 / 8531 / 01 / 87$ \\
\hline ED & Ed & 40 & $\mathrm{M}$ & Book & $01 / 04 / 8731 / 12 / 87$ \\
\hline ED & Edward & 40 & $\mathrm{M}$ & Book & $01 / 01 / 8827 / 04 / 98$ \\
\hline DI & Di & 30 & F & Toy & $01 / 01 / 8231 / 07 / 84$ \\
\hline DI & Di & 40 & F & Toy & $01 / 08 / 8431 / 08 / 86$ \\
\hline DI & Di & 50 & F & Toy & $01 / 09 / 8627 / 04 / 98$ \\
\hline
\end{tabular}

Tabela 2 - Instância da tabela EMP 


\begin{tabular}{|l|l|l|l|}
\hline Name & Budget & MgrID & TIMESTAMP \\
\hline Toy & 200 & DI & $01 / 08 / 8431 / 12 / 86$ \\
\hline Toy & 150 & DI & $01 / 01 / 8231 / 07 / 84$ \\
\hline Toy & 100 & DI & $01 / 01 / 8727 / 04 / 98$ \\
\hline Book & 50 & ED & $01 / 04 / 8727 / 04 / 98$ \\
\hline
\end{tabular}

Tabela 3 - Instância da tabela Dept

\section{SKILLS}

\begin{tabular}{|c|c|c|}
\hline EmpID & Skill & TIMESTAMP \\
\hline ED & Typing & $01 / 04 / 8227 / 04 / 98$ \\
\hline ED & Filing & $01 / 01 / 8527 / 04 / 98$ \\
\hline ED & Driving & $01 / 01 / 82$ 01/05/82 01/06/84 31/05/1988 \\
\hline DI & Directing & $01 / 01 / 8227 / 04 / 98$ \\
\hline
\end{tabular}

Tabela 4 - Instância da tabela Skills

\section{II.3.1. Arquitetura}

Como já foi explicado anteriormente, a incorporação de tempo de validade a um Banco de Dados Estático no projeto é feita através da implementação de uma Camada Temporal entre o Banco e o usuário.

A arquitetura do projeto está explicitada na Figura 22. As setas correspondem ao fluxo de dados entre as várias partes do sistema.

Segue a descrição dos módulos:

- Módulo de Codificação: corresponde às funções de transformação do formato do tempo de validade compreensível pelo usuário para sua representação interna, mais eficiente. As marcas de tempo de uma informação, por exemplo, a data "1 de Janeiro de 1997", serão armazenadas no Banco como sequências de números hexadecimais.

- Módulo Interface: este módulo corresponde à interface gráfica, desenvolvida em Delphi [5], em que a sentença TSQL2 é recebida. A TSLQ2 é um superconjunto da SQL-92, permitindo, portanto, consultas não temporais. 
Se a sentença for temporal, será enviada ao tradutor, caso contrário, será enviada diretamente ao Banco de Dados Estático. A distinção entre uma consulta temporal ou não é realizada pelo próprio usuário que deve acionar opções diferentes na tela, como explicado em II.3.4. A sentença processada pelo Banco de Dados é devolvida ao módulo.

- Módulo Tradutor: este é o módulo principal da Camada Temporal. A senteça TSQL2 temporal é traduzida para um script em SQL compreensível ao Banco Oracle. Sempre que necessário este módulo se utilizará das funções do módulo de Codificação.

- Módulo de Funções e Procedimentos Auxiliares: foram armazenados no Banco Oracle, funções e procedimentos que são chamados pelos scripts gerados pelo Tradutor para decodificação, coalescência e outros.

É importante notar que não existe nenhum módulo de Decodificação porque a Decodificação é realizada no último módulo mencionado.

Uma questão bastante relevante diz respeito à independência de plataforma, discutida abaixo:

- O reconhecedor foi desenvolvido com gcc, no Linux Red Hat [6], e as rotinas semânticas foram desenvolvidas em $C$, utilizando Visual $C++$ sobre Plataforma $N T$. O reconhecedor é portável, mas as rotinas semânticas, dependendo da plataforma, podem necessitar de algumas alteraçãoes já que funções não-ANSI foram utilizadas.

- O compilador recebe sentenças TSQL2 e gera uma série de scripts em SQL-O que são enviados ao Oracle. Como o Oracle é compatível no nível Entry [1] com a SQL-92, esses scripts são portáveis para Bancos que sejam também compatíveis no nível Entry com a SQL-92, independendo da plataforma.

- O front-end utilizado foi o Delphi por ter comunicação nativa com o Oracle. Como não houve uma preocupação muito grande com a apresentação dos dados, o desenvolvimento em Delphi foi bastante pequeno e seria facilmente reproduzido em outro programa de front-end.

- As funções e procedimentos armazenados no Banco podem ser migradas, desde que o Banco seja compatível com o SQL-O. 


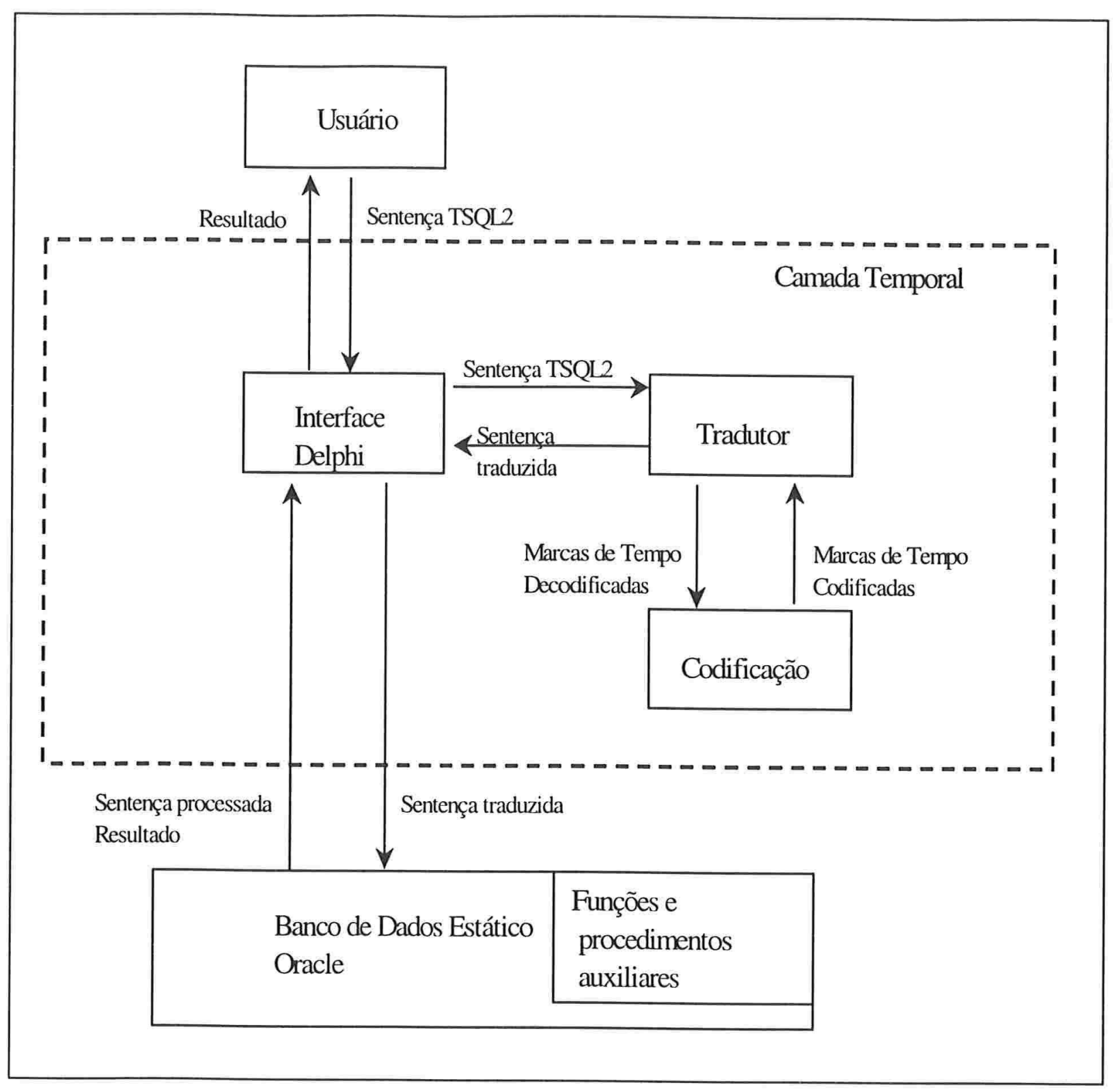

Figura 22 - Arquitetura da Camada Temporal

O processamento de uma consulta TSQL2 passa por vários estágios: análise sintática, análise semântica, gerador de scripts SQL-O, Interface, Banco Oracle. Não foi realizado tratamento de erros em nenhum desses níveis, ficando como sugestão para um futuro projeto. 


\section{II.3.2. Representação física do tempo}

Como Bancos de Dados Relacionais manipulam tabelas bi-dimensionais (colunas e linhas), é impositivo que se represente a marca de tempo relacionada a cada informação em forma de coluna. Apesar da marca de tempo ser representada fisicamente como uma coluna, precisa ser diferenciada tanto na sua interpretação quanto na sua manipulação. $\mathrm{Na}$ Relação 7, as colunas Nome e Título correspondem às colunas explícitas da tabela e são manipuladas nas sentenças TSQL2 diretamente (p.e. Presidentes.Nome); a coluna TIMESTAMP é implícita e representa a dimensão tempo de validade do evento representado pelas colunas explícitas. A Figura 23 mostra como as colunas explícitas Nome e Título são interpretadas diferentemente da coluna implícita TIMESTAMP. Apesar da representação física ser a mesma, a coluna que contém o tempo de validade está relacionada com a tupla inteira, pois representa o período em que a informação contido nas colunas explícitas foi válida no Universo de Discurso. Assim, se a relação for "fotografada" em 1930, o que se vê são os dados válidos de acordo com o conhecimento atual.

Em TSQL2, a marca de tempo não pode ser acessada diretamente (p.e. Presidentes.TIMESTAMP), apenas através da função VALID(<correlation name>) . Com isso fica transparente para o usuário sua representação física tornando mais intuitivo sua manipulação como dimensão e não como coluna.

Como já foi explicado em II.2, as tabelas terão marcas de tempo por tupla e não por atributo. 


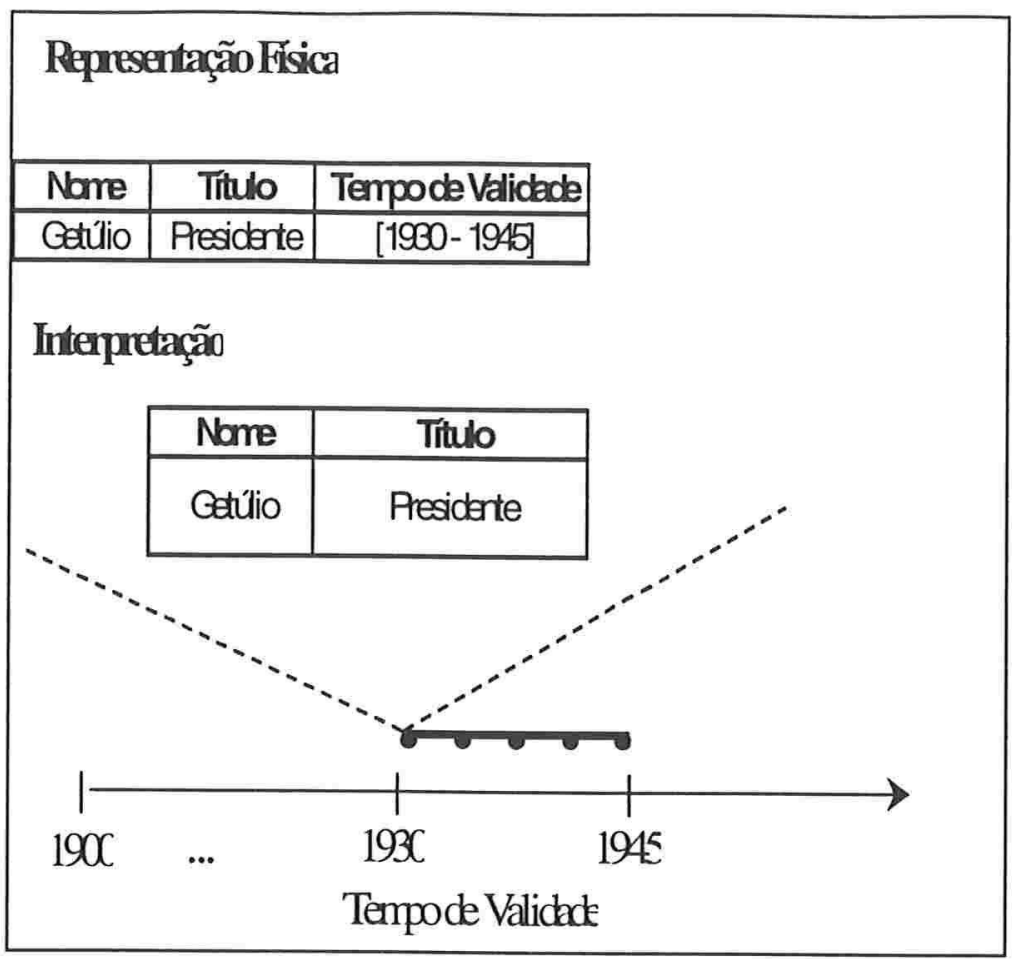

Figura 23 - A dimensão tempo é um atributo implícito

A Camada Temporal será testada por um subconjunto dos testes elaborados pelo Comitê de Desenho da TSQL2 para avaliar a linguagem [29]. Baseados nos testes escolhidos foram tomadas as seguintes decisões:

- A menor granularidade é Dia.

- As únicas granularidades aceitas são ANO, MÊS e DIA.

- Não se requer um suporte de mais de 100 anos para a linha do tempo.

Considerando que o tipo de dados escolhido para representar a marca de tempo possui um número limitado de bytes, ao se aumentar a granularidade (por exemplo de dias para segundos) diminui-se o intervalo possível de ser representado.

A marca de tempo é do tipo elemento temporal e o tipo de dados da coluna TIMESTAMP é $R A W$. O RAW é usado para armazenar dados binários ou sequências de bytes em que a interpretação depende da utilização. Um outro candidato seria o tipo de dados VARCHAR2, capaz de armazenar até 2000 bytes de caracteres. O problema é que, em Oracle, ao contrário do $R A W$, o VARCHAR2 é interpretado pelos utililitários $S Q L * N e t$ 
(conecta o usuário à instância) e Import/Export, ou seja, é automaticamente convertido para o character set da sessão destino caso os character sets sejam diferentes [1].

Cada período é representado por 8 bytes sendo 4 bytes para cada evento. Como a menor granularidade é dia, podem ser representados $2^{32}-1$ dias ou mais de $2^{23}$ anos, o que é mais do que suficiente para os testes. Os períodos serão armazenados em números hexadecimais, assim por exemplo o período 01/01/1982- 27/04/1998 será armazenado como o hexadecimal $00023992000250 \mathrm{DA}$ que ocupa 8 bytes. Os quatro primeiros bytes 00023992 corresponde ao número de dias entre 15/10/1582, data início do Calendário Gregoriano, e 01/01/1982. O mesmo acontece com os últimos quatro hexa 000250DA e a data final 27/04/1998. A cada tupla será possível associar 31 períodos, suficiente para os testes. A cada período maximal associado à tupla, um conjunto de 8bytes em hexadecimais é concatenado aos outros já existentes.

Para a manipulação das marca de tempo, por exemplo quando for necessária a coalescência da tabela, o $R A W$ é transformado no tipo de dados string. Com isso cada período passa a ocupar 16 bytes, um para cada dígito hexadecimal. Apesar do espaço de armazenamento dobrar, a situação só permanece durante a função ou procedimento que está manipulando as marcas de tempo.

Não é objetivo do projeto fazer uma análise profunda sobre qual a melhor representação física para a marca de tempo, mas notou-se que a representação utilizada não sobrecarrega o sistema, quer em tempo, quer em espaço. Por outro lado, esta representação dificulta bastante a tarefa de indexação temporal.

\section{II.3.3. Estrutura de dados do Tradutor}

O tradutor consta de um reconhecedor que fará a análise sintática da sentença TSQL2 que está entrando, e de rotinas semânticas que farão a geração de scripts SQL-O para o processamento no Banco. Essas rotinas semânticas usam programas de codificação para transformar os períodos das marcas de tempo, definidas pelos usuários, na representação interna hexadecimal. O tradutor é incorporado como DLL no front-end. 


\section{$\underline{\text { Reconhecedor }}$}

O analisador sintático foi desenvolvido com Bison [4], um gerador automático de analisadores sintático bottom-up com 1 lookahead [14]. O arquivo de entrada é uma gramática $\operatorname{LALR}(1)$ [14] representada com a notação BNF (Backus-Naur Form) [14], e o arquivo de saída é o analisador sintático em $C$ para esta gramática.

Segue abaixo uma descrição resumida da notação BNF.

- Todo tipo de unidade sintática ou grupo é chamada de símbolo.

- Os símbolos formados por um grupo de construções menores são não-terminais.

- Os símbolos que não podem ser divididos correspondem a terminais ou tipos de átomos.

No exemplo:

iden: IDEN;

iden é um não terminal e IDEN é um átomo e, portanto um terminal.

A gramática descrita é a TSQL2, com algumas simplificações. Estas simplificações foram feitas nas partes do grafo que não foram implementadas, como mostra a Figura 24. Na TSQL2, a <boolean factor> é composta pela <boolean test>, porém, como só a regra $<$ boolean primary>, componente da <boolean test $>$ foi implementada, optou-se por colocar a regra <boolean primary $>$ no lugar da $<$ boolean test $>$.

Como apenas uma parte pequena da TSQL2 seria implementada, partes do grafo foram simplificadas para que as estruturas para o processamento, detalhadas adiante, não ficassem muito complexas. O maior impacto desta decisão é quanto ao esforço a ser feito para a extensão das funcionalidades implementadas.

Para a análise léxica foi utilizado o programa Flex [3]. O código desenvolvido para a análise léxica não será detalhado por não ser relevante para projeto. 


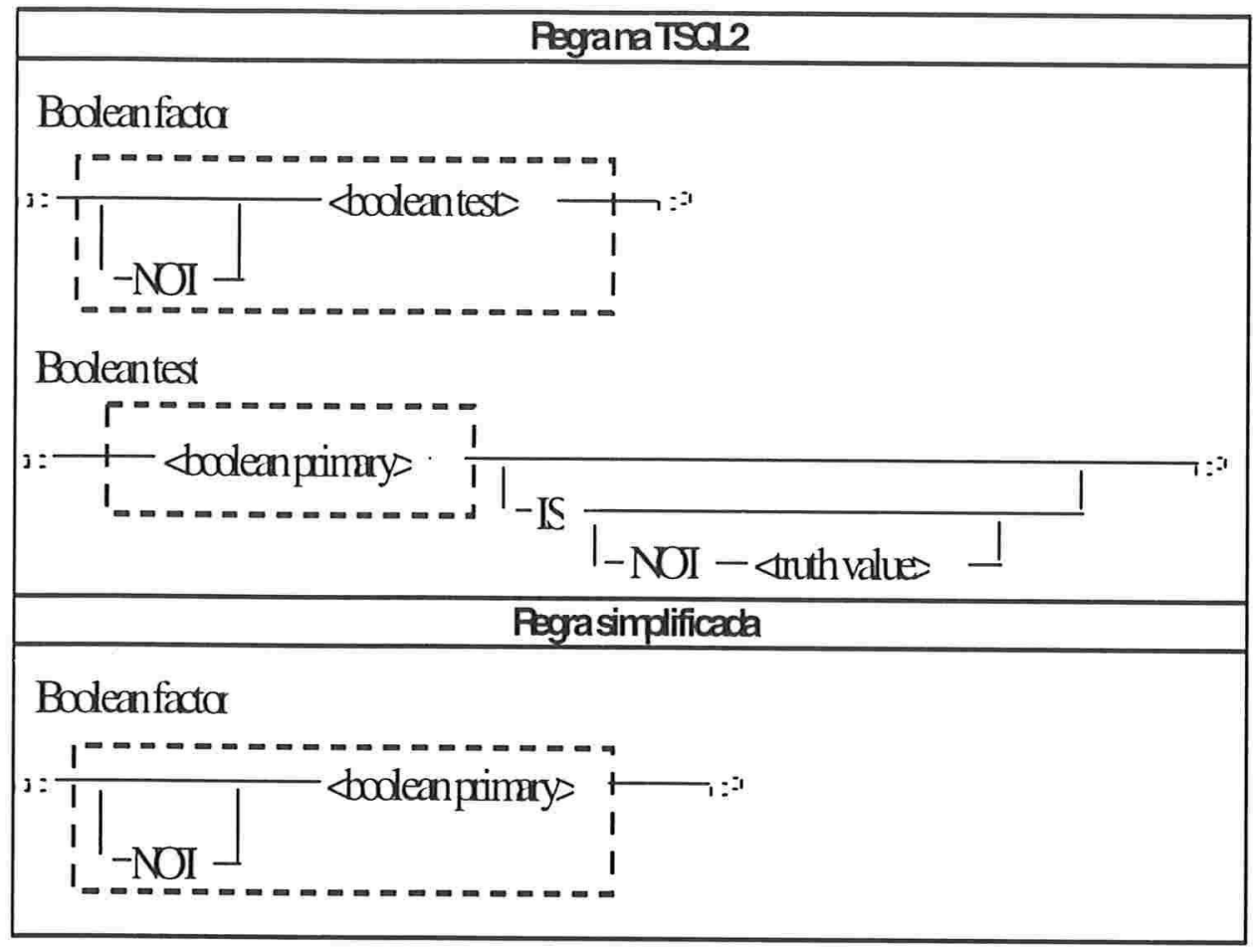

Figura 24 - Simplificação de uma regra TSQL2

\section{Árvore Sintática}

À medida que o reconhecimento acontece, uma árvore sintática, composta por uma série de estruturas com ponteiros, é gerada.

O intuito é de permitir o posterior processamento, na ordem adequada, da sentença corrente. A Figura 25 mostra a árvore gerada pela sentença:

SELECT empregados.nome

FROM empregados.

A estrutura inic define se a sentença é um Insert, SELECT (Query Spec) ou Create. No caso do exemplo a sentença é uma consulta, representada pela query_spec. Esta, contém: 
- um flag, dist_all_flag, indicando se a consulta permitirá ou não tuplas idênticas (ALL ou DISTINCT) [1];

- um ponteiro, sub_list, para uma possível lista de colunas sobre as quais será realizada a projeção;

- um flag, tipo_valid_clause, indicando ou não, a existência de uma <valid clause> explícita, que no caso em questão, não existe;

- um ponteiro, table_expression, para as <from clause $>$ e $<$ where clause $>$.

De forma semelhante, a lista de colunas, sub_list, é formada por uma série de estruturas que conterão todas as colunas que serão projetadas. A table_expression, por sua vez, possui ponteiros para a seleção, condition, para a $\langle$ valid clause $\rangle$, e para a $<$ from clause $>$, from. No caso do exemplo, que é bastante simples, não são especificados a $<$ valid clause $>$ nem a $<$ where clause $>$. Finalmente, a table_reference encabeça a estrutura na qual estarão "penduradas" todas as tabelas das quais serão retirados os dados da consulta. 


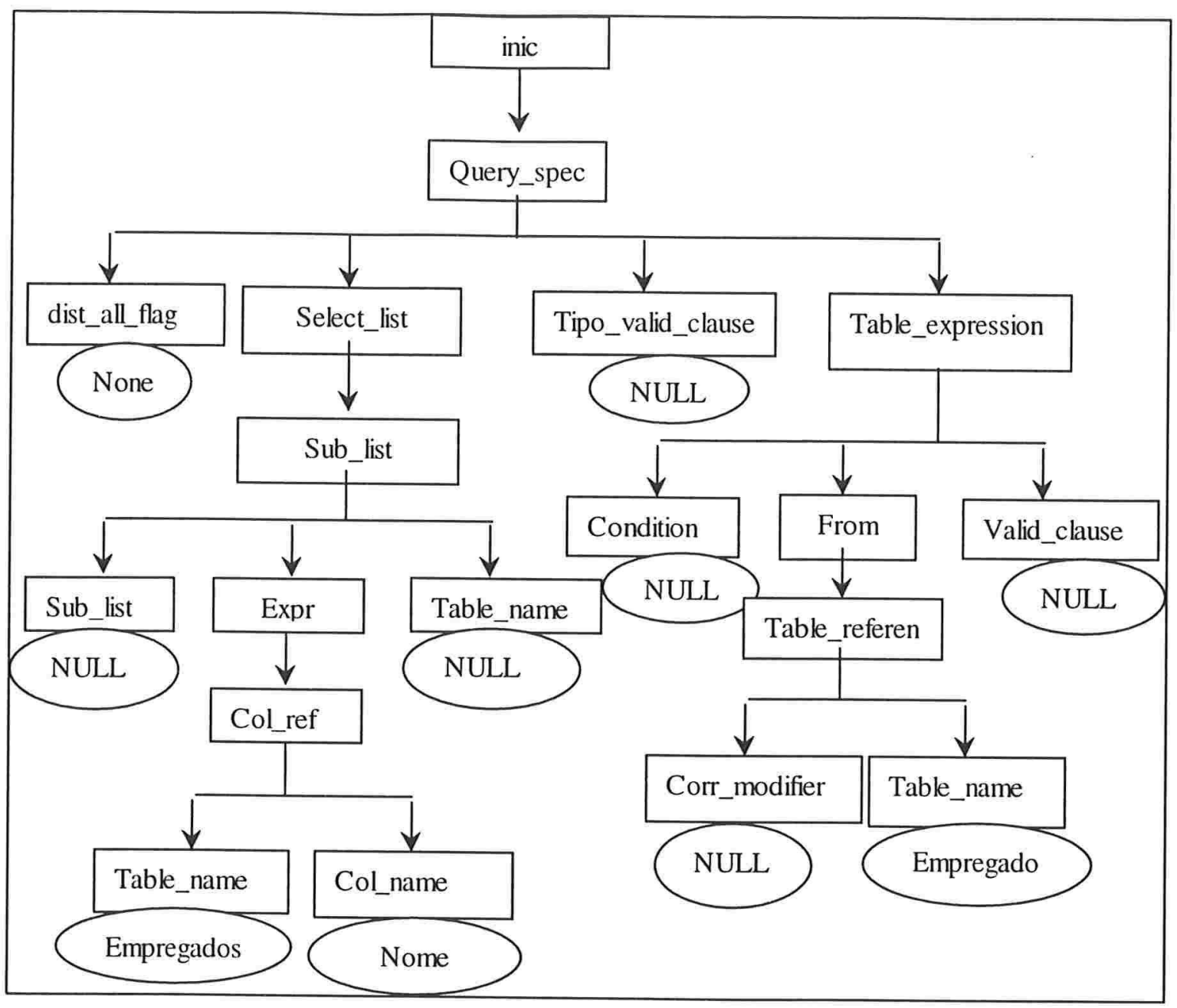

Figura 25 - Árvore sintática gerada pelo reconhecedor

Esta árvore sintática poderia ser transformada em uma notação algébrica e sobre esta, realizada otimização para processamento. Dado o escopo limitado do projeto, fica como sugestão o desenvolvimento da otimização das sentenças.

Após a geração da árvore sintática, o processamento é realizado seguindo a ordem mostrada na Figura 26. Inicia-se pela <from clause $>$ que contém as tabelas sobre as quais os dados serão obtidos. Para cada <table reference>, é verificada a necessidade de geração de uma tabela temporária, como será visto adiante. Com o processamento de todas as <table reference>, o produto cartesiano entre elas é feito e gerada a tabela temporária CT_RESULTADO_FROM. Para que não haja incompatibilidade de colunas, as colunas das tabelas são concatenadas com os nomes das tabelas correspondentes, acontecendo o mesmo com a coluna TIMESTAMP de cada uma delas. Neste momento, não se sabe se a consulta é temporal. 
Faz-se, então, a seleção sobre essa tabela gerando uma nova tabela, a CT_RESULTADO_WHERE. Apesar de ser apenas uma seleção de tuplas, é preciso lembrar que as colunas estão concatenadas com o nome de suas tabelas correspondentes.

Em seguida, verifica-se se o resultado deve conter marcas de tempo associadas as tuplas resultantes. Para isso, são verificados os tipos das tabelas envolvidas, a existência de uma $<$ valid clause > explícita e da palavra SNAPSHOT. Caso positivo, a coluna TIMESTAMP é criada e "populada" segundo a < valid clause > vigente. As projeções temporal e estática são aplicadas gerando a tabela CT_RESULTADO_SELECT à qual se aplica o processo de coalescência. .

O projeto assume que todas as tabelas são temporais, e portanto, não faz a verificação do tipo da tabela. Para tal, seria necessária a criação de uma tabela, que faria parte do dicionário de dados, em que se armazenaria o tipo de cada tabela, juntamente com outras características especificadas em [36]. A inclusão desta resultaria em mais interações com o Banco Oracle para busca de informação sobre as tabelas. Isto acarretaria uma complexidade maior de código que não impacta nas conclusões obtidas.

Esta seção mostrou de forma geral o processamento de uma consulta. Em II.3.5 serão enfocados os scripts gerados em cada uma das fases apresentadas na Figura 26. 


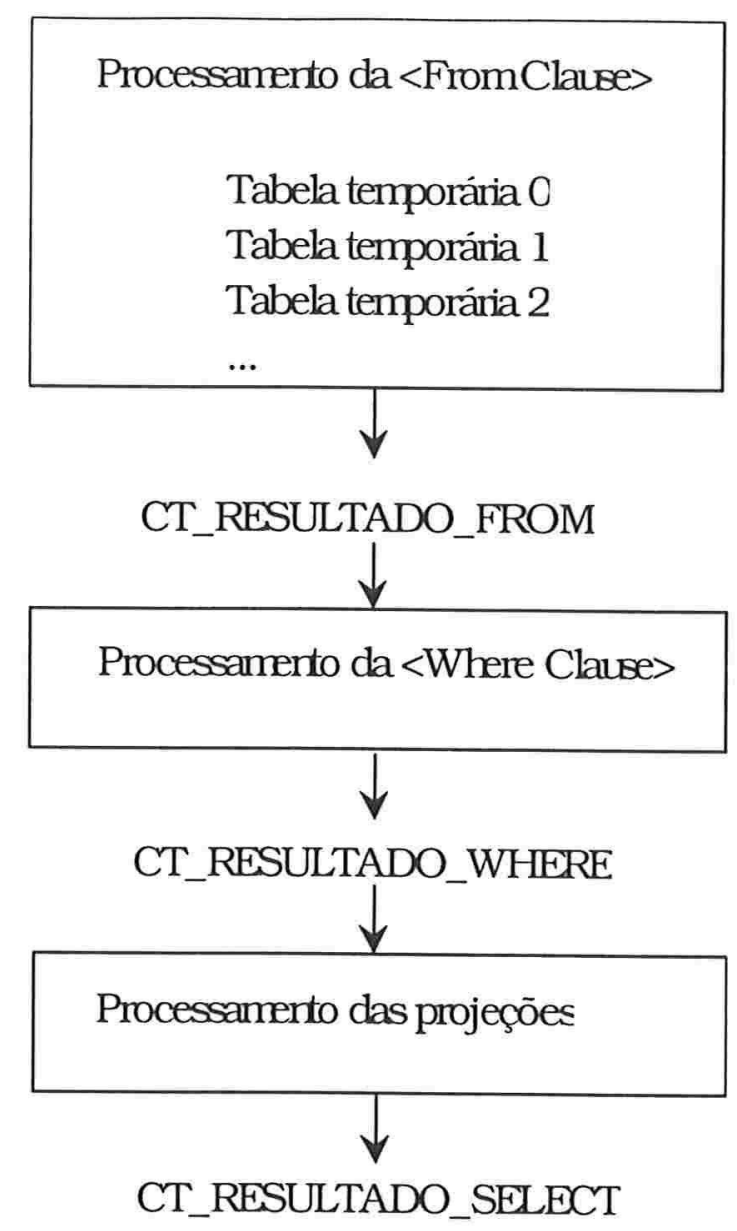

Figura 26 - Sequência de geração de scripts durante a tradução

\section{II.3.4. O front-end da Camada Temporal}

O front-end, desenvolvido em Delphi, permite que sejam feitas consultas ou sentenças de Create, Insert ou Delete. A Figura 27 mostra a tela principal, onde as sentenças são digitadas. 


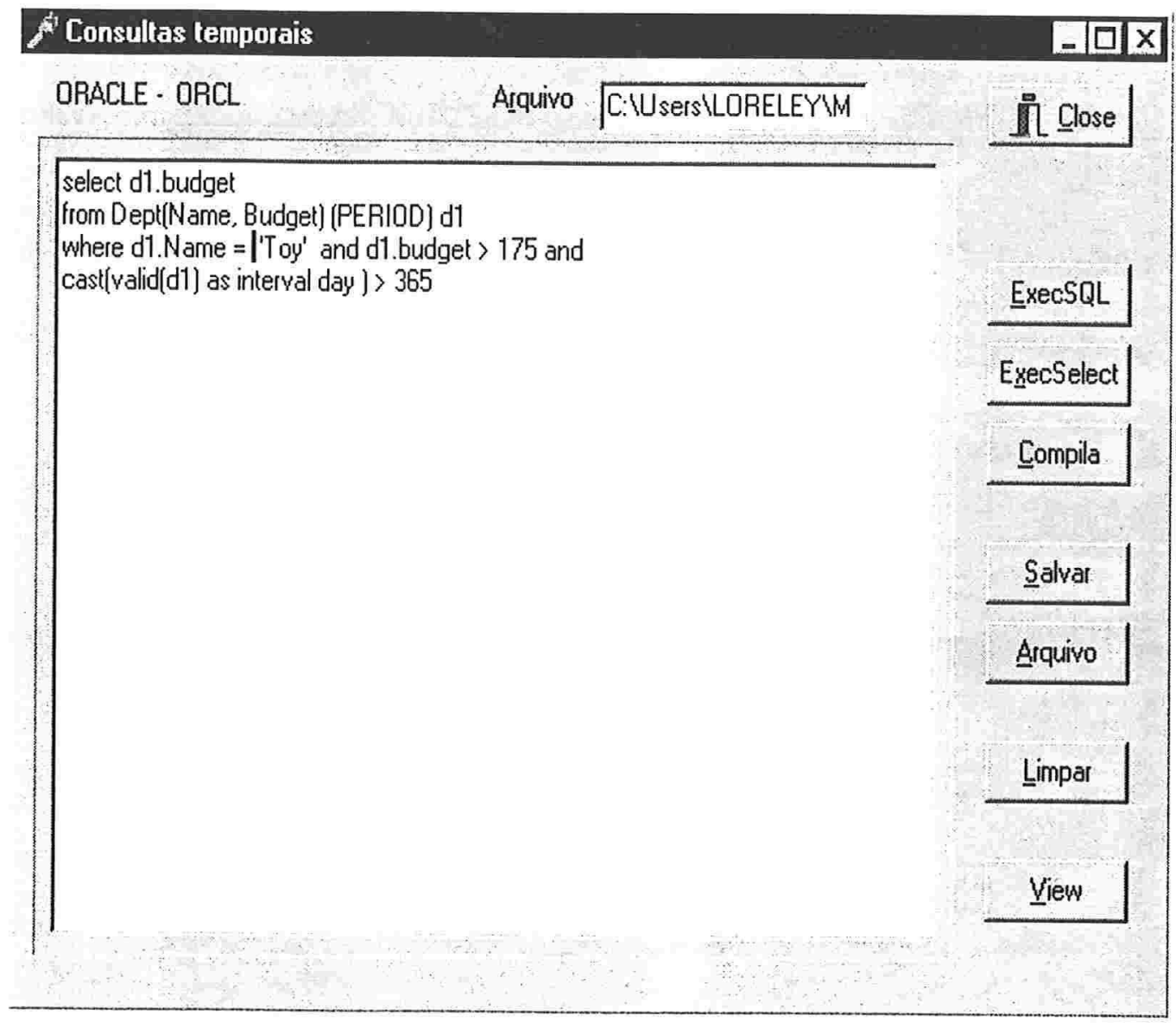

Figura 27 - Tela principal do sistema

Segue a descrição de cada um dos pontos de menu:

- Close: fecha a aplicação.

- ExecSQL: executa uma sentença que pode ser um create ou insert.

- ExecSelect: executa a consulta. A Figura 28 mostra o resultado da consulta apresentada em Figura 27. Nesta tela as colunas explícitas aparecem no grid do centro. O elemento temporal relacionado, caso seja um resultado temporal, à tupla destacada aparece no campo inferior intitulado MARCA DE TEMPO.

- Compila: executa a tradução da sentença TSQL2 para um script SQL-O. 
- Salvar: salva o script ou sentença que aparece na tela.

- Arquivo: carrega um script ou sentença armazenado em um arquivo.

- Limpar: limpa a tela.

- View: executa a consulta com visualização do resultado.

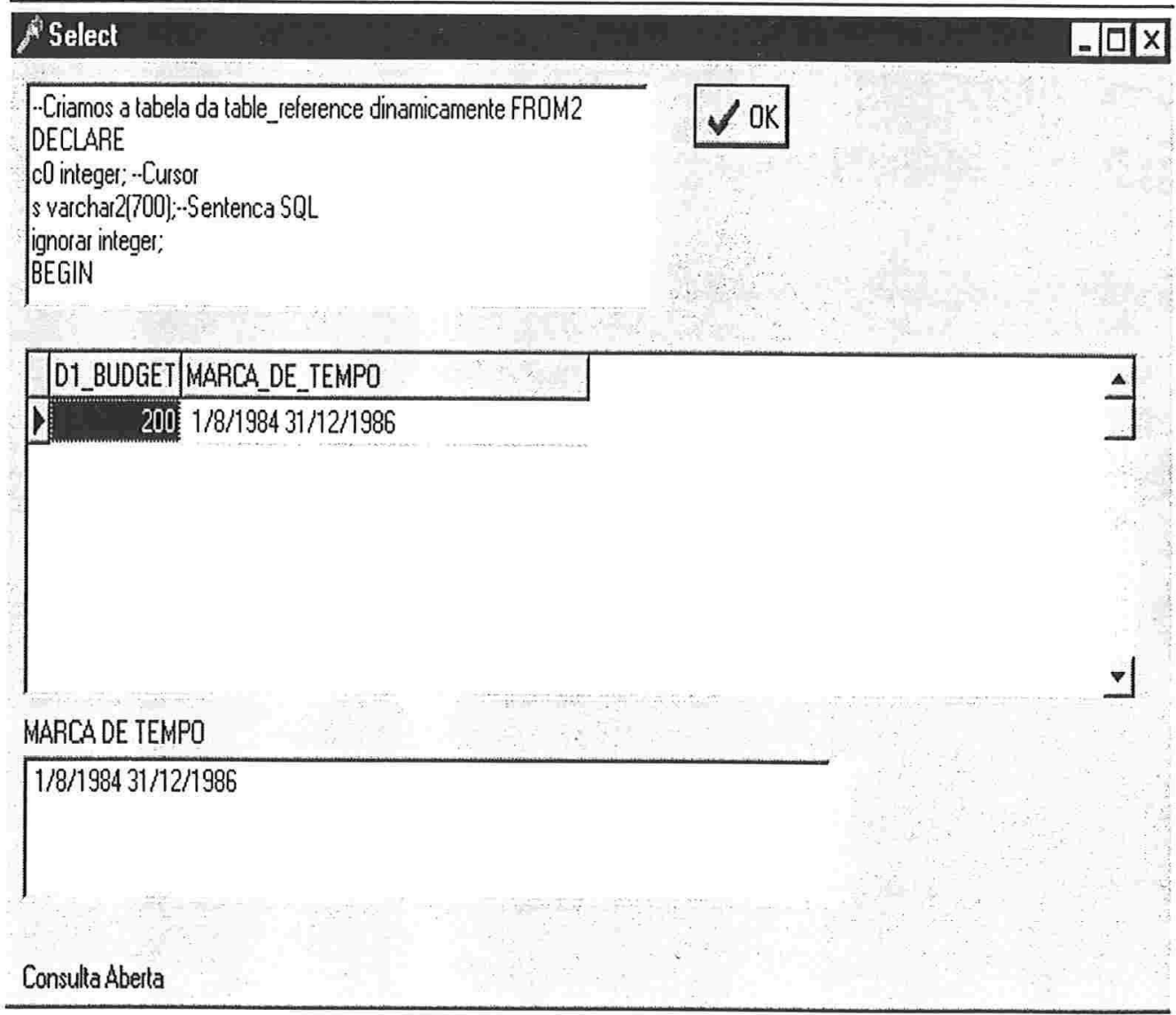

Figura 28 - Tela de resposta do sistema

A tela principal recebe também sentenças SQL-O. Isto porque a sentença só é traduzida de TSQL2 para SQL-Oracle ao se acionar a opção Compila. Desta forma é possível comparar o resultado de se realizar a mesma consulta usando o tradutor e enviando a sentença diretamente ao banco.

No Capítulo que segue, a Camada é testada através de exemplos temporais e não temporais. 


\section{II.3.5. Tópicos principais de implementação}

Nesta seção serão enfocados os scripts gerados em cada uma das fases apresentadas na Figura 26. No final da seção foi acrescentada uma tabela com a listagem e suscinta descrição de cada um doa procedimentos e funções armazenadas no Banco Oracle.

Como ilustração será utilizada a consulta:

SELECT SNAPSHOT E3. name

FROM Dept(Name, MgrId) D1, Emp (ID) EM, Emp (ID, DeptName) (PERIOD) E2, Emp (ID, Name, DeptName) E3

WHERE E2.ID $=$ E3. ID AND E2. DeptName $=$ E3. DeptName AND

D1.MgrId $=$ EM. ID AND D1. Name $=$ E2 . DeptName AND

CAST(VALID(E2) AS INTERVAL DAY) > CAST(VALID (EM) AS INTERVAL DAY) AND VALID (E2) OVERLAPS VALID (D1)

Esta consulta corrresponde à pergunta "Quem trabalhou continuamente em um departamento por mais tempo que seu gerente atual trabalhou no departamento?". A palavra SNAPSHOT indica que a consulta é estática. A função cast (valid(E2) as interval day) devolve a somatória dos dias existentes nos períodos das marca de tempo de E2.

O primeiro processamento a ser realizado é o da regra $<$ from clause $>$.

Para cada <table reference> é gerado um script de um ou mais blocos, conforme necessário. À medida que as <table reference > são processadas, um vetor com as tabelas originais ou tabelas intermediárias é criado para posterior criação da CT_RESULTADO_FROM. No caso da consulta em questão, serão criadas quatro tabelas intermediárias, uma para cada <table reference $>$. 
A Figura 30 mostra a localização das rotinas semânticas que fazem parte do processamento da $<$ from clause $>$. As produções apresentadas são as simplificadas, ou seja, contém apenas as partes implementadas.

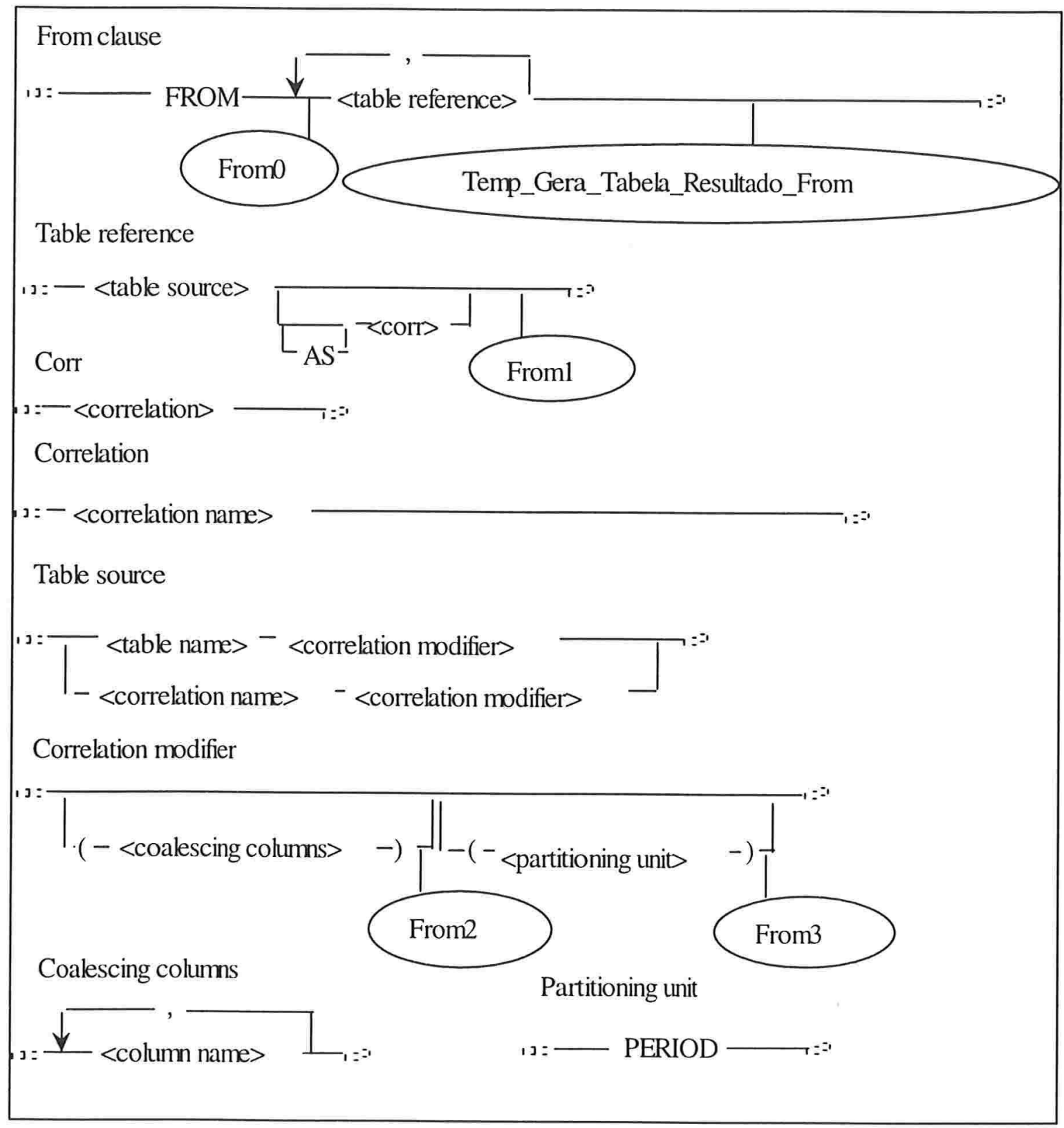

Figura 29 - Rotinas Semânticas na cláusula from

Para cada <table reference $>$ a ordem das rotinas é a seguinte: 
- from0: se a <table reference> for apenas o nome de uma tabela sem nenhuma regra $<$ correlation modifier>, então nada é preciso ser feito; caso contrário, scripts precisam ser gerados e para isso a rotina froml é chamada.

- froml: se não há um alias para a tabela que está sendo modificada pela <correlation modifier $>$ gera-se a temporária. No caso, os alias seriam D1, EM, E2 e E3. Após a criação, chama-se a rotina from 2 .

- from2: se existem <colaescing columns>, é gerado um script em que é criada uma tabela intermediária com o nome do alias relacionado. Essa tabela corresponde à projeção das colunas da <coalescing columns $>$ sobre a tabela original. No caso da primeira <table reference> do exemplo (Emp (ID, DeptName) (PERIOD) E2), é criada uma tabela intermediária chamada E2 com as colunas explícitas ID, DeptName e uma coluna implícita de marca de tempo TIMESTAMP, através do script:

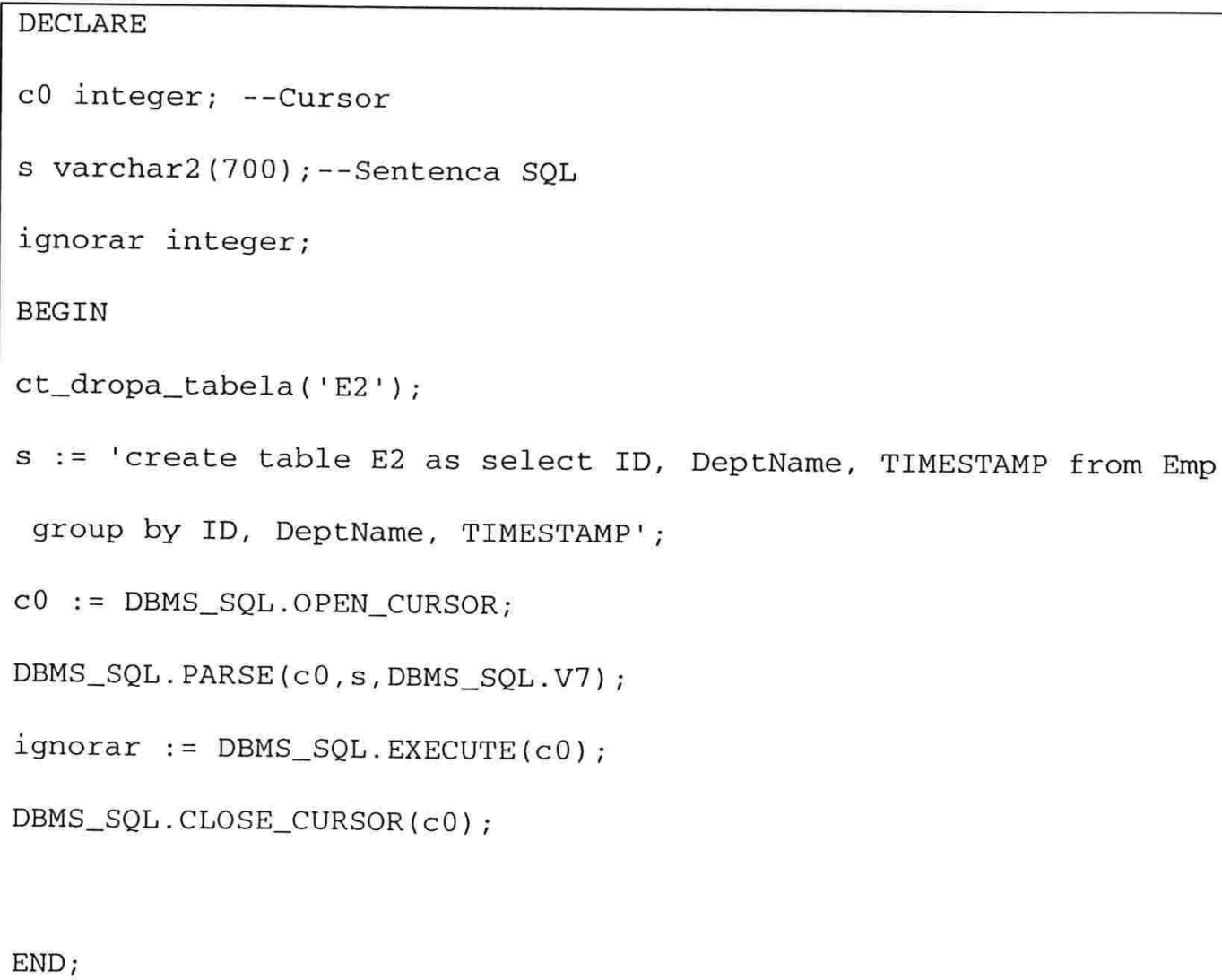


O $D B M S \_S Q L$ é um pacote interno do Oracle que permite a execução de sentenças SQL construídas em tempo de execução [1]. Como mostra o script, a tabela é gerada com as tuplas ordenadas (GROUP BY). Esta ordenação é importante para otimizar a rotina de coalescência apresentada a seguir. Como a projeção pode resultar em tabelas não coalesçadas, é preciso coalesçar a tabela gerada. O script para coalescência da D1 é o seguinte: 


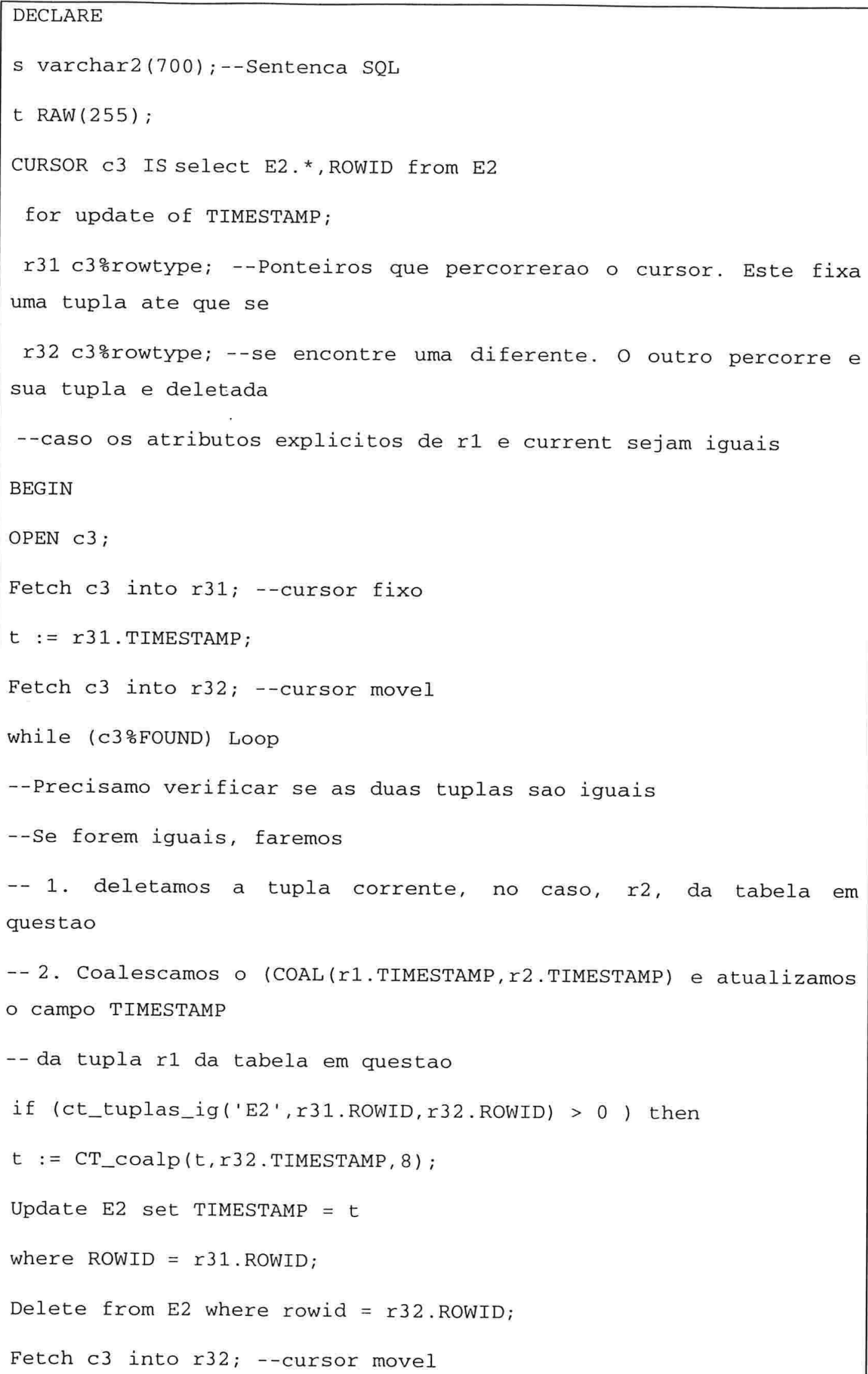




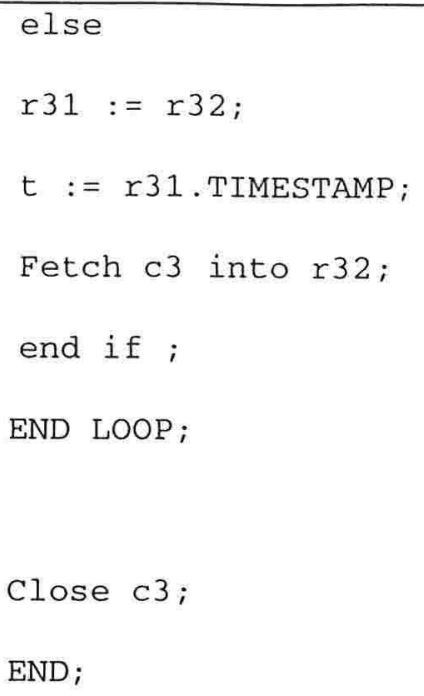

O script para coalescência assume que as tabelas estão ordenadas. Esta premissa é garantida pelo script anterior que ordena as tuplas. O algoritmo de coalescência trabalha com um cursor (c3) da tabela a ser coalesçada e duas variáveis de cursor r31 e r32 Uma delas serve como um apontador para a tupla sendo coalesçada enquanto a outra variável move-se através das outras tuplas com atributos explícitos idênticos a aqueles da tupla apontados pela primeira variável. À medida que as tuplas são coalesçadas, uma delas é excluída. Depois da coalescência, a rotina from3 é chamada.

- from3: caso um particionamento seja requerido, dada a presença da palavra reservada PERIOD, um script transforma a tabela coalesçada em uma tabela particionada em períodos maximais. Este é o único caso em que a tabela temporal pode possuir tuplas com valores explícitos idênticos. A seguir está o código para particionar a tabela E2:

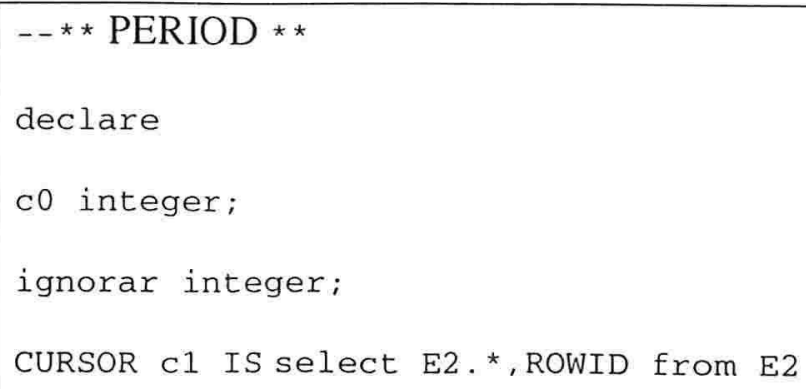




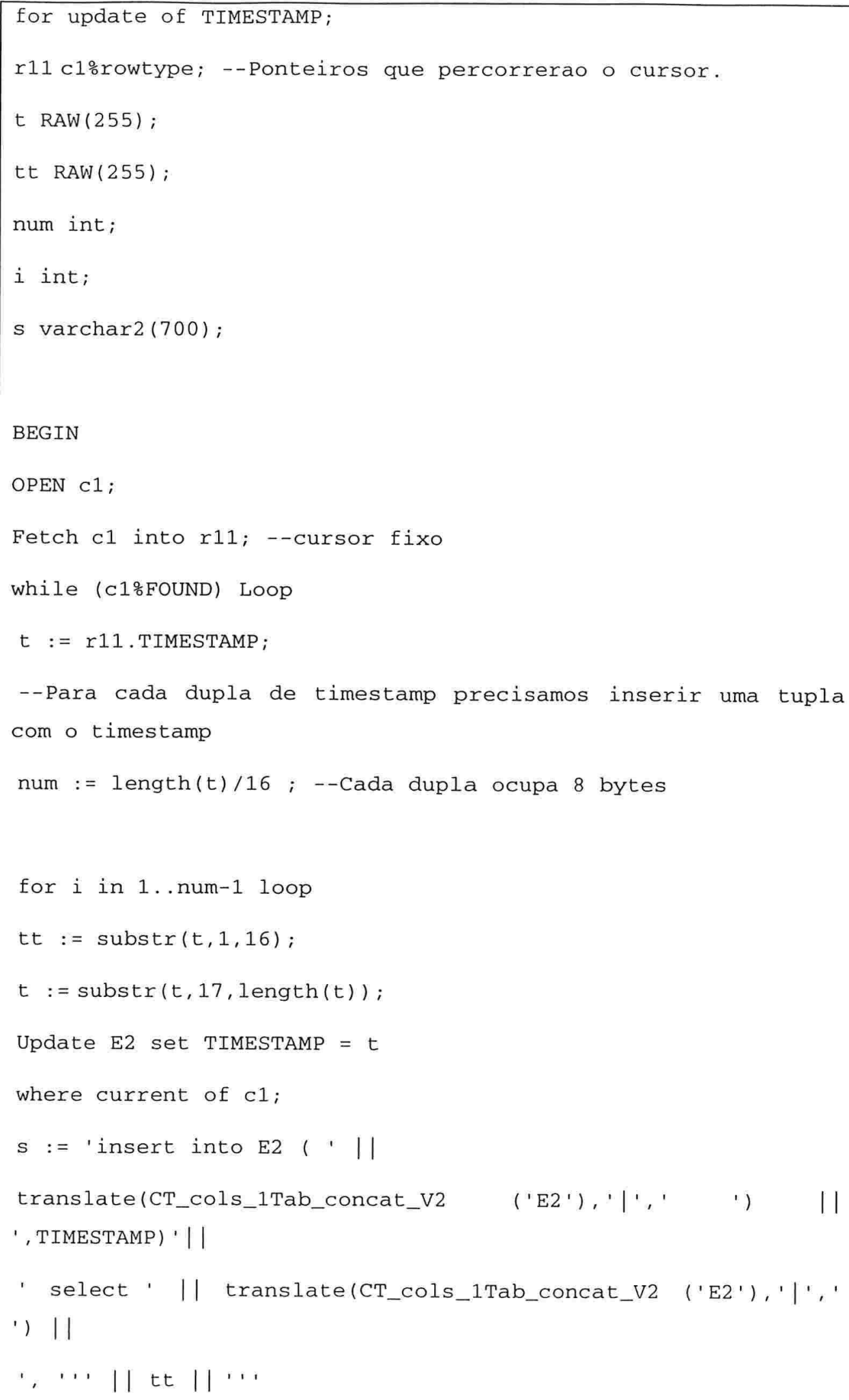




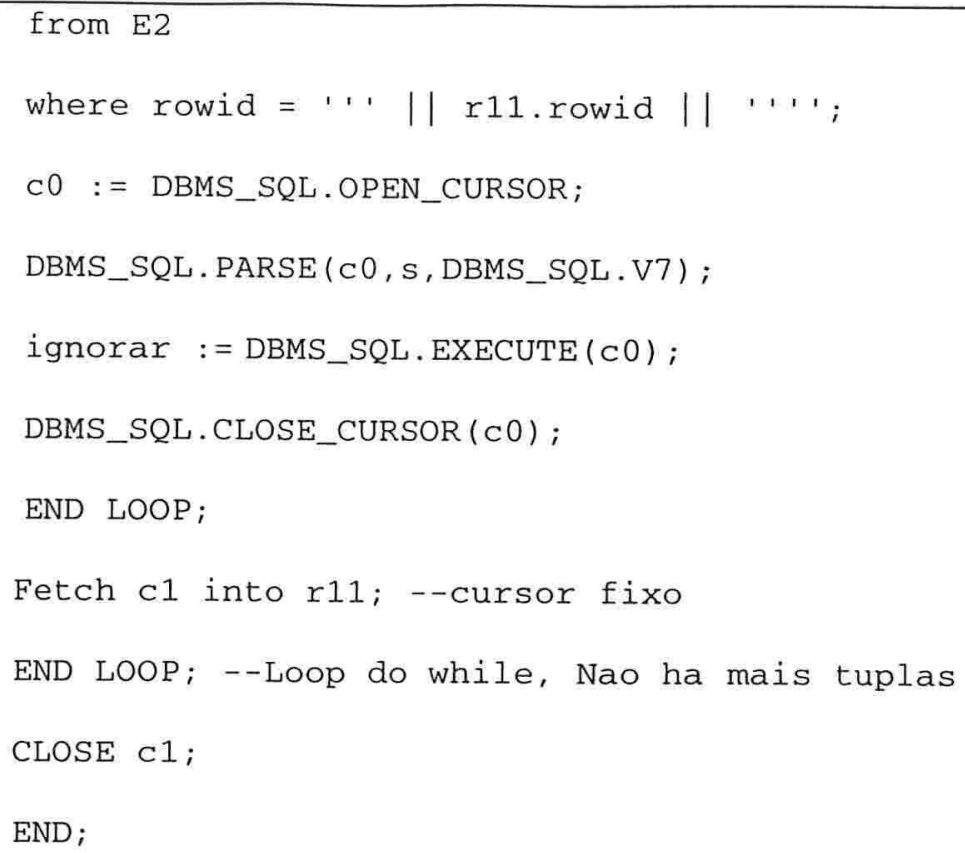

Para cada tupla, são geradas tantas tuplas quantos forem os períodos maximais que compõem a marca de tempo.

Após o processamento de todas as <table reference $>$, é feito um produto cartesiano com todas as tabelas relacionadas, gerando-se a tabela CT_RESULTADO_FROM, como mostra o script a seguir:

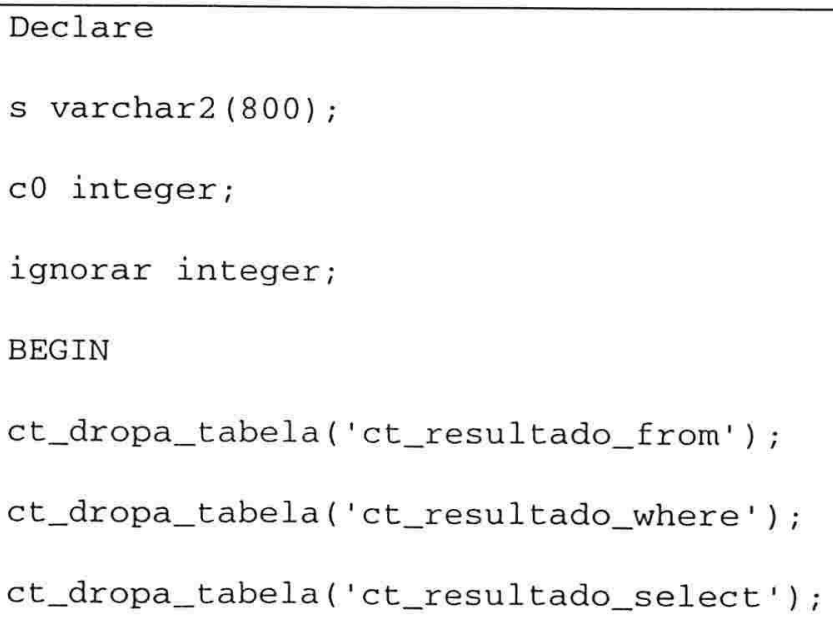




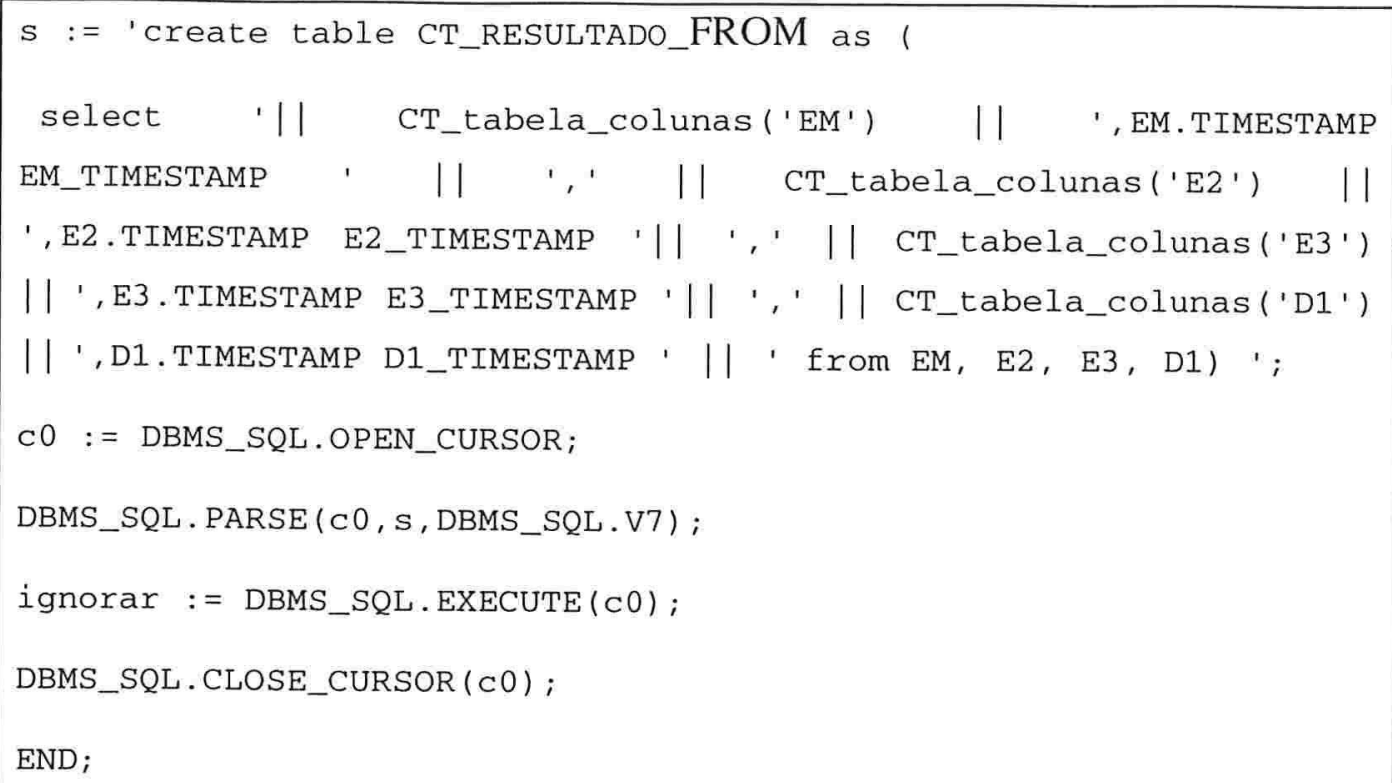

Os nomes das colunas são concatenados aos das tabelas de origem para que não haja problemas com nomes de colunas iguais. Assim por exemplo, a coluna Name da tabela temporária D1 corresponde à coluna D1_Name na CT_RESULTADO_FROM.

A <where clause $>$ é processada sobre a tabela CT_RESULTADO_FROM e cria-se a tabela CT_RESULTADO_WHERE:

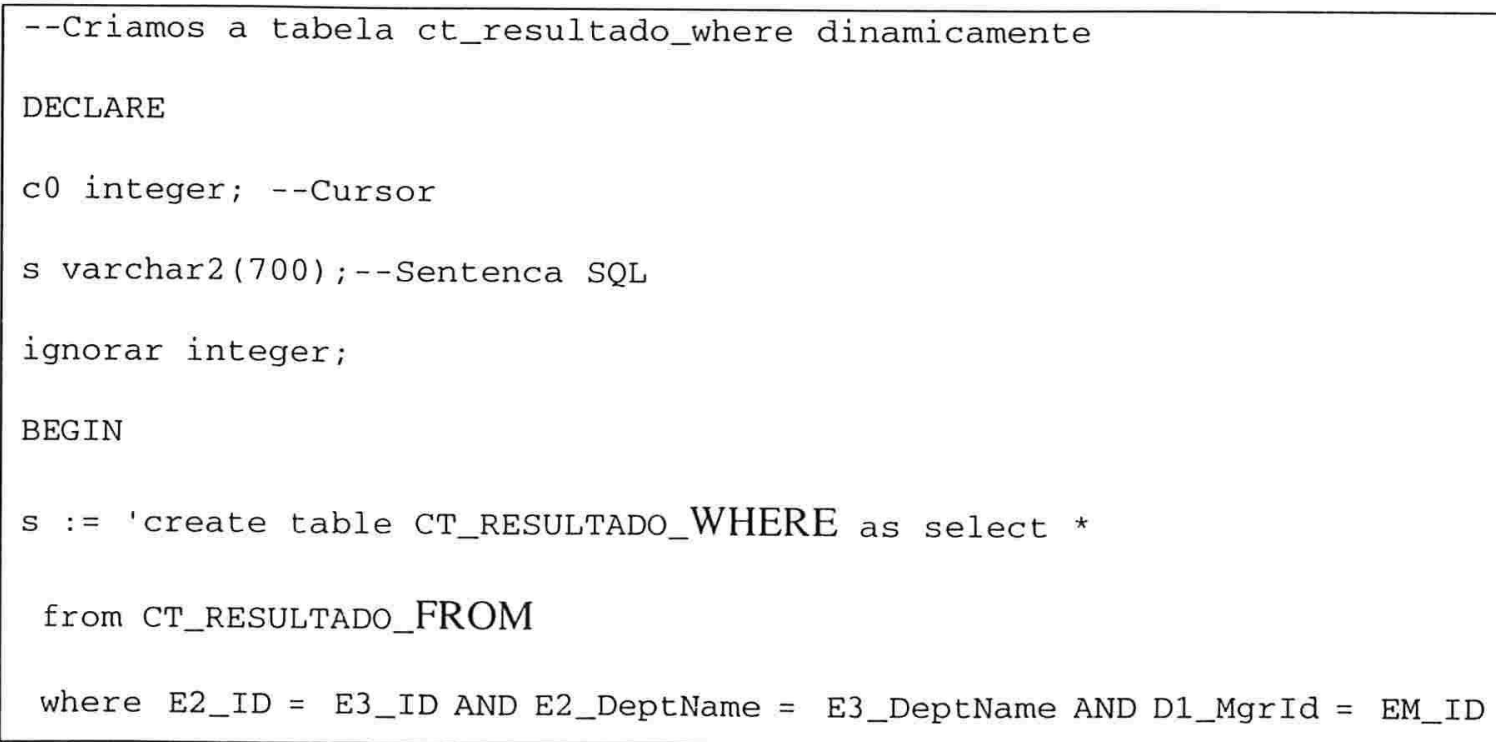




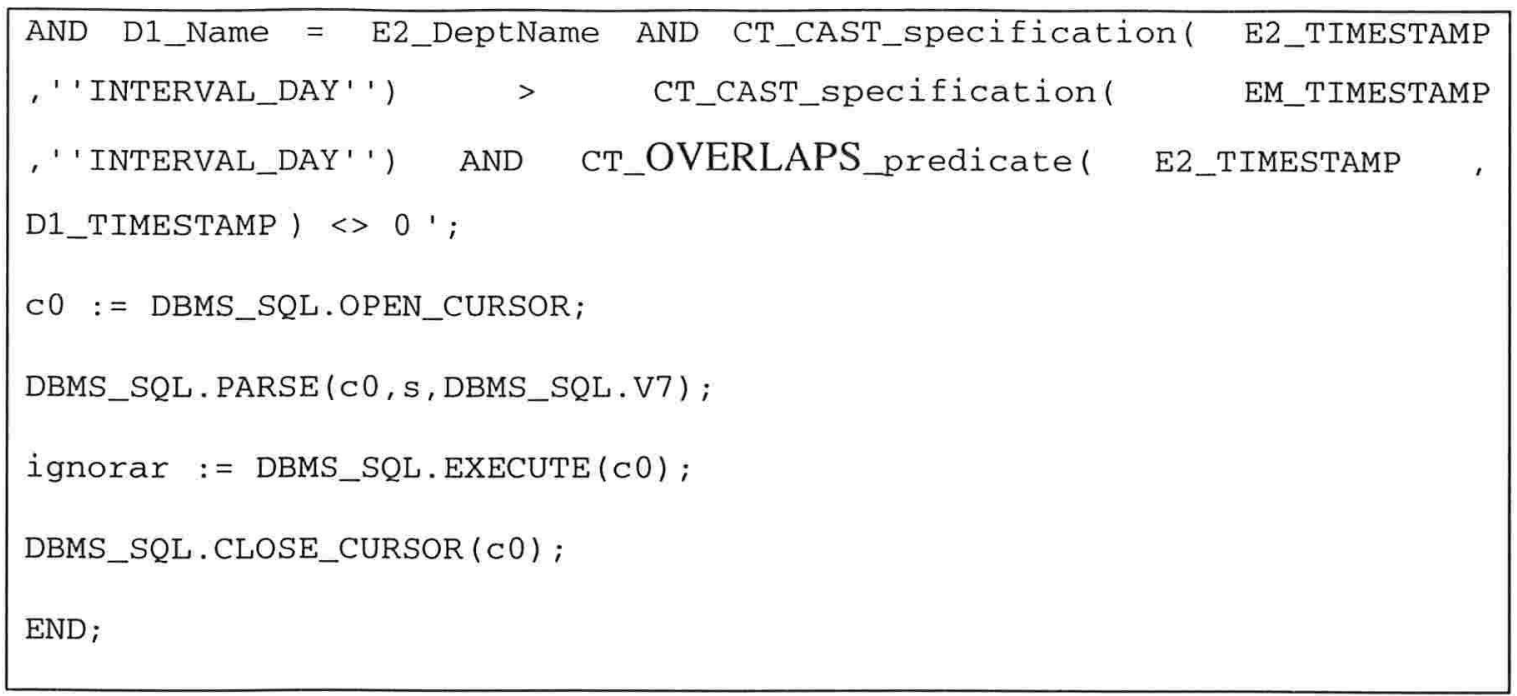

Após a palavra reservada WHERE a regra <predicate> é processada. Serão analisados cada uma das < predicate> presentes na consulta exemplo para ilustração. Todas as referências a colunas são traduzidas como a concatenação do nome da tabela de origem com o nome da coluna. Desta forma, os predicados E2. ID $=$ E3. ID, E2. DeptName = E3. DeptName, D1.MgrId = EM.ID, D1. Name = E2. DeptName, são traduzidos respectivamente para E2_ID $=$ E3_ID, E2_DeptName = E3_DeptName, D1_MgrId = EM_ID, D1_Name = E2_DeptName.

No caso dos predicados temporais são usadas funções armazenadas no Banco de Dados.

O predicado CAST(VALID (E2) AS INTERVAL DAY) > CAST(VALID(EM) AS INTERVAL DAY) é traduzido para CT_CAST_specification(E2_TIMESTAMP , ' ' INTERVAL_DAY' ' ) >CT_CAST_specification(EM_TIMESTAMP, ' ' INT ERVAL_DAY' '). A rotina CT_CAST_specification recebe como parâmetro o nome da coluna da marca de tempo (neste caso o nome da coluna de origem concatenado com TIMESTAMP) e a granularidade (neste caso intervalo em dias), e devolve a conversão do elemento temporal na granularidade especificada. Neste caso específico será devolvido o total da somatória do número de dias contidos em cada um dos períodos maximais do elemento temporal da marca de tempo em questão. Já o predicado VALID (E2) OVERLAPS VALID (D1) será traduzido como CT_OVERLAPS_predicate ( E2_TIMESTAMP , D1_TIMESTAMP ) <> 0, em 
que a rotina CT_OVERLAPS_predicate recebe o nome de duas colunas de marca de tempo e devolve 0 se nenhum dos períodos maximais dos elementos temporais das duas marcas de tempo se interseccionam.

A tabela CT_RESULTADO_WHERE contém todos as marcas de tempo das tabelas que eram temporais como colunas explícitas cujos nomes são a concatenação da tabela de origem com TIMESTAMP.

Após a geração da CT_RESULTADO_WHERE verifica-se se o resultado da consulta é ou não temporal. Caso SNAPSHOT não esteja presente e alguma das tabelas da <from clause > seja temporal, acrescenta-se a coluna TIMESTAMP e é chamada uma rotina para verificar qual cláusula de validade deve ser aplicada. No caso da consulta em questão, esse script não é gerado porque o resultado é uma tabela estática como mostra a presença da palavra reservada SNAPSHOT.

Segue o procedimento executado caso a consulta seja temporal e a cláusula de validade seja a padrão:

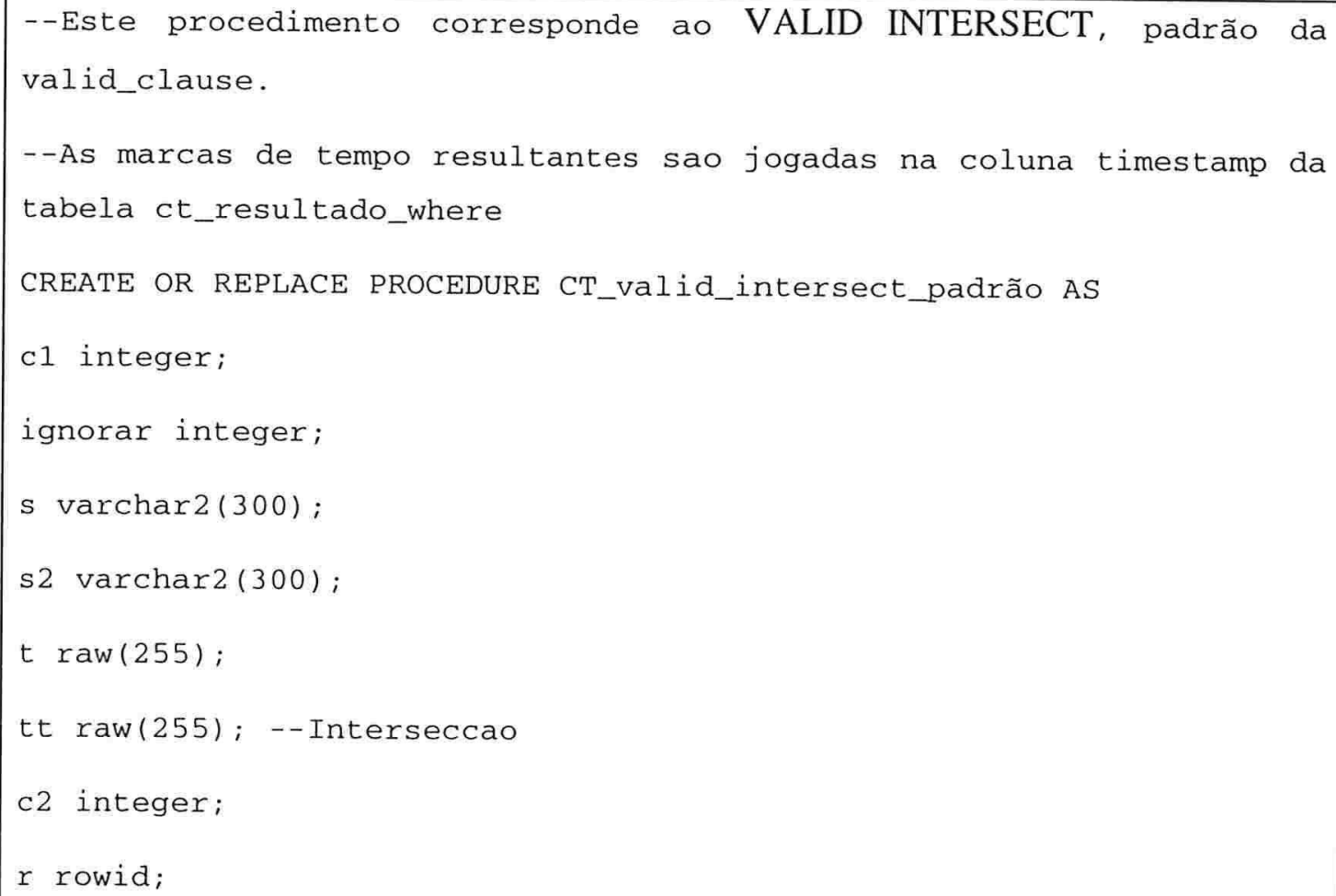




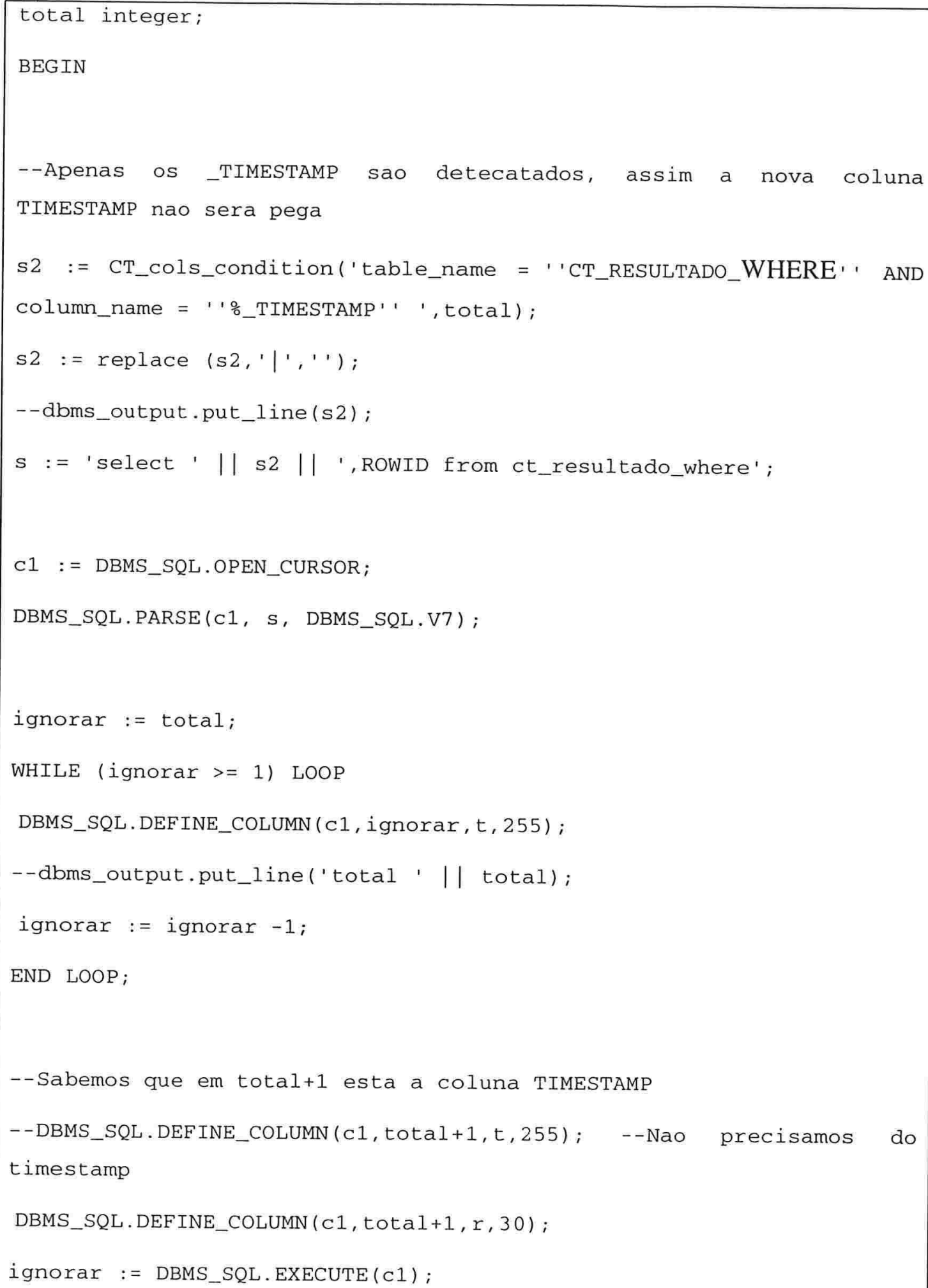




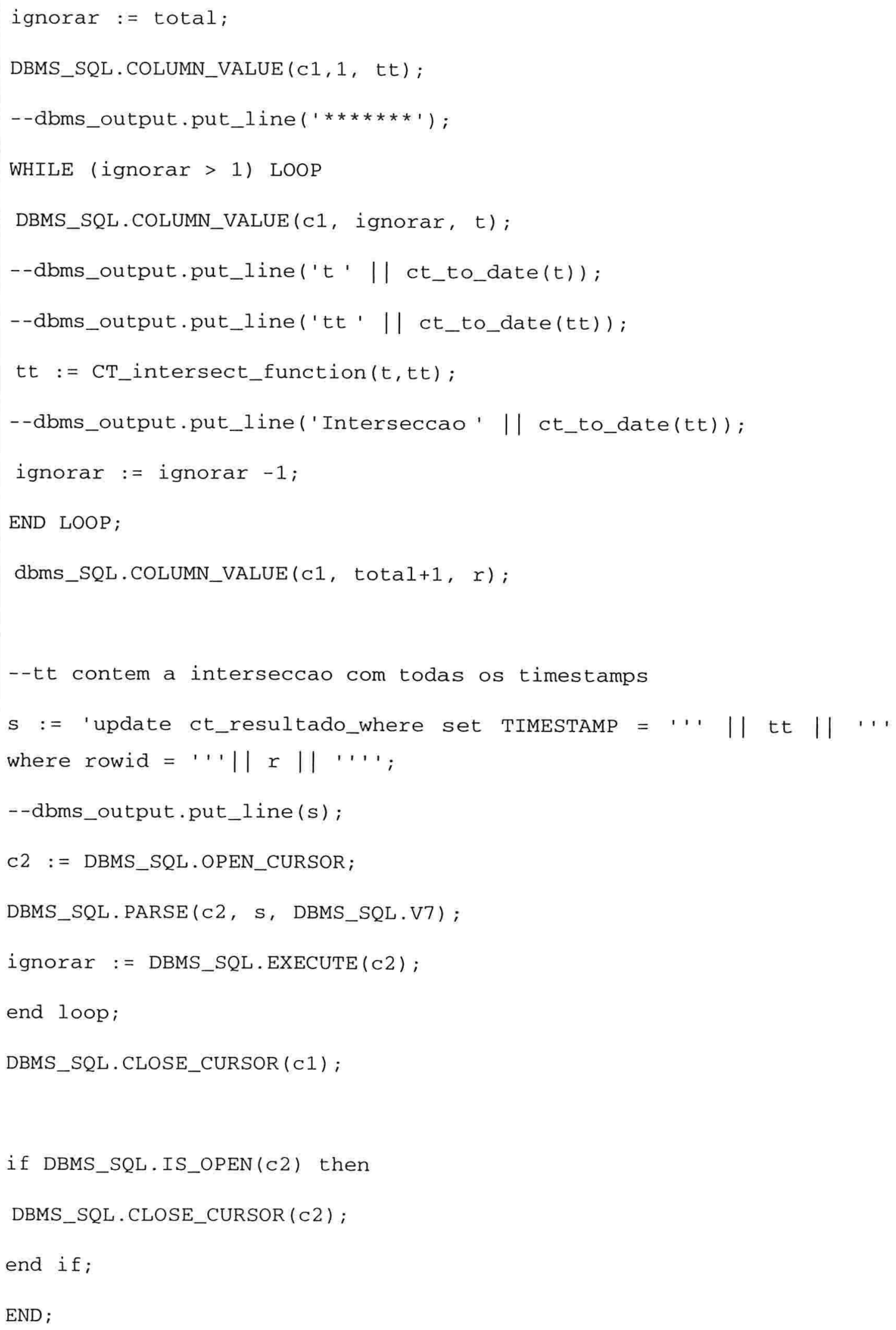


O procedimento não recebe nenhum parâmetro porque a coalescência padrão sempre será realizada sobre a tabela CT_RESULTADO_WHERE.

Por fim é gerada a última tabela intermediária CT_RESULTADO_SELECT. Esta é o resultado da projeção das colunas que aparecem na <select list> e da coluna TIMESTAMP, caso o resultado seja uma tabela de tempo de validade. No caso do exemplo, a geração desta tabela corresponde ao código:

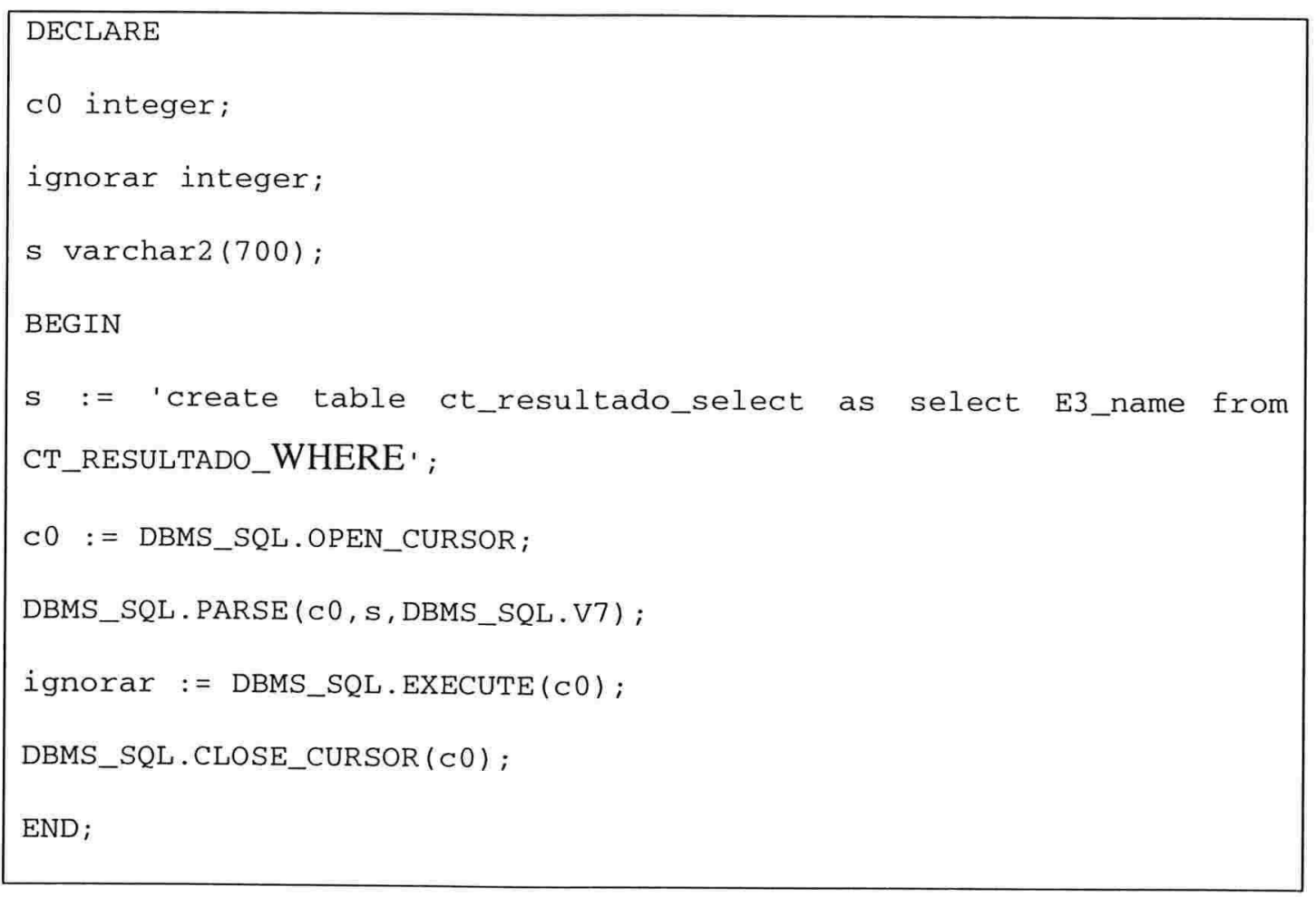

Se o resultado fosse uma tabela de tempo de validade, mais um script, correspondente à coalescência desta tabela, seria gerado, pois como já foi visto, a projeção temporal pode gerar tabelas não coalesçadas.

As tabelas intermediárias são eliminadas e uma sentença de consulta a todas as colunas da tabela CT_RESULTADO_SELECT é criada como resultado a ser devolvido à Camada Temporal. No caso do exemplo: 


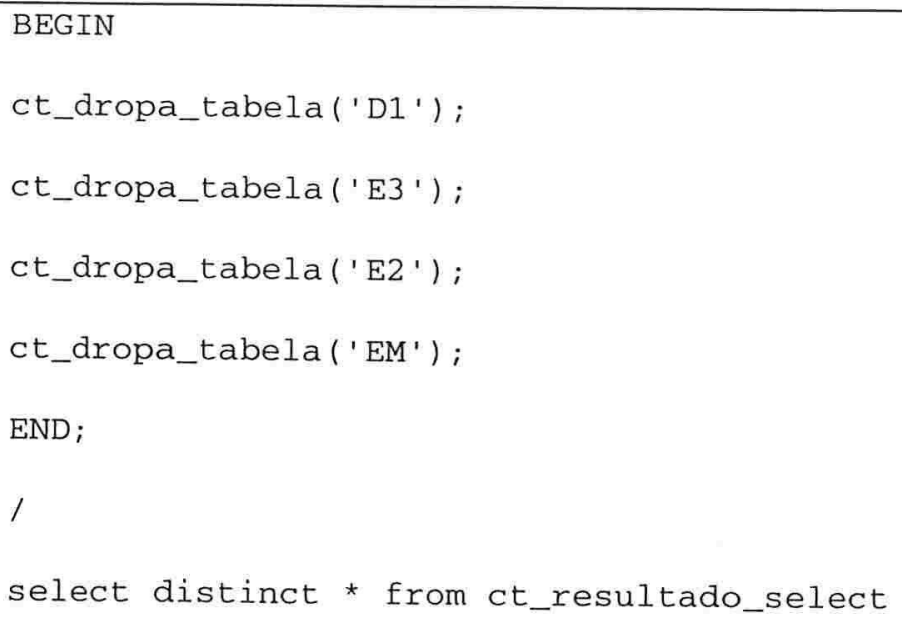

A sequência de scripts é então enviada ao Banco.

Foram notadas as seguintes dificuldades e limitações na geração dos scripts:

- Como não há acesso ao cache do Banco para realizar as junções, muitas tabelas temporárias tiveram que ser geradas.

- O PL/SQL não permite que se crie uma tabela e, um cursor a abra em um mesmo bloco (BEGIN...END), forçando o aumento do número de blocos.

- Foram criadas muitas funções e procedimentos armazenados no Banco. Apesar da PL/SQL (linguagem estruturada extendida do SQL-O) permitir que se recebam cursores criados dinamicamente, não é possível executar uma série de comandos possíveis com cursores estáticos. Esta limitação impediu que muitas outras funções e procedimentos fossem criadas, evitando a geração do código repetitivo.

Não foi feito nenhum tipo de otimização dos scripts gerados resultando em uma execução lenta; fica como sugestão para um futuro projeto.

Segue a tabela com a descrição das rotinas armazenadas no Banco. 


\begin{tabular}{|c|c|}
\hline Nome & Descrição \\
\hline CT_coalp & Coalesca dois elementos temporais. \\
\hline CT_cols_2Tab_concat & $\begin{array}{l}\text { Recebe duas tabelas e devolve as colunas } \\
\text { das duas concatenadas. }\end{array}$ \\
\hline CT_cols_1Tab_concat & $\begin{array}{l}\text { Recebe uma tabela e devolve as colunas } \\
\text { concatenadas em formato específico. }\end{array}$ \\
\hline CT_calendar & $\begin{array}{l}\text { Recebe um número de dias e devolve uma } \\
\text { data a partir de uma data base. }\end{array}$ \\
\hline CT_hex_to_dec & $\begin{array}{l}\text { Auxiliar de CT_Calendar: Recebe um número } \\
\text { e devolve um decimal. }\end{array}$ \\
\hline CT_to_date & $\begin{array}{l}\text { Auxiliar de CT_Calendar: recebe um raw e } \\
\text { devolve as datas concatenadas. }\end{array}$ \\
\hline CT_devolve_col & $\begin{array}{l}\text { Recebe uma posição e as colunas } \\
\text { concatenadas no formato de } \\
\text { CT_cols_Tab1_concat e devolve a coluna } \\
\text { correspondente. }\end{array}$ \\
\hline CT_tuplas_ig & $\begin{array}{l}\text { Recebe o nome de uma tabela e dois Rowid. } \\
\text { Retorna se os atributos explícitos das } \\
\text { tuplas referenciadas pelo valor dos } \\
\text { rowids são iguais ou não. }\end{array}$ \\
\hline CT_dropa_tabela & $\begin{array}{l}\text { Elimina, se existir, a tabela passada } \\
\text { como parâmetro. }\end{array}$ \\
\hline CT_pck_coalescing & $\begin{array}{l}\text { Recebe o nome de uma tabela e dois Raws. } \\
\text { Devolve um Raw com os dois coalesçados. }\end{array}$ \\
\hline CT_join_inter_temp & $\begin{array}{l}\text { Recebe dois elemento temporais e devolve } \\
\text { a intersecçao entre eles. }\end{array}$ \\
\hline CT_sql_join_2Tab & $\begin{array}{l}\text { Recebe duas tabelas para que seja feita a } \\
\text { junção e a tabela resultado. Devolve a } \\
\text { string com o script. }\end{array}$ \\
\hline CT_sql_join_2Tab_v2 & $\begin{array}{l}\text { Recebe duas tabelas para seja feita a } \\
\text { junção. } \\
\text { A diferença para o anterior é que este } \\
\text { não altera o nome das colunas da primeira } \\
\text { tabela. Devolve o script como string. }\end{array}$ \\
\hline CT_tabela_colunas & $\begin{array}{l}\text { Devolve as colunas da tabela recebida } \\
\text { como paramâmetro no formato <tabela.coll> } \\
\text { <tabela>_<coll>. }\end{array}$ \\
\hline CT_diferenca_day & $\begin{array}{l}\text { Devolve a diferença, em dias, de um } \\
\text { período maximal. }\end{array}$ \\
\hline CT_first_function & $\begin{array}{l}\text { Devolve o primeiro período maximal de um } \\
\text { elemento temporal. }\end{array}$ \\
\hline CT_last_function & $\begin{array}{l}\text { Devolve o último periodo maximal de um } \\
\text { elemento temporal. }\end{array}$ \\
\hline
\end{tabular}




\begin{tabular}{|c|c|}
\hline CT_cast_specification & $\begin{array}{l}\text { Devolve o cast resultante dependendo do } \\
\text { elemento ou período temporal e o cast } \\
\text { target. }\end{array}$ \\
\hline CT_precedes_predicate & $\begin{array}{l}\text { Devolve } 1 \text { se } T 1 \text { precedes T2. (END(T1) < } \\
\text { BEGIN(T2)) } \\
\text { Devolve } 0 \text { se E1 nao precedes E2. E1 e E2 } \\
\text { são elementos temporais ou períodos. No } \\
\text { caso de serem elementos temporais E1 } \\
\text { precedes E2 se todos os períodos maximais } \\
\text { de E1 precedes todos os períodos maximais } \\
\text { de E2. }\end{array}$ \\
\hline CT_overlaps_predicate & $\begin{array}{l}\text { Devolve } 0 \text { se E1 overlaps E2, ou seja } \\
\text { existe pelo menos um chronon que pertence } \\
\text { à interseç̧ão e dos dois elementos } \\
\text { temporais. E1 e E2 são elementos } \\
\text { temporais. }\end{array}$ \\
\hline CT_meets_predicate & $\begin{array}{l}\text { P1 MEETS P2 se END(P1) + } 1=\text { BEGIN(P2). } \\
\text { P1 e P2 não podem ser elementos } \\
\text { temporais. }\end{array}$ \\
\hline CT_intersect_function & $\begin{array}{l}\text { Recebe dois elementos temporais e devolve } \\
\text { a itersecção entre eles. }\end{array}$ \\
\hline CT_contains_predicate & $\begin{array}{l}\text { Recebe dois elementos temporais e devolve } \\
1 \text { se E1 contains E2. } \\
X \text { contains } Y \text { se BEGIN }(Y)>=\text { BEGIN }(X) \text { AND } \\
\text { END }(Y)<=E N D(X) \text {. } \\
\text { Caso X e Y forem elementos temporais, ( } X \\
\text { contains } Y \text { ) == } 1 \text { se para todo período de } \\
Y \text { existe um de } X \text { que o contém. }\end{array}$ \\
\hline CT_cols_condition & $\begin{array}{l}\text { Recebe uma condição sobre as colunas que } \\
\text { se quer recuperar e devolve as colunas } \\
\text { concatenadas. }\end{array}$ \\
\hline CT_valid_intersect_default & $\begin{array}{l}\text { Este procedimento corresponde ao VALID } \\
\text { INTERSECT, default da valid_clause. As } \\
\text { marcas de tempo resultantes são jogadas } \\
\text { na coluna timestamp da tabela } \\
\text { ct_resultado_where. }\end{array}$ \\
\hline
\end{tabular}




\section{II.3.6. Disponibilização do software}

Nesta seção são apresentados os requisitos mínimos para a execução do programa bem como os procedimentos para tal.

\section{Disponibilização do Aplicativo}

O software será disponibilizado em www.ime.usp.br/ mfinger/loreley.

Devem constar os seguintes aquivos:

- Temporal.exe: executável do Windows NT-Workstation da interface gráfica.

- Converte.dll: DLL que contém as rotinas de conversão das marcas de tempo para a representação interna no Oracle.

- Parse.dll: DLL que contém todas as funções e procedimentos para o reconhecimento e tradução das sentenças TSQL2.

- Converte.zip: fontes das rotinas de conversão.

- Parse.zip: fontes das rotinas de reconhecimento e tradução das sentenças TSQL2.

- ScriptsSQL: fontes das rotinas e procedimentos SQL armazenados no Banco Oracle.

- Interface.zip: fontes do front-end desenvolvido em Delphi.

\section{Pré-requisitos}

Computador com no mínimo $16 \mathrm{Mb}$ de RAM e $100 \mathrm{Mz}$ de processador.

Para rodar a Camada Temporal é preciso ter o Oracle 7.3 Server ou superior e o sistema operacional Windows NT-Workstation. Caso o sistema operacional seja Windows 95 será preciso gerar as dlls Converte e Parse, e o executável, Temporal, do front-end. Neste caso os aplicativos Microsoft Visual $C++4.0$ ou superior e o Borland Delphi 3 ou superior, são requeridos.

\section{Execução}

Para a execução, basta copiar os arquivos Temporal.exe, Converte.dll e Parse.dll para o mesmo diretório. As rotinas SQL devem ser compiladas no Oracle. Isso pode ser feito 
através do script compall.sql presente no ScripsSQL.zip. Com isso, basta acionar o Temporal.exe para executar o aplicativo. 


\section{II.4. Testes}

Nesta seção serão apresentados os seguintes testes:

1. Consulta Estática que utilize função temporal

2. Consulta Temporal

3. Uma consulta temporal expressa em TSQL2 e SQL-92

4. Uma consulta SQL-92 processada diretamente pelo Banco e a mesma consulta sendo compilada antes de ser enviada ao Banco

Para os testes serão utilizadas as tabelas descritas em II.3.

A Camada foi submetida a alguns dos testes criados pelo próprio comitê de definição da linguagem [29]. A comparação entre os resultados esperados pelos testes e dados pela Camada estão no Anexo A. Para o teste 2.9.6, discutiu-se sobre a diferença de resultados entre o que foi obtido pela Camada Temporal e o que foi apresentado em [29] como "resposta correta". Este foi o único caso de discrepância entre esta implementação e os testes de [29]. Apesar dos outros testes estarem de acordo com os resultados obtidos no benchmark, acreditamos válida sua apresentação para mostrar as funcionalidades implementadas no projeto desta tese.

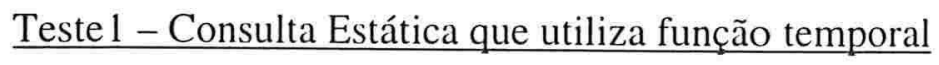

Este teste supõe a presença da seguinte tupla na tabela EMP:

\begin{tabular}{|c|l|l|l|l|c|}
\hline ID & Name & Salary & Gender & DeptName & TIMESTAMP \\
\hline MA & Ma & 10 & F & Toy & $01 / 01 / 6001 / 01 / 80$ \\
\hline
\end{tabular}

A consulta é: 
"Quem trabalhou continuamente no departamento Toy por mais tempo do que Di trabalhou no mesmo departamento?"

A consulta não requer que os eventos "trabalhou continuamente no departamento Toy" e "Di trabalhou no departamento Toy" possuam uma relação na dimensão tempo de validade restritiva. Isto significa que não interessa se os eventos aconteceram no Universo de Discurso de forma simultânea ou não, apenas estão se comparando os intervalos em valor absoluto, independentemente de quando ocorreram na linha do tempo de validade. Não há necessidade da regra <valid clause>, e portanto é necessário utilizar a palavra reservada SNAPSHOT. A consulta está expressa a seguir:

\section{SELECT SNAPSHOT E2.Name}

VALID emp (Name, DeptName) (PERIOD) E1, emp (Name, DeptName) (PERIOD) E2

WHERE E1.Name $=$ 'Di' AND E1. DeptName = 'Toy' AND E2. DeptName $=$ 'ToY' AND CAST(VALID(E2) AS INTERVAL DAY) > CAST(VALID (E1) AS INTERVAL DAY)

$\mathrm{Na}<$ from clause > são necessárias duas instâncias (E1,E2) da tabela EMP projetadas sobre ID e DeptName para que uma corresponda à Di e a outra, ao outro funcionário. E1 corresponde às tuplas em que Di $\left(\mathrm{E} 1\right.$. Name $=$ ' $\left.\mathrm{Di}^{\prime}\right)$ trabalhou no departamento Toy (E1. DeptName = 'ToY') e E2 corresponde a todas as pessoas (SELECT SNAPSHOT E2. Name) que trabalharam no departamento Toy. Como a pergunta leva em conta apenas o tempo trabalhado continuamente no departamento Toy, é preciso fazer um particionamento maximal em E1 e E2, através da utilização da palavra reservada PERIOD. Por fim, apenas as tuplas em que o total de tempo continuamente trabalhado no Toy seja maior ao tempo trabalhado por Di no mesmo departamento são selecionadas (CAST(VALID(E2) AS INTERVAL DAY) > CAST(VALID(E1) AS 
INTERVAL DAY)). A resposta esperada é Ma, já que é a única pessoa que trabalhou em Toy por mais tempo do que Di. A Tabela 5 foi construída de forma que fosse fácil perceber que a resposta da consulta é Ma. Foram retiradas as colunas Salary, Gender e acrescentada a coluna Dias do Intervalo que corresponde ao número de dias do período da coluna TIMESTAMP.

EMP'

\begin{tabular}{|l|l|l|l|l|}
\hline \multicolumn{1}{|c|}{ ID } & Name & \multicolumn{1}{c|}{ DeptName } & \multicolumn{1}{c|}{ TIMESTAMP } & \multicolumn{1}{c|}{ Dias do Intervalo } \\
\hline ED & Ed & Toy & $01 / 02 / 8231 / 05 / 82$ & 119 \\
\hline ED & Ed & Toy & $01 / 06 / 8231 / 01 / 85$ & 975 \\
\hline ED & Ed & Toy & $01 / 02 / 8531 / 01 / 87$ & 729 \\
\hline ED & Ed & Book & $01 / 04 / 8731 / 12 / 87$ & 274 \\
\hline ED & Edward & Book & $01 / 01 / 8827 / 04 / 98$ & 3769 \\
\hline DI & Di & Toy & $01 / 01 / 8231 / 07 / 84$ & 942 \\
\hline DI & Di & Toy & $01 / 08 / 8431 / 08 / 86$ & 760 \\
\hline DI & Di & Toy & $01 / 09 / 8627 / 04 / 98$ & 4256 \\
\hline MA & $\mathrm{Ma}$ & Toy & $01 / 01 / 6001 / 01 / 80$ & 7305 \\
\hline
\end{tabular}

Tabela 5 - Tabela EMP' baseada na EMP

Ed trabalhou continuamente em Toy durante 1823 dias $(119+975+729)$, Di trabalhou continuamente durante 5958 dias $(942+760+4256)$ e Ma durante 7305 dias. Desta forma percebe-se que Ma foi a única que trabalhou mais que $\mathrm{Di}$ no Toy.

Seguem abaixo as tabelas intermediárias geradas durante o processamento:

- Gera-se a tabela intermediária E1 projetada em Name e DeptName:

\begin{tabular}{|l|l|l|}
\hline \multicolumn{1}{|c|}{ NAME } & \multicolumn{1}{|c|}{ DEPTNAME } & \multicolumn{1}{c|}{ TIMESTAMP } \\
\hline Di & Toy & $01 / 01 / 8231 / 07 / 84$ \\
\hline $\mathrm{Di}$ & Toy & $01 / 08 / 8431 / 08 / 86$ \\
\hline $\mathrm{Di}$ & Toy & $01 / 09 / 8627 / 04 / 98$ \\
\hline
\end{tabular}




\begin{tabular}{|l|l|l|}
\hline Ed & Book & $01 / 04 / 8731 / 12 / 87$ \\
\hline Ed & Toy & $01 / 02 / 8231 / 05 / 82$ \\
\hline Ed & Toy & $01 / 06 / 8231 / 01 / 85$ \\
\hline Ed & Toy & $01 / 02 / 8531 / 01 / 87$ \\
\hline Edward & Book & $01 / 01 / 8827 / 04 / 98$ \\
\hline Ma & Toy & $01 / 01 / 6001 / 01 / 80$ \\
\hline
\end{tabular}

- Faz-se a coalescência das tuplas de E1:

\begin{tabular}{|l|l|l|}
\hline \multicolumn{1}{|c|}{ NAME } & \multicolumn{1}{|c|}{ DEPTNAME } & \multicolumn{1}{c|}{ TIMESTAMP } \\
\hline $\mathrm{Di}$ & Toy & $01 / 01 / 8227 / 04 / 98$ \\
\hline Ed & Book & $01 / 04 / 8731 / 12 / 87$ \\
\hline Ed & Toy & $01 / 02 / 8231 / 01 / 87$ \\
\hline Edward & Book & $01 / 01 / 8827 / 04 / 98$ \\
\hline Ma & Toy & $01 / 01 / 6001 / 01 / 80$ \\
\hline
\end{tabular}

- Particiona-se a tabela em períodos maximais:

\begin{tabular}{|l|l|l|}
\hline \multicolumn{1}{|c|}{ NAME } & \multicolumn{1}{c|}{ DEPTNAME } & \multicolumn{1}{c|}{ TIMESTAMP } \\
\hline $\mathrm{Di}$ & Toy & $01 / 01 / 8227 / 04 / 98$ \\
\hline Ed & Book & $01 / 04 / 8731 / 12 / 87$ \\
\hline Ed & Toy & $01 / 02 / 8231 / 01 / 87$ \\
\hline Edward & Book & $01 / 01 / 8827 / 04 / 98$ \\
\hline Ma & Toy & $01 / 01 / 6001 / 01 / 80$ \\
\hline
\end{tabular}

- Os três passos anteriores são executados para a tabela intermediária $\mathrm{E} 2$, resultando na mesma tabela anterior.

- É realizado o produto cartesiano entre E1 e E2. 


\begin{tabular}{|c|c|c|c|c|c|}
\hline $\begin{array}{c}\text { E1_ } \\
\text { NAME }\end{array}$ & $\begin{array}{c}\text { E1_- } \\
\text { DEPTNAME }\end{array}$ & $\begin{array}{c}\text { E1_- } \\
\text { TIMESTAMP }\end{array}$ & $\begin{array}{c}\text { E2 } \\
\text { NAME }\end{array}$ & $\begin{array}{c}\text { E2_ } \\
\text { DEPTNAME }\end{array}$ & $\begin{array}{c}\text { E2_ } \\
\text { TIMESTAMP }\end{array}$ \\
\hline $\mathrm{Di}$ & Toy & $\begin{array}{l}01 / 01 / 82 \\
27 / 04 / 98\end{array}$ & $\mathrm{Di}$ & Toy & $01 / 01 / 8227 / 04 / 98$ \\
\hline $\mathrm{Di}$ & Toy & $\begin{array}{l}01 / 01 / 82 \\
27 / 04 / 98\end{array}$ & Ed & Book & $01 / 04 / 8731 / 12 / 87$ \\
\hline $\mathrm{Di}$ & Toy & $\begin{array}{l}01 / 01 / 82 \\
27 / 04 / 98\end{array}$ & Ed & Toy & $01 / 02 / 8231 / 01 / 87$ \\
\hline $\mathrm{Di}$ & Toy & $\begin{array}{l}01 / 01 / 82 \\
27 / 04 / 98\end{array}$ & Edward & Book & $01 / 01 / 8827 / 04 / 98$ \\
\hline$\overline{\mathrm{Di}}$ & Toy & $\begin{array}{l}01 / 01 / 82 \\
27 / 04 / 98\end{array}$ & $\mathrm{Ma}$ & Toy & $01 / 01 / 6001 / 01 / 80$ \\
\hline Ed & Book & $\begin{array}{l}01 / 04 / 87 \\
31 / 12 / 87\end{array}$ & $\mathrm{Di}$ & Toy & $01 / 01 / 8227 / 04 / 98$ \\
\hline Ed & Book & $\begin{array}{l}01 / 04 / 87 \\
31 / 12 / 87\end{array}$ & Ed & Book & $01 / 04 / 8731 / 12 / 87$ \\
\hline$\overline{E d}$ & Book & $\begin{array}{l}01 / 04 / 87 \\
31 / 12 / 87\end{array}$ & Ed & Toy & $01 / 02 / 8231 / 01 / 87$ \\
\hline Ed & Book & $\begin{array}{l}01 / 04 / 87 \\
31 / 12 / 87\end{array}$ & Edward & Book & $01 / 01 / 887 / 04 / 98$ \\
\hline Ed & Book & $\begin{array}{l}01 / 04 / 87 \\
31 / 12 / 87\end{array}$ & $\mathrm{Ma}$ & Toy & $01 / 01 / 6001 / 01 / 80$ \\
\hline Ed & Toy & $\begin{array}{l}01 / 02 / 82 \\
31 / 01 / 87\end{array}$ & $\mathrm{Di}$ & Toy & $01 / 01 / 8227 / 04 / 98$ \\
\hline Ed & Toy & $\begin{array}{l}01 / 02 / 82 \\
31 / 01 / 87\end{array}$ & Ed & Book & $01 / 04 / 8731 / 12 / 87$ \\
\hline Ed & Toy & $\begin{array}{l}01 / 02 / 82 \\
31 / 01 / 87\end{array}$ & Ed & Toy & $01 / 02 / 8231 / 01 / 87$ \\
\hline Ed & Toy & $\begin{array}{l}01 / 02 / 82 \\
31 / 01 / 87\end{array}$ & Edward & Book & $01 / 01 / 88$ 27/04/98 \\
\hline Ed & Toy & $\begin{array}{l}01 / 02 / 82 \\
31 / 01 / 87\end{array}$ & $\mathrm{Ma}$ & Toy & $01 / 01 / 6001 / 01 / 80$ \\
\hline Edward & Book & $\begin{array}{l}01 / 01 / 88 \\
27 / 04 / 98\end{array}$ & $\mathrm{Di}$ & Toy & $01 / 01 / 8227 / 04 / 98$ \\
\hline Edward & Book & $\begin{array}{l}01 / 01 / 88 \\
27 / 04 / 98\end{array}$ & Ed & Book & $01 / 04 / 8731 / 12 / 87$ \\
\hline Edward & Book & $\begin{array}{l}01 / 01 / 88 \\
27 / 04 / 98\end{array}$ & Ed & Toy & $01 / 02 / 8231 / 01 / 87$ \\
\hline Edward & Book & $\begin{array}{l}01 / 01 / 88 \\
27 / 04 / 98\end{array}$ & Edward & Book & $01 / 01 / 8827 / 04 / 98$ \\
\hline Edward & Book & $\begin{array}{l}01 / 01 / 88 \\
27 / 04 / 98\end{array}$ & $\mathrm{Ma}$ & Toy & $01 / 01 / 6001 / 01 / 80$ \\
\hline $\mathrm{Ma}$ & Toy & $01 / 01 / 60$ & $\mathrm{Di}$ & Toy & $01 / 01 / 8227 / 04 / 98$ \\
\hline
\end{tabular}




\begin{tabular}{|l|l|l|l|l|l|}
\hline & & $01 / 01 / 80$ & & & \\
\hline Ma & Toy & $01 / 01 / 60$ & Ed & Book & $01 / 04 / 8731 / 12 / 87$ \\
& & $01 / 01 / 80$ & & & \\
\hline Ma & Toy & $01 / 01 / 60$ & Ed & Toy & $01 / 02 / 8231 / 01 / 87$ \\
& & $01 / 01 / 80$ & & & \\
\hline Ma & Toy & $01 / 01 / 60$ & Edward & Book & $01 / 01 / 8827 / 04 / 98$ \\
& & $01 / 01 / 80$ & & & $01 / 01 / 6001 / 01 / 80$ \\
\hline Ma & Toy & $01 / 01 / 60$ & Ma & Toy & \\
\hline
\end{tabular}

- $\mathrm{A}<$ where clause $>$ é processada:

\begin{tabular}{|l|l|c|c|c|c|}
\hline $\begin{array}{c}\text { E1 } \\
\text { NAME }\end{array}$ & $\begin{array}{c}\text { E1_ } \\
\text { DEPTNAME }\end{array}$ & $\begin{array}{c}\text { E1_ } \\
\text { TIMESTAMP }\end{array}$ & $\begin{array}{c}\text { E2 } \\
\text { NAME }\end{array}$ & $\begin{array}{c}\text { E2 } \\
\text { DEPTNAME }\end{array}$ & $\begin{array}{c}\text { E2 } \\
\text { TIMESTAMP }\end{array}$ \\
\hline Di & Toy & $01 / 01 / 8227 / 04 / 98$ & Ma & Toy & $01 / 01 / 6001 / 01 / 80$ \\
\hline
\end{tabular}

- Finalmente, a projeção (não temporal) é aplicada:

\begin{tabular}{|l|}
\hline \multicolumn{1}{|c|}{ E2_NAME } \\
\hline $\mathrm{Ma}$ \\
\hline
\end{tabular}

A resposta esperada foi obtida.

$\underline{\text { Teste } 2 \text { - Consulta Temporal }}$

Seja a consulta:

"Quem trabalhou continuamente no departamento Toy por tanto tempo quanto Di trabalhou no mesmo departamento e ao mesmo tempo do que ela em algum momento? Em que períodos trabalharam simultaneamente?" 
Percebe-se que a restrição temporal "ao mesmo tempo do que ela" em algum momento aparece na consulta. Isto requer que os eventos "trabalhou continuamente no departamento Toy" e "Di trabalhou no departamento Toy" estejam relacionados no tempo de forma que em algum momento da sua validade no Universo de Discurso, tenham acontecido simultaneamente. Essa restrição requer que as marcas de tempo entre as tabelas usadas para a consulta sejam interseccionadas. Cada tupla resultante terá associada uma marca de tempo que é o resultado da intersecção das marcas de tempo relacionadas nas tabelas base. Em TSQL2 a consulta fica:

SELECT E2. Name

FROM emp (Name, DeptName) (PERIOD) E1, emp (Name, DeptName) (PERIOD) E2

WHERE E1.Name $=$ 'Di' AND E1. DeptName = 'Toy' AND E2. DeptName = 'Toy' AND CAST(VALID(E2) AS INTERVAL DAY) > CAST(VALID (E1) AS INTERVAL DAY)

Esta consulta é igual a anterior à exceção da inexistência da palavra reservada SNAPSHOT.

Para que fique clara a diferença entre o processamento desta e da anterior serão discriminadas novamente as tabelas intermediárias. Não serão mostradas as tabelas resultantes que forem idênticas àquelas da consulta anterior:

- Gera-se a tabela intermediária E1 projetada em Name e DeptName.

- Faz-se a coalescência das tuplas de E1.

- Particiona-se a tabela em períodos maximais:

- Os três passos anteriores são executados para a tabela intermediária E2, resultando na mesma tabela do teste anterior. 
- É realizado o produto cartesiano entre E1 e E2.

- A <where clause $>$ é processada.

- Como a consulta anterior era não temporal, foi aplicada diretamente a projeção estática. No entanto, neste caso é preciso aplicar a projeção temporal na qual serão geradas as marcas de tempo das tuplas resultantes. Se a marca de tempo resultante for $N U L L$, a tupla é excluída do resultado. O resultado da projeção temporal é vazia já que a única tupla selecionada no passo anterior foi:

\begin{tabular}{|l|l|c|c|c|c|}
\hline $\begin{array}{c}\text { E1_ } \\
\text { NAME }\end{array}$ & $\begin{array}{c}\text { E1_ } \\
\text { DEPTNAME }\end{array}$ & $\begin{array}{c}\text { E1 } \text { _ }_{-} \\
\text {TIMESTAMP }\end{array}$ & $\begin{array}{c}\text { E2 } \\
\text { NAME }\end{array}$ & $\begin{array}{c}\text { E2_ } \\
\text { DEPTNAME }\end{array}$ & $\begin{array}{c}\text { E2 } \\
\text { TIMESTAMP }\end{array}$ \\
\hline Di & Toy & $01 / 01 / 8227 / 04 / 98$ & Ma & Toy & $01 / 01 / 6001 / 01 / 80$ \\
\hline
\end{tabular}

e como se pode perceber, os períodos maximais em que $\mathrm{Di}$ trabalhou no departamento Toy $(01 / 01 / 82$ - 27/04/98) e que Ma trabalhou no Toy $(01 / 01 / 60$ - 01/01/80) possuem intersecção vazia.

- Finalmente, a projeção (não temporal) é aplicada e o resultado é vazio:

\begin{tabular}{|c|c|c|c|c|c|}
\hline $\begin{array}{c}\text { E1_- } \\
\text { NAME }\end{array}$ & $\begin{array}{c}\text { E1_ } \\
\text { DEPTNAME }\end{array}$ & $\begin{array}{c}\text { E1_- } \\
\text { TIMESTAMP }\end{array}$ & $\begin{array}{c}\text { E2 } \\
\text { NAME }\end{array}$ & $\begin{array}{c}\text { E2_ } \\
\text { DEPTNAME }\end{array}$ & $\begin{array}{c}\text { E2 } \\
\text { TIMESTAMP }\end{array}$ \\
\hline & & & & & \\
\hline
\end{tabular}

De fato, nenhuma das pessoas que trabalharam com Di no departamento Toy o fizeram por um período contínuo, igual ou maior do que $\mathrm{Di}$.

\section{$\underline{\text { Teste3 - Uma consulta temporal expressa em TSQL2 e SQL-92 }}$}

Este teste tem por objetivo mostrar a flexibilidade da TSQL2 em relação à SQL-92 na construção de consultas temporais. Para isso utilizamos um exemplo descrito em [36]. 
Suponha que se queira saber o histórico de salário do funcionário com identificação ED. A resposta esperada está na Tabela 6 .

\begin{tabular}{|l|l|l|}
\hline \multicolumn{1}{|c|}{ ID } & \multicolumn{1}{|c|}{ Salary } & \multicolumn{1}{c|}{ TIMESTAMP } \\
\hline ED & 20 & $01 / 02 / 82-31 / 05 / 82$ \\
\hline ED & 30 & $01 / 06 / 82-31 / 01 / 85$ \\
\hline ED & 40 & $01 / 02 / 85-31 / 01 / 8701 / 04 / 87-27 / 04 / 98$ \\
\hline
\end{tabular}

Tabela 6 - Histórico salarial de ED

Para a execução dessa consulta en TSQL2 seria necessário construir a seguinte sentença:

\section{SELECT Salary}

FROM Emp

WHERE ID $='$ 'ED'.

Trata-se de uma consulta temporal e portanto, irá agrupar os salários de ED em períodos maximais, independentemente de Departamento, Nome ou Sexo.

Para expressar a mesma consulta em SQL-92, supõe-se que a Tabela 7 pertence a um Banco de Dados Estático, sendo portanto, estática. As colunas Start e Stop foram acrescentadas de forma a permitir a associação do tempo aos fatos modelados pela tupla. É importante ter claro que essas duas colunas não serão interpretadas pelo Banco, sendo consideradas atributos explícitos como os outros.

\begin{tabular}{|l|l|l|l|l|l|l|}
\hline \multicolumn{1}{|c|}{ ID } & Name & \multicolumn{1}{c|}{ Salary } & \multicolumn{1}{c|}{ Gender } & \multicolumn{1}{c|}{ DeptName } & \multicolumn{1}{c|}{ Start } & \multicolumn{1}{c|}{ Stop } \\
\hline ED & Ed & 20 & $\mathrm{M}$ & Toy & $01 / 02 / 82$ & $31 / 05 / 82$ \\
\hline ED & Ed & 30 & $\mathrm{M}$ & Toy & $01 / 06 / 82$ & $31 / 01 / 85$ \\
\hline ED & Ed & 40 & $\mathrm{M}$ & Toy & $01 / 02 / 85$ & $31 / 01 / 87$ \\
\hline ED & Ed & 40 & $\mathrm{M}$ & Book & $01 / 04 / 87$ & $31 / 12 / 87$ \\
\hline ED & Edward & 40 & $\mathrm{M}$ & Book & $01 / 01 / 88$ & $27 / 04 / 98$ \\
\hline DI & Di & 30 & F & Toy & $01 / 01 / 82$ & $31 / 07 / 84$ \\
\hline DI & Di & 40 & F & Toy & $01 / 08 / 84$ & $31 / 08 / 86$ \\
\hline DI & Di & 50 & F & Toy & $01 / 09 / 86$ & $27 / 04 / 98$ \\
\hline
\end{tabular}

Tabela 7 - Tabela temporal em um Banco Estático 
Uma das formas de se refletir a consulta em SQL-92 é a mostrada na Figura 30.

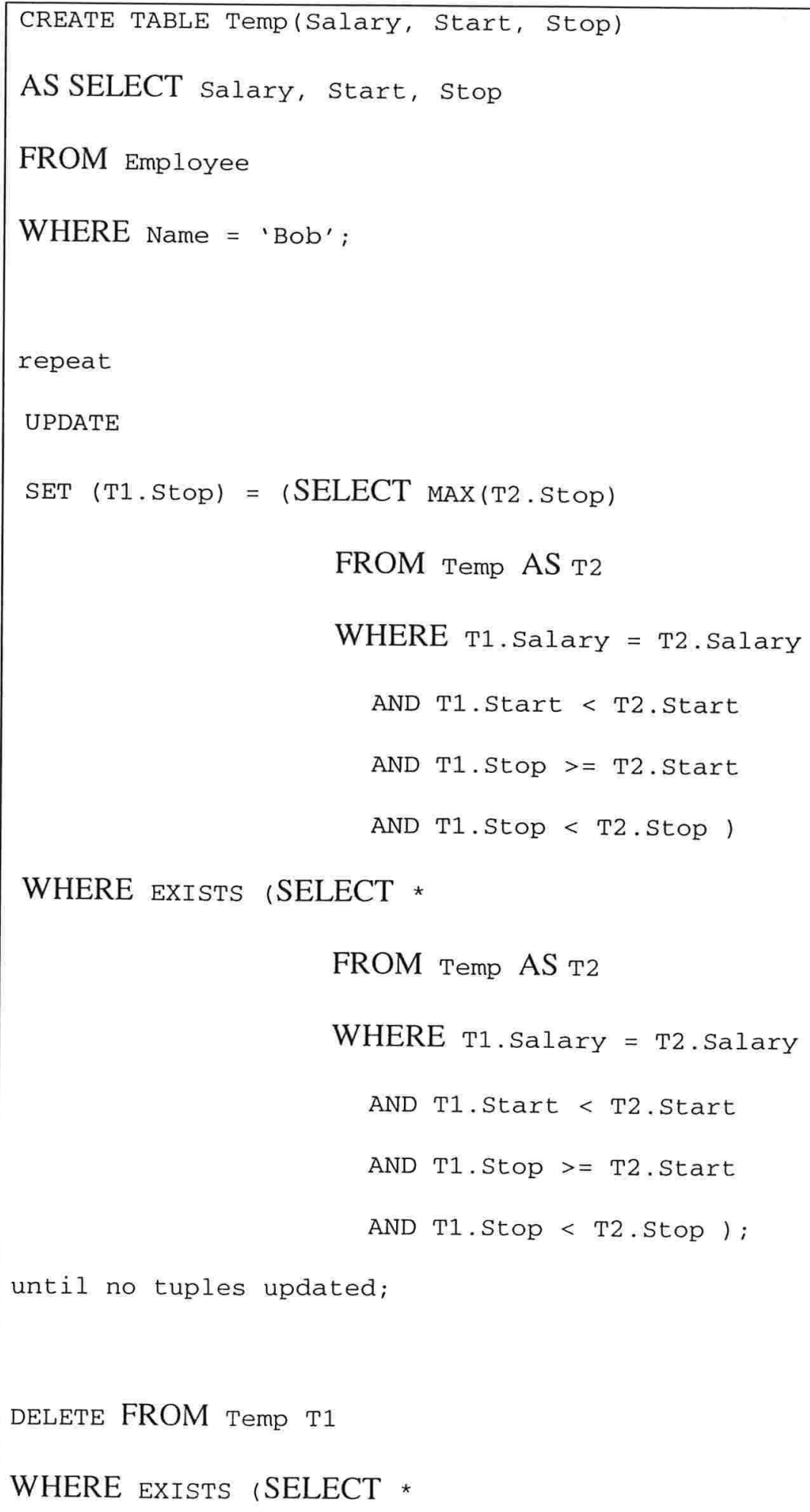




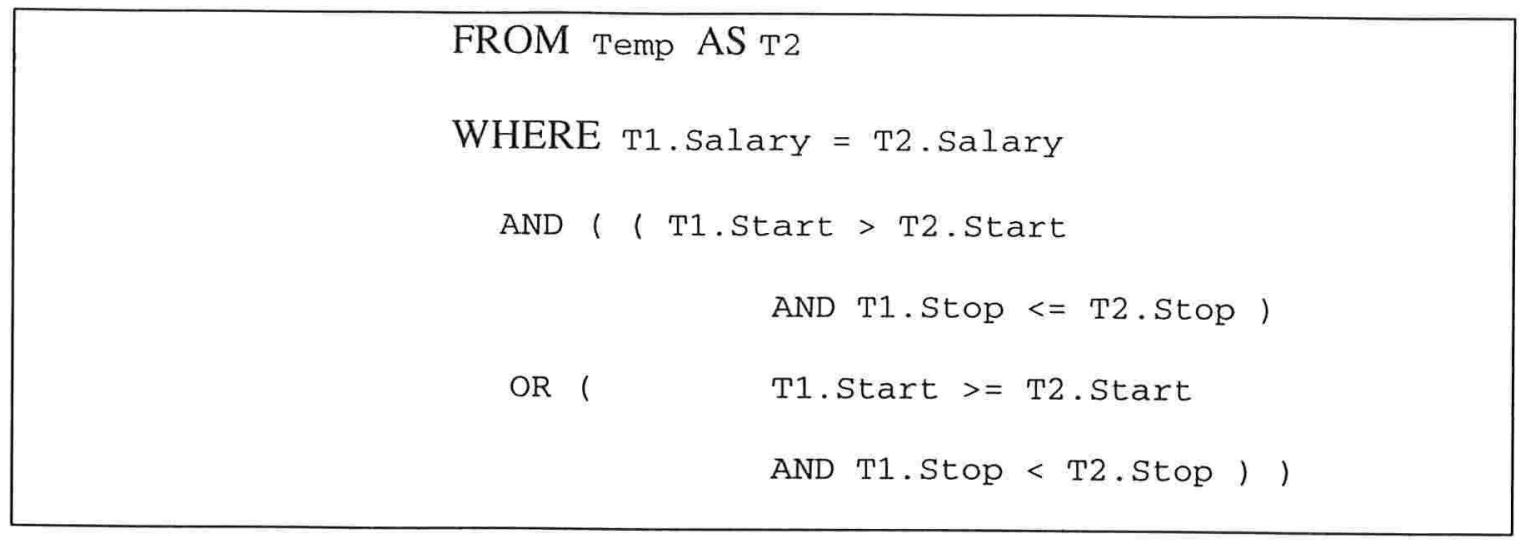

\section{Figura 30 - Script SQL-92 de consulta temporal}

Como se pode perceber, as colunas start e stop devem ser manipuladas explicitamente tornando a consulta nada intuitiva e complexa. Após a tabela temporária Temp ser criada, para todos os salários iguais, são atualizados os períodos adjacentes ou com intersecção não vazia. O processo pára quando nenhuma tupla é atualizada. São removidas então as tuplas, cujos períodos estão contidos em períodos de outras tuplas de mesmo salário.

Outra forma de expressar essa consulta em SQL-92 é utilizando cursores [1].

Nesta consulta especificamente, a TSQL2 se mostrou muito mais flexível para expressar a consulta temporal do que a linguagem estática SQL-92.

Teste4 - consulta SQL-92 processada diretamente pelo Banco e a mesma consulta sendo compilada antes de ser enviada ao Banco

Como já foi dito, a TSQL2 é um superconjunto da SQL-92, sendo possível consultas estáticas. No entanto, é preciso estar atento ao construir consultas estáticas usando TSQL2.

Para ilustrar tomem-se as tabelas de II.3. Acrescenta-se a seguinte tupla à tabela SKILLS:

\begin{tabular}{|l|l|c|}
\hline \multicolumn{1}{|c|}{ EmpID } & \multicolumn{1}{|c|}{ Skill } & TIMESTAMP \\
\hline DI & Typing & $01 / 01 / 80-27 / 04 / 81$ \\
\hline
\end{tabular}


Para selecionar os skills dos gerentes de departamento basta fazer a consulta:

SELECT Dept.MgrId, Skills.Skill

VALID Skills, Dept

WHERE Skills.EmpId = Dept.MgrId;

A resposta esperada é:

\begin{tabular}{|l|l|}
\hline MgrID & \multicolumn{1}{|c|}{ Skill } \\
\hline DI & Directing \\
\hline DI & Typing \\
\hline ED & Typing \\
\hline ED & Filing \\
\hline ED & Driving \\
\hline
\end{tabular}

No entanto, ao executar-se a consulta na Camada Temporal, obtem-se:

\begin{tabular}{|l|l|c|}
\hline MgrID & \multicolumn{1}{|c|}{ Skill } & TIMESTAMP \\
\hline DI & Directing & $1 / 1 / 198227 / 4 / 1998$ \\
\hline ED & Typing & $1 / 4 / 198727 / 4 / 1998$ \\
\hline ED & Filing & $1 / 4 / 198727 / 4 / 1998$ \\
\hline ED & Driving & $1 / 4 / 198731 / 5 / 1988$ \\
\hline
\end{tabular}

DI não aparece como possuindo o skill Typing. Isto porque, como a consulta foi realizada em TSQL2, as marcas de tempo das tuplas foram interpretadas de forma que apenas as tuplas em que o período em que a pessoa possuia o skill, e o período em que ela foi gerente, tivessem intersecção não nula. Como DI possuía o skill de digitadora em $1 / 1 / 1980$ - 27/4/1981, e foi gerente em 1/1/1982 - 27/4/1998, períodos com intersecção vazia, a tupla não foi considerada na resposta. 
Para obter a resposta esperada, usando TSQL2, é preciso transformar a consulta em estática, adicionando a palavra reservada SNAPSHOT:

SELECT SNAPSHOT Dept.MgrId, Skills.Skill

FROM Skills, Dept

WHERE Skills.EmpId = Dept.MgrId;

Este problema não aconteceria se alguma das tabelas, SKILLS ou DEPT fosse estática, pois, como foi visto em II.3, o padrão passaria a ser a consulta estática.

A obtenção da semântica desejada das sentenças depende do correto entendimento da associação da dimensão tempo aos fatos, a interação entre os tipos de tabelas utilizadas com os padrãos definidos.

Na seção subsequente é feita uma compilação dos principais pontos apresentados durante o trabalho, destacando alguns dos resultados.

\section{II.4.1. Conclusões dos Testes}

Não é intenção fazer uma avaliação da linguagem ou da Camada implementada, no entanto, os quatro testes apresentados permite que algumas observações sejam feitas.

Os testes 1 e 2 mostram as facilidades que a TSQL2 oferece para construção de consultas temporais e não temporais, com a incorporação de funções como CAST e VALID e de operadores como PERIOD.

O teste 3 compara uma consulta temporal escrita em TSQL2 e em SQL-92. A TSQL2 é bem mais clara, já que muitos processamentos são implícitos, permitindo ao programador preocupar-se apenas com a semântica de sua sentença.

Esses processamentos implícitos citados anteriormente, apesar de tornarem a linguagem mais flexível, podem atrapalhar quando não se domina o funcionamento da TSQL2, como mostra o teste 4 . 


\section{II.5. Conclusões}

Muitas aplicações utilizam o tempo associado aos fatos. Cada uma delas precisa implementar o suporte ao tempo, já que os Bancos Comerciais não o fazem. O objetivo de Bancos de Dados Temporais é de trazer a responsabilidade de dar suporte ao tempo, para os Bancos de Dados, evitando implementações redundantes. Muitos projetos [22,17,31] estudaram aspectos da incorporação do suporte ao tempo em Bancos de Dados Estáticos. Este trabalho teve por objetivo a implementação de um fragmento da TSQL2 para avaliar as dificuldades e facilidades que essa linguagem traz.

Neste Capítulo é apresentada a consolidação dos resultados obtidos deste trabalho. As qualidades e dificuldades da TSQL2 aparecem em II.5.1, os resultados obtidos da implementação constam em II.5.2. Em II.5.4 descrevem-se vários temas que poderiam dar continuação a este trabalho. Finalmente em II.5.3, dá-se um panorama da penetração da área Temporal em Bancos de Dados Comerciais.

\section{II.5.1. TSQL2}

Como extensão da SQL-92, a TSQL2 absorve diretamente toda a padronização e aceitabilidade daquela. Criada por um Comitê com bastante experiência na área [36], a TSQL2 teve por objetivo servir como base para futuras pesquisas em Bancos de Dados Temporais.

Entre as vantagens da TSQL2 encontram-se a possibilidade de definição de calendários pelos usuários [36] e a flexibilidade na construção de expressões temporais. Como mostrado em II.2.7, a linguagem oferece total transparência na manipulação das marcas de tempo das tuplas, através utilização de funções como VALID. Por exemplo, a sentença:

SELECT SNAPSHOT Name

FROM Emp E1 E2 
WHERE VALID(E1) OVERLAPS VALID(E2) AND E1.Name $!=$ E2 . NAme,

corresponde à consulta dos empregados que trabalharam simultaneamente na empresa. A função valid (<correlation name>) faz referência à marca de tempo das tuplas sem que sua representação física seja conhecida. Esta característica permite que as consultas se tornem portáveis, já que a senteça será a mesma para qualquer representação física.

A opção de fazer da coalescência, um processo implícito, executado sempre que a tabela (intermediária ou não) resultar não coalesçada, simplifica e torna a linguagem mais intuitiva para o programador. Adicionalmente, como o processo afeta a performance, o código pode ser otimizado de forma que não aconteça desnecessariamente.

Apesar da TSQL2 ter sido produto de experiência adquirida ao longo de vários anos com a definição de outras linguagens temporais [36], não se trata da palavra final. Muitas de suas construções são pouco intuitivas como:

FROM Empregados (Nome) E, E(Salário) F, apresentada em II.2.11. Além disso, a determinação do tipo de consulta resultante é complexa, pois, o padrão, SNAPSHOT ou VALID CLAUSE, depende, entre outros fatores, do tipo das tabelas. O livro [36] não é muito claro quanto ao processo de determinação do tipo da consulta resultante. Foram necessários esclarecimentos de Richard Snodgrass e Mike Soo para que o projeto fosse o mais fiel possível às definições do livro .

No capítulo II.4, é mostrada, através de testes, como a complexidade, afirmada no parágrafo anterior, pode resultar em uma má formulação de consultas. 


\section{II.5.2. Implementação}

Nesta seção, serão discutidas melhoras na implementação e suas implicações na arquitetura do sistema.

Poucos projetos implementaram marcas de tempo físicas como sendo do tipo elemento temporal [31]. Este projeto o faz.

O espaço de armazenamento reduz-se bastante se vários períodos estiverem associados aos mesmos atributos explícitos. Isto porque, no caso de marcas de tempo do tipo período, seria necessário repetir os atributos explícitos tantas vezes quantos fossem os períodos maximais associados.

Para o processo de coalescência, há uma forte manipulação de strings e de tuplas. No caso de marcas por períodos, haveria apenas manipulação de tuplas, o que, provavelmente seria mais eficiente. Por outro lado, a visualização de resultados temporais é facilitada com a utilização de elementos temporais, pois exige apenas manipulação de strings e não de tuplas.

As marcas de tempo do tipo elemento temporal tem a desvantagem de dificultar bastante a tarefa de indexação temporal, além de limitar o número de períodos por tupla ao máximo permitido pelo tipo de dados selecionado para armazenamento da marca de tempo. No caso do projeto esse número corresponde a 31, como explicado em II.3.2. Claramente, não seria possível utilizar a Camada para aplicações que necessitem mais do que isso. Em uma próxima oportunidade a opção certamente será pela implementação do período como tipo de marca de tempo.

A utilização de scripts $P L / S Q L$ [1] para a tradução, apesar de facilitar a implementação, é bastante lenta. Se performance for um fator crítico, uma opção seria utilizar $\operatorname{Pro}{ }^{*} C$ [8], já que se trata de um código mais otimizado, além de permitir melhores estruturas. A performance é muito baixa para o processamento de consultas estáticas, podendo ser aumentada com a não tradução dessas consultas. Seria necessária apenas uma modificação no tradutor de forma que, durante a compilação, fosse verificada a presença de construções que demandassem tradução. No entanto, é preciso levar em conta que, mesmo consultas estáticas, podem conter extensões temporais que precisem ser 
traduzidas, e ainda, uma consulta aparentemente estática, como o teste4 apresentado em II.4, é na verdade temporal. Estas últimas observações podem tornar complexa a verificação, durante a compilação, da necessidade de tradução.

Não há uma interação muito grande entre a Camada Temporal e o banco Oracle. Para a incorporação do suporte a múltiplas granularidades e calendários, seria necessária uma interação maior entre o Banco e a Camada para busca de informações sobre tabelas e campos. A arquitetura permaneceria a mesma, à exceção da inserção de uma tabela no dicionário de dados que conteria informações sobre as tabelas do sistema. $\mathrm{O}$ tradutor ficaria mais complexo, já que a geração dos scripts dependeria do resultado de consultas realizadas à essa tabela. Essa interação mais intensa com o banco, afetaria a performance, sendo necessária a otimização dos scripts. Uma possível solução seria "inchar" um pouco mais a Camada Temporal com informações sobre as tabelas. Também as rotinas de decodificação poderiam ser desenvolvidas em uma linguagem mais eficiente que a SQL, e armazenadas na Camada Temporal, como DLL's, em vez de armazená-las no Banco de Dados como rotinas SQL.

A independência de plataforma é outro aspecto importante. A parte desenvolvida em Delphi é facilmente reproduzida em outro aplicativo de front-end, pois é bastante simples. Os scripts gerados pelo tradutor e as rotinas armazenadas no Banco Oracle podem ser transportados para outro Banco que seja compatível com o SQL-92 nível Entry [1]. Quanto ao tradutor, por não ter sido desenvolvido em Ansi $C$, alterações podem ser necessárias ao se mudar de plataforma. A Arquitetura não seria alterada, sendo necessários ajustes no módulo tradutor.

\section{II.5.3. Aplicações práticas de TSQL2}

Não existe no mercado nenhum Bancos de Dados Comercial que dê suporte ao tempo de transação ou ao tempo de validade. Este trabalho de implementação e teste, juntamente com as asserções de [22], apontam várias razões para isto, a saber:

- Apesar da área ser objeto de pesquisa há mais de 20 anos, projetos de implementações começaram a surgir a partir da década de 90. 
- Não existe uma linguagem padrão temporal. A TSQL2 é amplamente aceita mas não é a palavra final.

- A performance das implementações realizadas deixa a desejar.

- Apesar da preocupação com a compatibilidade dos sistemas legados após a incorporação do suporte ao tempo, não há garantia de que estes funcionariam perfeitamente sem alteração.

- A incorporação do suporte ao tempo requer, entre outras, a escolha do tipo da marca de tempo e de sua representação física. Estas escolhas devem ser feitas de forma que qualquer aplicação possa ser implementada da melhor forma possível. Pesquisas precisam ser realizadas a fim de verificar a dependência entre as marcas de tempo e cada tipo de aplicação, e demonstrar a possibilidade da adoção de um modelo único para todos os sistemas.

- Dificuldade de manipular a dimensão tempo dos dados. O teste4 apresentado em II.4 mostra claramente como, a falta de domínio da relação entre a dimensão tempo e os fatos pode levar a construções errôneas de senteças de consulta. A questão torna-se mais complexa quando há necessidade de utilização das duas dimensões do tempo, a de validade e a de transação.

Ainda há muito que fazer na área de Bancos de Dados Temporais para que os Bancos Comerciais possam incorporar suporte maior ao tempo. A necessidade do suporte temporal é confirmada com a existência da empresa comercial if..., que oferece uma série de ferramentas de análise temporal, desenvolvidas para entender as relações dos dados no tempo, permitindo consultas complexas de data warehouse [7]. A tecnologia temporal utilizada extende os sistemas de banco de dados relacionais existentes, sem interferir na integridade dos Bancos de Dados correntes, incorporando funcionalidades temporais para sofisticadas análises de dados. Para consultas é utilizada a $S Q L / T$, linguagem temporal extendida da SQL-92. Esta iniciativa demonstra o interesse em se manipular os dados em função da dimensão tempo. 


\section{II.5.4. Sugestão de futuros trabalhos}

Nesta seção dá-se sugestões de alguns temas para continuação deste projeto.

A performance é bastante penalizada ao se incorporar suporte temporal a Bancos Estáticos. A otimização das consultas temporais antes de serem enviadas ao Banco reduziria o tempo de resposta, ficando mais atraente para Bancos Comerciais.

Várias outras características interessantes podem ser implementadas, entre elas suporte a múltiplos calendários e granularidades [36].

Ampliação do tradutor de forma a permitir outras expressões da <valid clause $>$ além da padrão.

Criação de uma interface para consultas temporais gráficas, focando a manipulação temporal em alto nível (Entidade Relacionamento).

Por fim, o tratamento de erros dos vários níveis (sintático, semântico, do front-end, do próprio Banco) traria à Camada Temporal mais robustez e facilidade de uso. 


\section{Glossário}

\begin{tabular}{|c|c|}
\hline Termos em inglês & Tradução \\
\hline Temporal Database & Banco de Dados Temporal \\
\hline Valid time & Tempo de validade \\
\hline Transaction time & Tempo de transação \\
\hline Snapshot Database & Banco de Dados Estático \\
\hline Valid Database & Banco de Dados de Tempo de Validade \\
\hline Transaction Database & Banco de Dados de Tempo de Transação \\
\hline Bitemporal Database & Banco de Dados Bitemporal \\
\hline Valid relation & Relação de tempo de validade \\
\hline Transaction relation & Relação de tempo de transação \\
\hline Bitemporal relation & Relação bitemporal \\
\hline $\begin{array}{lll}\text { Bitemporal } & \text { Conceptual Data } \\
\text { Model } & & \\
\end{array}$ & Modelo de Dados Conceitual Bitemporal \\
\hline Valid Time Data Model & Modelo de Dados de Tempo de Validade \\
\hline Transaction Time Data Model & Modelo de Dados de Tempo de Transação \\
\hline Bitemporal Data Model & Modelo de Dados Bitemporal \\
\hline Coalescing & Coalescência \\
\hline Overlap & Sobrepor \\
\hline Snapshot equivalence & Equivalência estática \\
\hline Granules & Grânulos \\
\hline Chronon & Este termo não foi traduzido \\
\hline
\end{tabular}




\begin{tabular}{|l|l|}
\hline Datetime & Este termo não foi traduzido \\
\hline Timestamp & Marca de tempo \\
\hline
\end{tabular}




\section{Bibliografia}

[1]Oracle7 Server. SQL Language Reference Manual. Part Number 778-70-1292. Cooperative Server Technology for Transaparent Data Sharing.

[2] Oracle 7 Server Administrator's Guide. Part N. A32535-1

[3] The Lexical Sanner Generator, Version 2.3.7. G.T. Nicol. ISBN 1882114213

[4]The Bison Manual: Using the YACC- compatible Parser Generator, for Version 1.25. Chris Donnelly, Richard Stallman ISBN: 1882114450 .

[5]Delphi 2 - Developers Guide - Second Edition. Xavier Pacheco e Steve Teixeira. SAMS Publishing. 1996.

[6]Special Edition - Using Linux - Second Edition. Jack Tackett Jr and David Gunter,1996. Editora QUE.

[7] www. iftime.com.

[8] Programmer's Guide to the Oracle Pro* $\mathrm{C} / \mathrm{C}++$ Precompiler. Release 2.2. February 1996. Part No. A32548-1.

[9] Abraham Silberschatz, Henry F. Korth, Sudarshan. "Database System Concepts". MC Graw Hill International. $3^{\text {rd }}$ Edition. 1997. 
[10]A. Bolour et al., "The Role of Time in Information Processing: A survey" SIG ART Newsletter- vol 80, Apr 1982, pp 28-48.

[11]Johan van Benthem. "The Logic of Time" publisher- Riedel, 1983.

[12]Clifford, J., and Warren, D. S. "Formal semantics for time in databases." ACM Trans. Database Syst. 8,2 (June 1983), 214254 .

[13]J.D. Ullman "Principles of Database Systems", Computer Sciense Press, 1984.

[14]Jean-Paul Trembley, Paul G. Sorenson "The Theory and Practice of Compiler". 1985.

[15]R. Snodgrass and I. Ahn. "A taxonomy of time in databases" In Proceedings of ACM SIGMOD International Conference on Management of Data, pages 236-246, Austin, TX, May 1985.

[16]R. Snodgrass and I.Ahn. "Temporal Databases" IEEE Computer, $19(9): 35-42$, September 1986 .

[17]R. Snodgrass(ed.) "Research concerning time in databases: Project Summaries" ACM SIGMOD Record, Vol. 15, N. 4:19-39, December 1986. 
[18]McKenzie, E.L. "Bibliography: Temporal Databases." ACM SIGMOD Record,15, No. 4, Dec. 1986, pp40-52.

[19]R. Snodgrass. "The Temporal Query Language Tquel." ACM Transactions Database Systems, Vol 12, N. 2, June 1987.

[20]R. Snodgrass. "Special issue on temporal databases". Data Engineering, 11(4), December 1988.

[21]S. K. Gadia. "A Homogeneous Relational Model and Query Languages for Temporal Databases".ACM Transactions on Database Systems, Vol13, N. 4, Dec 1988, pgs 418-448.

[22]R. Snodgrass. "Temporal Databases: Status and Research Directions". ACM SIGMOD Record, 19(4), December 1990, pages 83-89.

[23]R. T. Snodgrass. "Temporal Databases". In Proceedings of the International Conference on GIS: From Space to Territory, vol639, sep 1992 .

[24] ISO/IEC 9075:1992, "Database Language SQL" (SQL-92).

[25] Michael Soo and Richard Snodgrass. "Overview of MultiCal" November 2, 1993. multical@cs.arizona.edu.

[26]M. Böhlen. "The Temporal Deductive Database System ChronoLog". Phd Thesis, Departament Informatik, ETH Zürick, 1994. 
[27]C.S. Jensen, J.Clifford, R.Elmasri, S.K. Gadia, P.Hayes and S. Jajodia [eds]. "A Consensus Glossary of Temporal Database Concepts". ACM SIGMOD Record, 23(1): 52-64, March 1994.

[28]R. Snodgrass (chair). "TSQL2 Language Specification".September, 1994.

[29]R. Snodgrass (editor). "An Evaluation of TSQL2". Oct 9, 1994.

[30]M. H. Böhlen. "Tiger - Reference Manual", 1995.

[31]M. H. Bohlen. "Temporal Database System Implementations". SIGMOD Record, vol 24, N. 4, Dec 1995.

[32] Marcelo Finger, December 1995 "A logical reconstruction of Temporal Databases".

[33]M. H. Bohlen, R. T. Snodgrass, M. D. Soo. "Coalescing in Temporal Databases". Proceedings of the 22nd VLDB Conference Mumbai(Bombay), India, 1996.

[34]C. S. Jensen, R. Snodgrass. "Semantics of Time-Varying Attributes and their Use for Temporal Database Design". Time Center Technical Report, Jan 29, 1997.

[35]Tansel CLifford Gadia Jajodia Segeu Snodgrass. "Temporal Databases". Theory, Design and implementation. 
[36]Richard T. Snodgrass "The TSQL2 Temporal Query Language". The TSQL2 Language Design Comitte.

[37]. Carlo Zaniolo, Stefano Ceri, Christos Faloutsos, R. T. Snodgrass, V.S. Subrahmanian, Roberto Zicari. "Advanced Database Systems". 1997. 
ANEXOS 


\section{ANEXO A. TESTES REALIZADOS SOBRE A CAMADA TEMPORAL}

Neste Anexo são apresentados testes realizados sobre a Camada Temporal. Estes, foram retirados de um conjunto de testes, criados pelo próprio comitê que definiu a TSQL2, para avaliar a facilidade de se gerar consultas temporais [29]. Apesar desse conjunto de testes não ter sido aplicados a nenhum sistema de Banco de Dados Temporal, os autores apresentam a resposta esperada para cada um deles.

Para cada um dos testes, são apresentados a resposta dada pelo comitê, a resposta da Camada e comentários sobre os resultados. As tabelas utilizadas para consulta são especificadas em II.3. A numeração dada aos testes coincide com a numeração do teste no artigo [29], de forma a facilitar consultas.

Q 1.1.2 - Quem trabalhou continuamente no departamento Book por um período, no mínimo, tão longo quanto Di?

TSQL2:

SELECT SNAPSHOT E2 . name

FROM Emp (Name, DeptName) (Period) E1 E2

WHERE E1. Name $=$ Di AND E1. DeptName = Book AND E2. DeptName $=$ Book AND CAST(VALID (E2) AS INTERVAL DAY) > CAST(VALID(E1) AS INTERVAL DAY)

Resposta esperada no artigo: Tabela vazia. 
Resposta da Camada Temporal: Tabela vazia.

Comentário: A resposta vazia deve-se ao fato de que Di nunca trabalhou no departamento Book.

Q 1.1.3 - Quem trabalhou continuamente no departamento Toy por tanto tempo quanto Di trabalhou no mesmo departamento?

TSQL2:

SELECT SNAPSHOT E4. Name

FROM emp (ID, DeptName) (Period) E1, emp (ID, DeptName) (Period) E2, emp (ID, Name) E3, emp(ID, Name) E4

WHERE E1.ID $=$ E3.ID AND E2.ID = E4.ID AND E3. Name = 'Di' AND E1. DeptName $=$ 'Toy' ANDE2. DeptName $=$ 'Toy' AND

CAST(VALID(E2) AS INTERVAL DAY) > CAST(VALID(E1) AS INTERVAL DAY)

Resposta esperada no artigo: Tabela vazia.

Resposta da Camada Temporal: Tabela vazia.

Comentário: Di trabalhou por muito mais tempo do que Ed no departamento Toy.

Q 1.1.4 - Quem trabalhou continuamente em um departamento por mais tempo que seu gerente trabalhou no departamento?

TSQL2: 
SELECT SNAPSHOT E3. name

FROM Dept(Name, MgrId) D1, Emp(ID) EM, Emp (ID, DeptName) (Period) E2, Emp (ID, Name, DeptName) E3

WHERE E2.ID $=$ E3. ID AND E2. DeptName $=$ E3. DeptName AND

D1.MgrId $=$ EM. ID AND D1. Name = E2. DeptName AND

CAST(VALID (E2) AS INTERVAL DAY) > CAST(VALID(EM) AS

INTERVAL DAY) AND VALID(E2) OVERLAPS VALID(EM)

Resposta esperada no artigo: Tabela vazia.

Resposta da Camada Temporal: Tabela vazia.

Comentário: Nesta consulta está-se comparando a duração de um intervalo com a duração de um elemento temporal, dado que um é especificado como 'continuamente' e o outro não.

Q 1.1.6 - Quem trabalhou para um gerente em um departamento por um período tão longo quanto o gerente gerenciou o departamento?

TSQL2:

SELECT SNAPSHOT E2. Name

FROM Emp(ID, DeptName) E, Dept (Name, MgrID) (PERIOD) D, Emp (Name, ID) E2

WHERE E.DeptName = D.Name AND VALID(E) CONTAINS vaLid(D) AND $E 2 \cdot I D=E \cdot I D$ 
Resposta esperada no artigo: $\{($ 'Ed',('Edward'),('Di') $\}$

Resposta da Camada Temporal: $\{($ 'Ed',('Edward'),('Di') $\}$

Comentário: O particionamento da tabela DEPT em períodos maximais não parece ter muito sentido, já que a consulta, em nenhum momento, pede o intervalo contínuo que o gerente gerenciou o departamento. Foi feita a mesma consulta sem o PERIOD e o resultado obtido foi o mesmo. Isto porque todo gerente é um funcionário, e portanto ele "se gerenciou" por tanto tempo quanto ele foi gerente, fazendo parte, consequentemente, da resposta.

Q 1.3.3 - Quais gerentes gerenciaram quais departamentos por mais tempo do que Di gerenciou o departamento Toy?

TSQL2:

SELECT SNAPSHOT E2.Name, D2.Name

FROM Emp (ID, Name) E, Emp(ID, Name) E2, Dept (Name,MgrId) D, Dept (Name,MgrId) D2

WHERE D.MgrId = E.Id AND E.Name = 'Di' AND D.Name = 'Toy' AND D2.MgrID = E2.Id AND CAST (VALID(D2) AS INTERVAL DAY) $>$ CAST (VALID (D) AS INTERVAL DAY)

Resposta esperada no artigo: Tabela vazia.

Resposta da Camada Temporal: Tabela vazia.

\section{Comentário: -}


Q 2.1.2 - Encontre os períodos de trabalho das pessoas que tiveram um salário igual a 40, por mais tempo do que DI.

\section{TSQL2:}

SELECT VALID (E1)

FROM emp(id, salary) E1, emp (id, salary) E2

WHERE E1.Salary $=40$ AND E2.SAlary $=40$ AND E2.id $=$ 'DI' AND CAST(VALID(E1) AS INTERVAL DAY) > CAST(VALID(E2) AS INTERVAL DAY)

Resposta esperada no artigo: $\{(1 / 2 / 1982-31 / 1 / 1987),(1 / 4 / 1987-27 / 4 / 1998)\}$

Resposta da Camada Temporal: $\{(1 / 2 / 1985$ - 31/1/1987), (1/4/1987 - 27/4/1998) $\}$

Comentário: - A única diferença na resposta é quanto ao ano da primeira data do primeiro período. Como o ano de 1982 não faz parte de nenhuma tupla da tabela EMP com salário 40, supõe-se que o erro foi apenas gráfico.

Q 2.1.5 - Encontrar os períodos trabalhados por pessoas que ficaram empregadas por menos tempo do que DI.

TSQL2:

SELECT valid(E1)

FROM Emp (Id) E1, Emp (id) E2 
WHERE E2.Id = 'DI' AND CAST (VALID(E1) AS INTERVAL DAY) < CAST (VALID (E2) AS INTERVAL DAY)

Resposta esperada no artigo: $\{(1 / 2 / 1982-31 / 1 / 1987),(1 / 4 / 1987-27 / 04 / 1998)\}$

Resposta da Camada Temporal: $\{(1 / 2 / 1982$ - 31/1/1987), (1/4/1987 - 27/4/1998) $\}$

Comentário: -

Q 2.9.6 - Quando, um empregado chamado Edward, esteve apto a dirigir ?

\section{TSQL2:}

SELECT valid(E1)

FROM Emp (ID, Name) E, Skills (EmpID, Skill) (PERIOD) E1

WHERE E.Name = 'Edward' AND E.ID = E1.EmpID AND E1.Skill $=$ 'Driving'

Resposta esperada no artigo: $\{(1 / 1 / 1982-1 / 5 / 1982),(1 / 6 / 1984-31 / 5 / 1988)\}$

Resposta da Camada Temporal: $\{(1 / 6 / 1984-31 / 5 / 1988)\}$

Comentário: Para que a Camada dê o resultado esperado pelo artigo, seria necessário acrescentar a palavra SNAPSHOT, tornando a consulta estática. A seguir explica-se como ocorre o processamento realizado pela Camada Temporal. A tabela EMP é projetada sobre as colunas ID e Name resultando em E; da mesma forma, SKILLS é projetada sobre as colunas EmpID e Skil1, e é particionada em períodos maximais, resultando em E1. Faz-se o produto cartesiano e a seleção, resultando na seguinte tabela intermediária: 


\begin{tabular}{|c|c|l|l|l|l|}
\hline VALID_E1 & VALID_E & E_NAME & E_ID & E1_SKILL & E1_EMPID \\
\hline $1 / 1 / 1982-1 / 5 / 1982$ & $1 / 1 / 1988-27 / 4 / 1998$ & Edward & ED & Driving & ED \\
\hline $1 / 6 / 1984-31 / 5 / 1988$ & $1 / 1 / 1988-27 / 4 / 1998$ & Edward & ED & Driving & ED \\
\hline
\end{tabular}

Como vê-se, se a consulta fosse estática, bastaria fazer a projeção estática sobre VALID_E1, obtendo-se o resultado esperado no artigo. Como a consulta é dinâmica, é preciso fazer a projeção dinâmica, em que só serão consideradas tuplas em que a intersecção entre VALID_E1 e VALID_E seja não NULA. Como, para a primeira tupla, isso não acontece, ela é eliminada do resultado, constando apenas a segunda.

Foi testada a mesma consulta com a utilização de SNAPSHOT e o resultado obtido foi o esperado pelo artigo.

Q 3.2.1 - Quando o orçamento do departamento Toy foi constante e maior do que $\$ 175$ por mais de 365 dias?

TSQL2:

SELECT d1. budget

FROM Dept (Name, Budget) (PERIOD) d1

WHERE d1. Name $=$ 'Toy' AND d1. budget $>175$ AND

CAST(VALID (d1) AS INTERVAL DAY ) > 365

Resposta esperada no artigo: $\{(200 \mid 1 / 8 / 198431 / 12 / 1986)\}$

Resposta da Camada Temporal: $\{(200$ | 1/8/1984 31/12/1986) $\}$

\section{Comentário: -}




\section{ANEXO B. FRAGMENTO SELECIONADO DA TSQL2}

Neste Anexo, encontra-se parte do grafo da TSQL2. As extensões criadas sobre a SQL92 [24] estão em negrito e os fragmentos implementados neste projeto estão limitados por um retângulo tracejado.

A forma de apresentação deste grafo é inédita, pois no livro da TSQL2 [36] constam apenas as regras adicionadas à norma SQL-92 [24].

O grafo a seguir foi obtido a partir da junção da cópia manual da SQL-92 [24] e das definições apresentadas no livro da TSQL2. O procedimento de cópia do grafo foi necessário devido ao fato da norma SQL-92 [24] não estar disponível gratuitamente para cópia eletrônica ao público interessado. 
Query specificatior

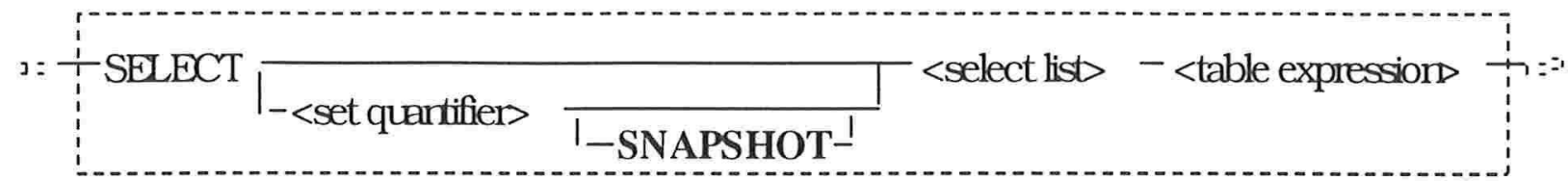

Set quantifier

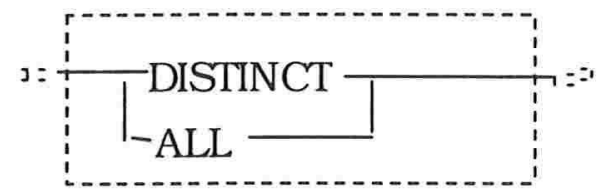

Select list

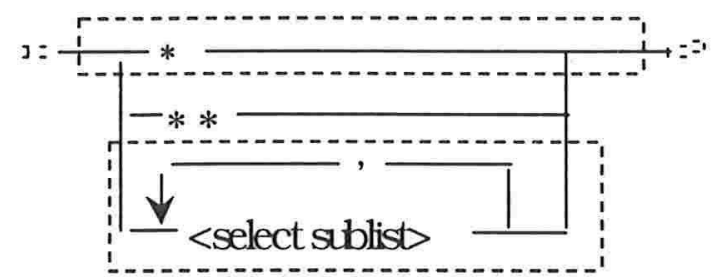

Select sublist

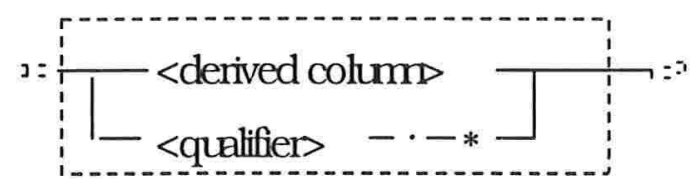

Qualifier

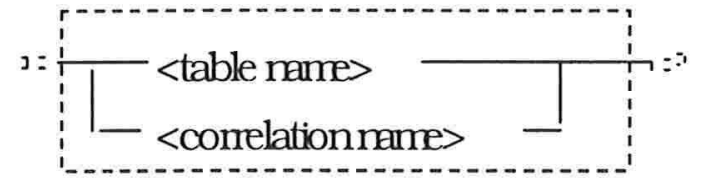

Denived columr.

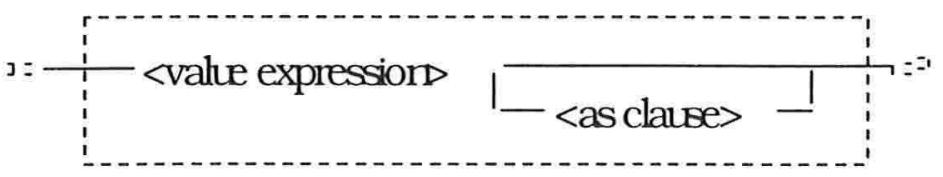




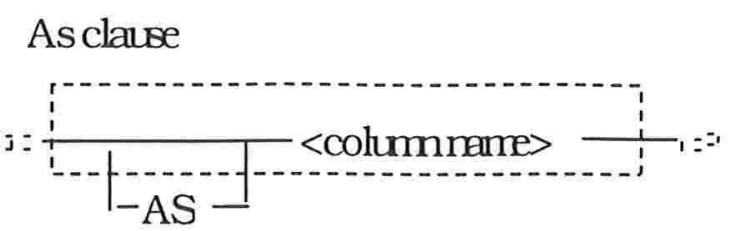

Vahe expressior.

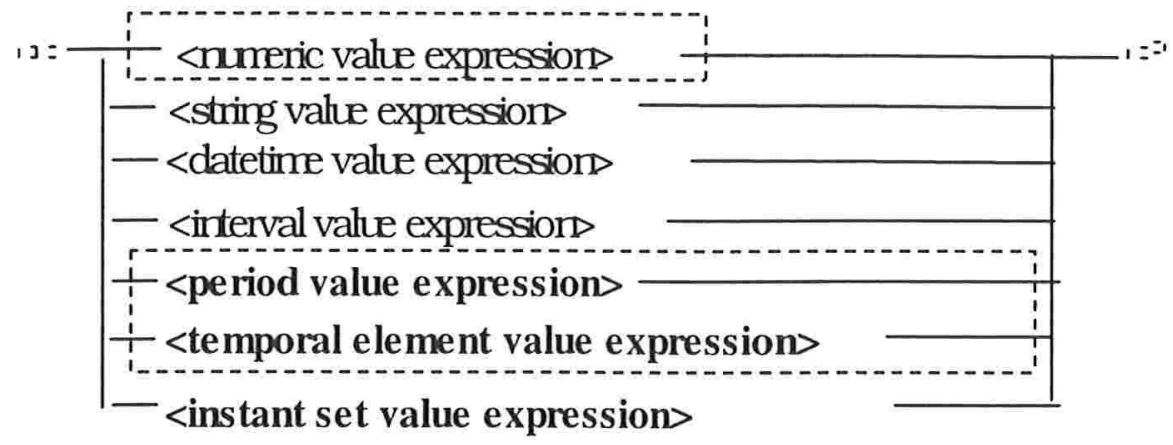

Numeric value expressior.

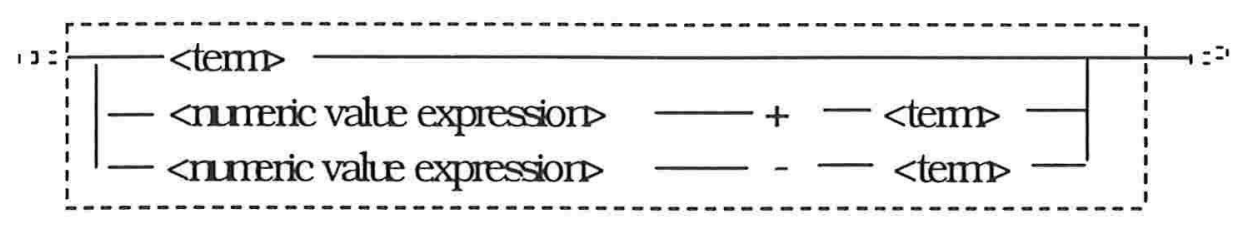

Temr

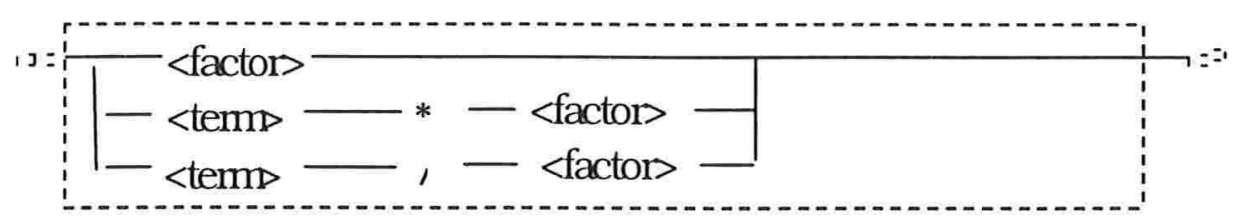

Factor

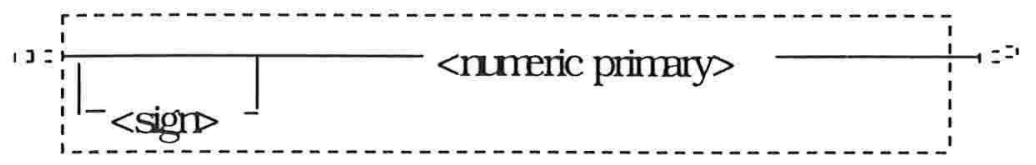


Numeric Primary

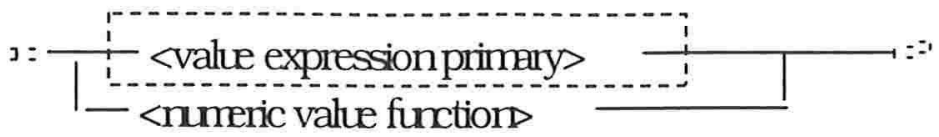

Vahe expression primary

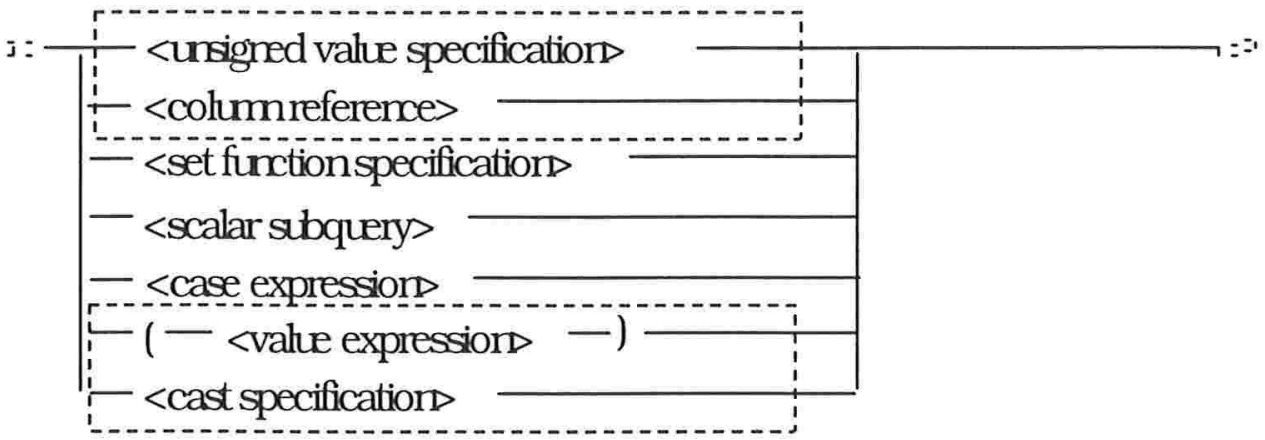

Unsigned value specificatior.

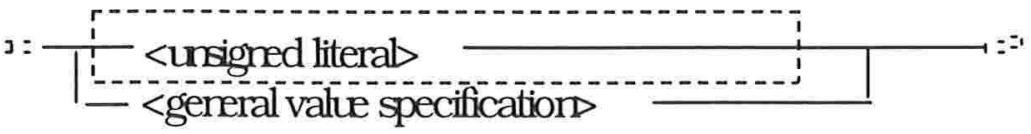

Unsigned literal

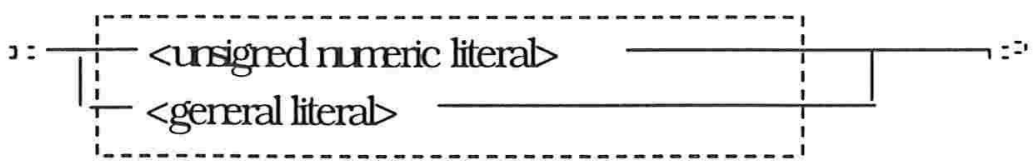

General literal

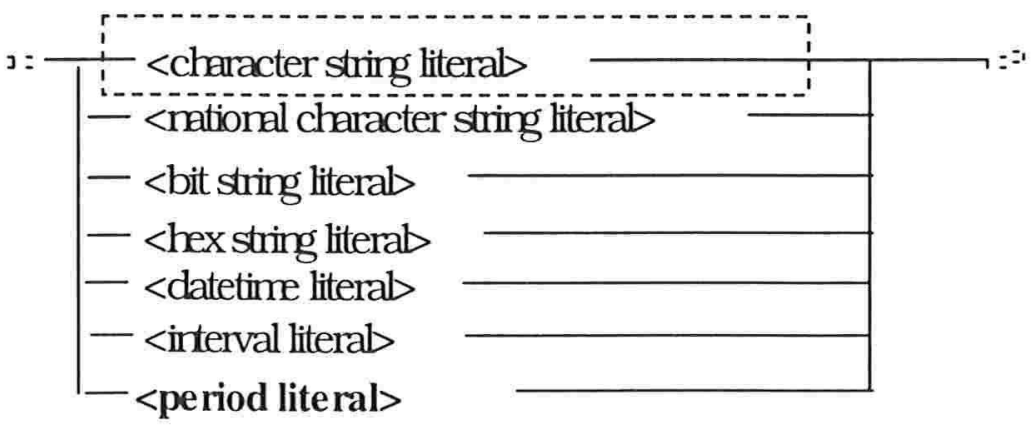


Columnreference

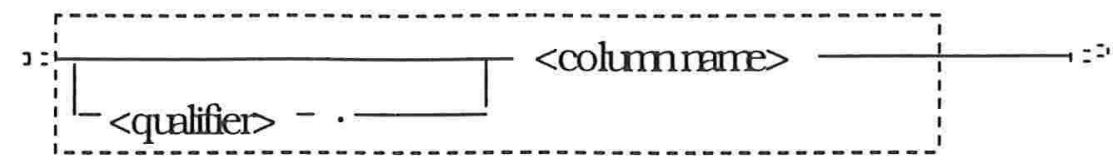

Cast specificatior.

$\mathrm{s}=\frac{1}{\mathrm{~T}} \mathrm{CAST}-(-<$ cast operand $-\mathrm{AS}-<$ cast tanget -$)-{ }_{1}=$

Cast operand

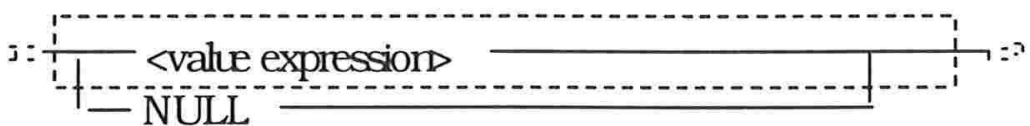

Cast target

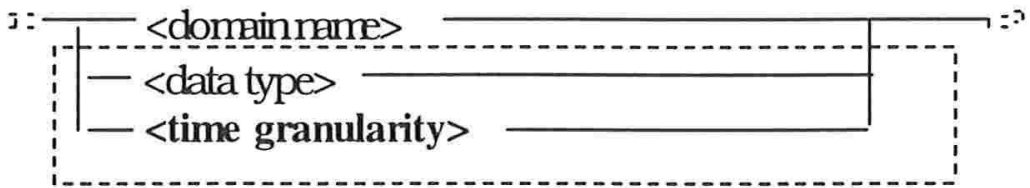

Period value expression

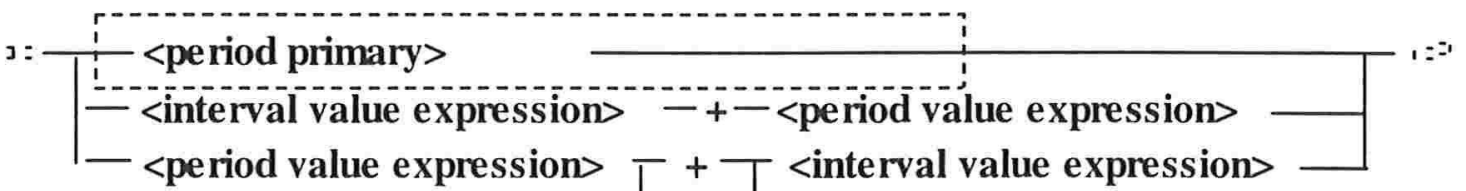

Period primary

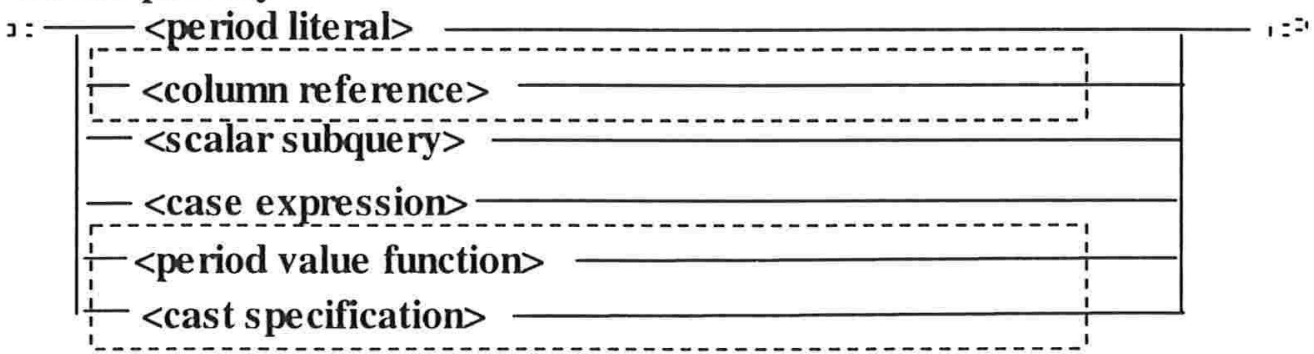


Period value function

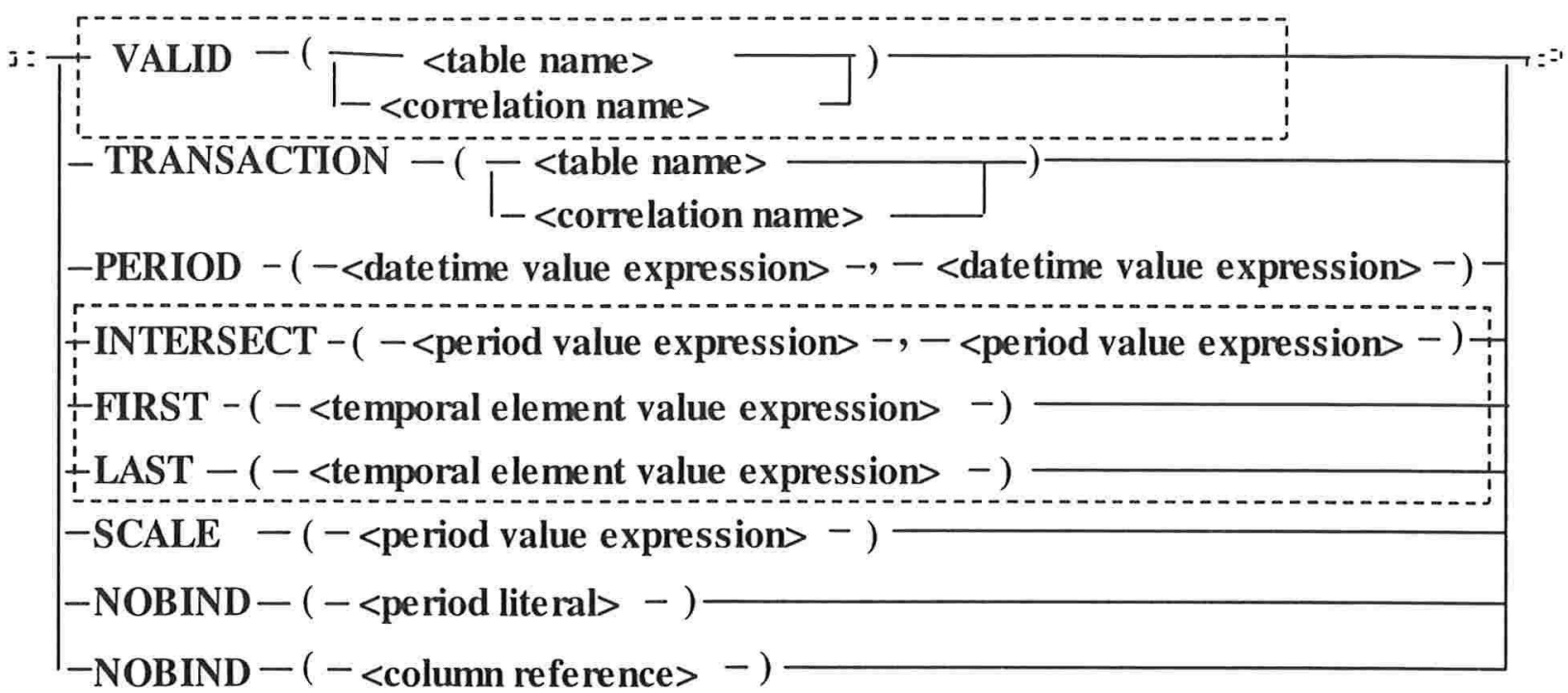

Temporal element value expression

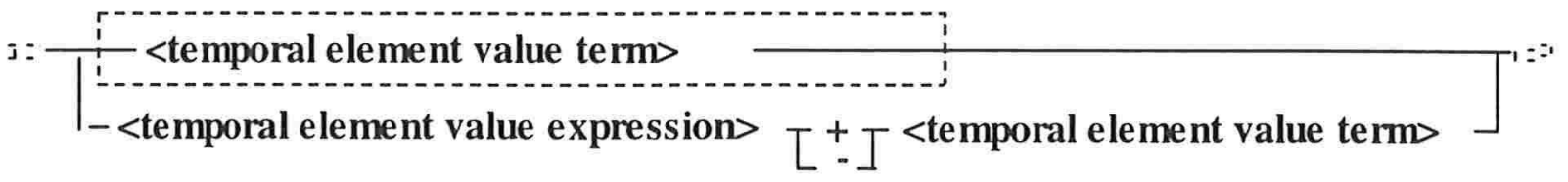

Temporal element value term

I $=\frac{r}{1}<$ temporal element value factor $>$

Temporal element value factor

$j: \frac{{ }_{1}}{1}<$ temporal element value primary $>$,

Temporal element value primary

$\Xi=\frac{r}{1}<$ temporal element value function $>$ 
Temporal element value function

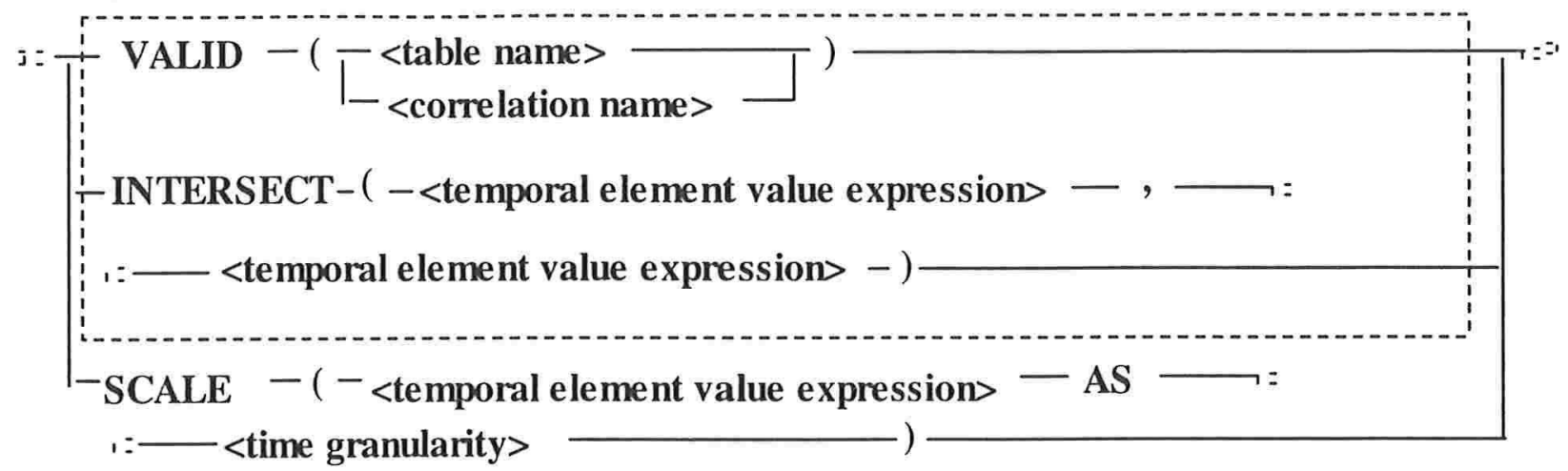

Table expression
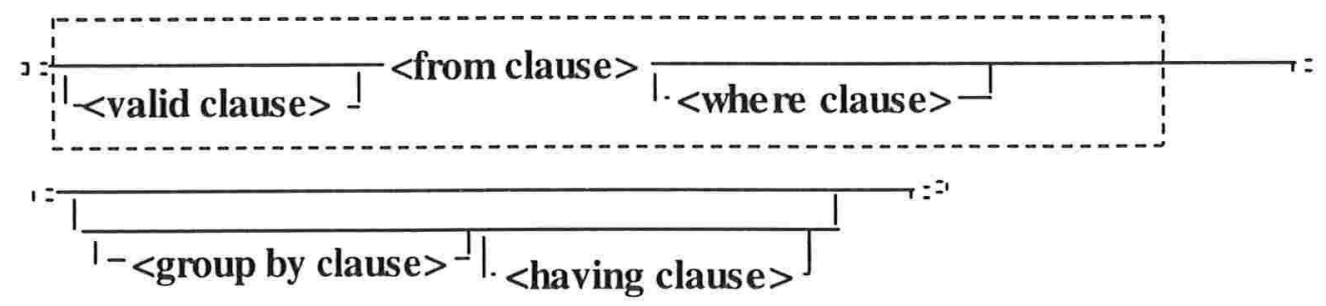

\section{Valid Clause}

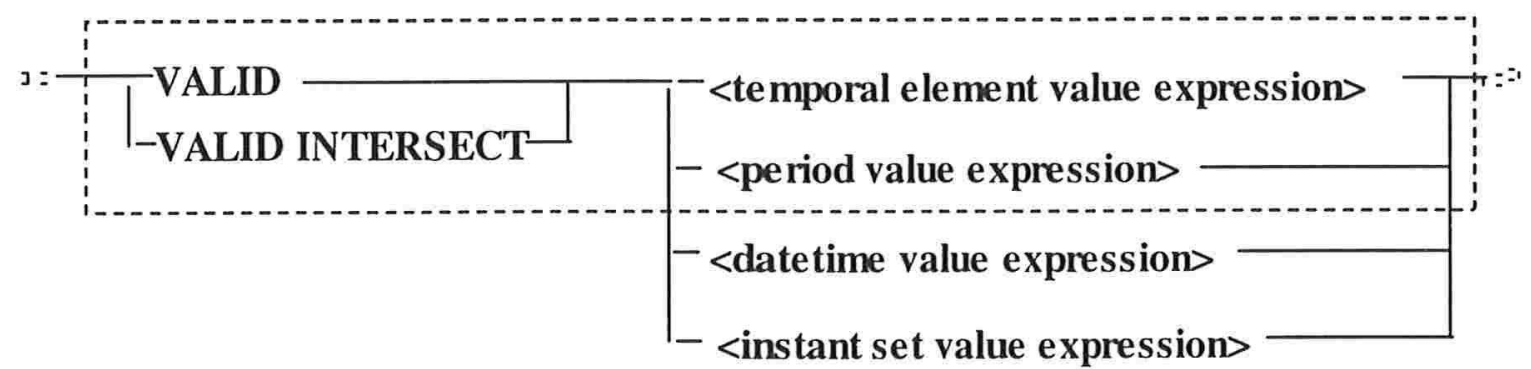

From clause

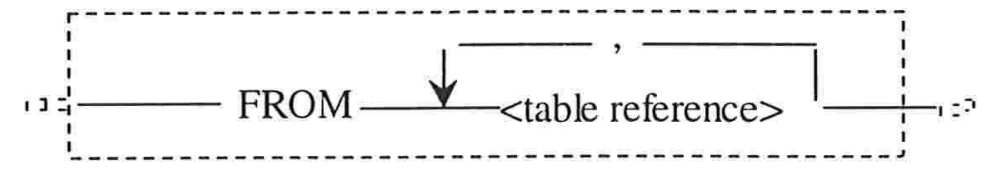


Table reference

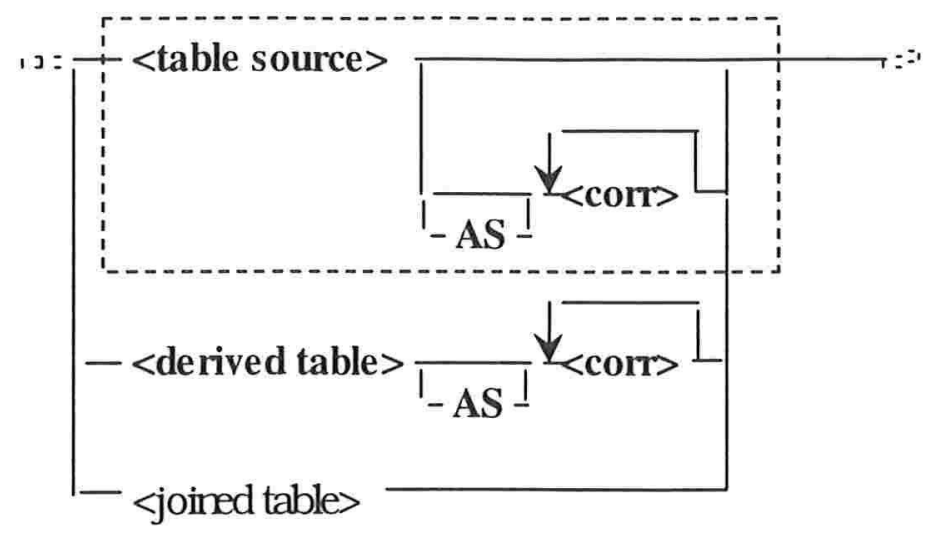

\section{Corr}

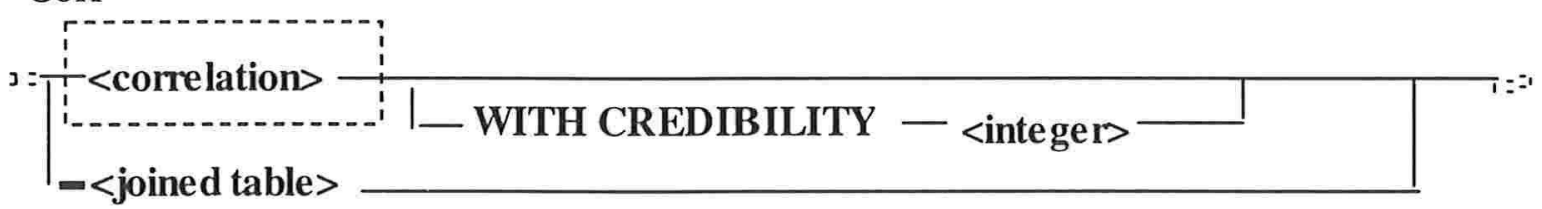

\section{Correlation}

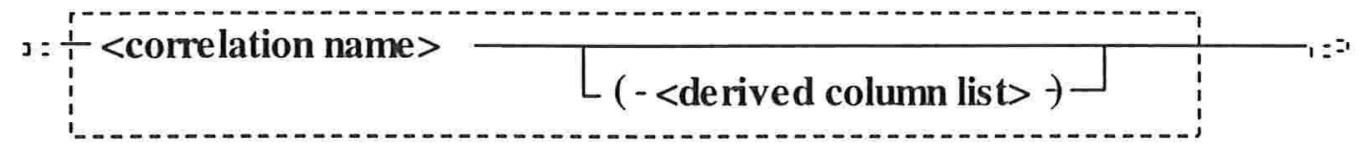

Table source

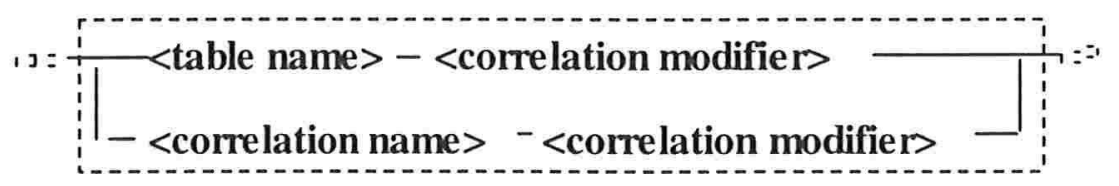

Correlation modifier

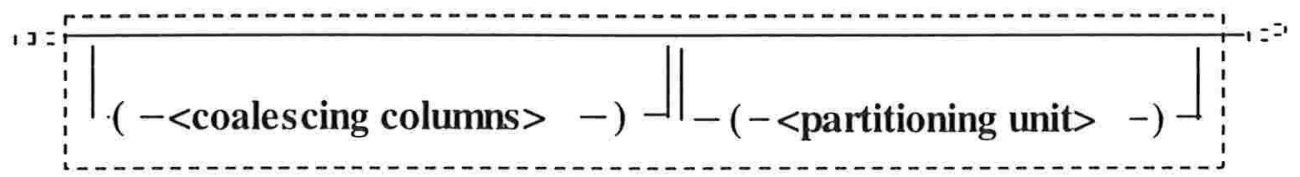

Coalescing columns

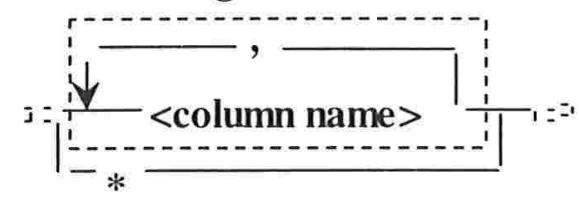

Partitioning unit

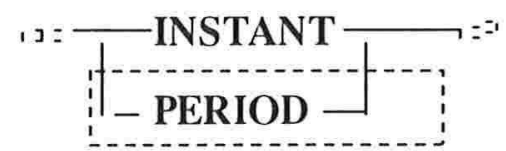


Where clause

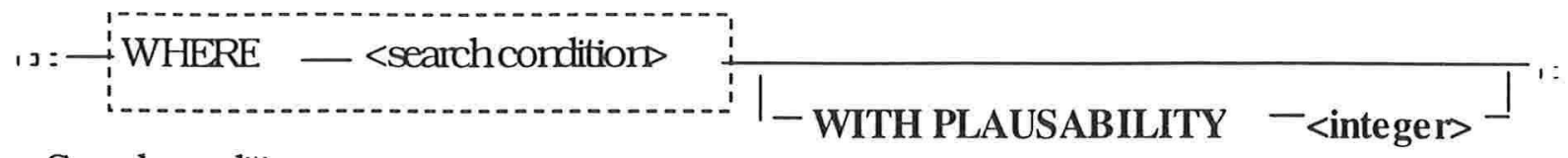

Search conditior.

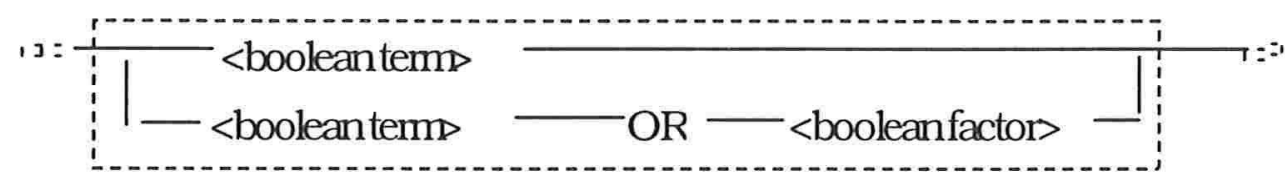

Booleantem

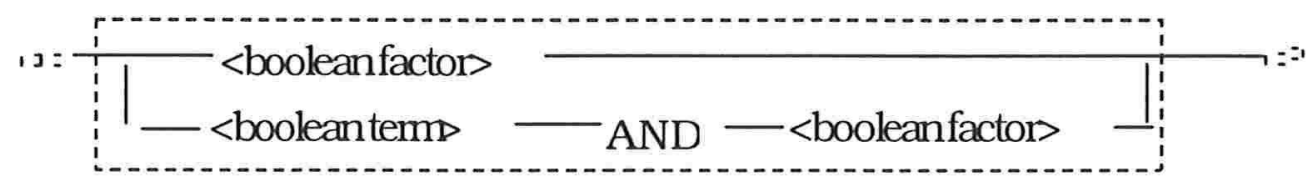

Booleanfactor

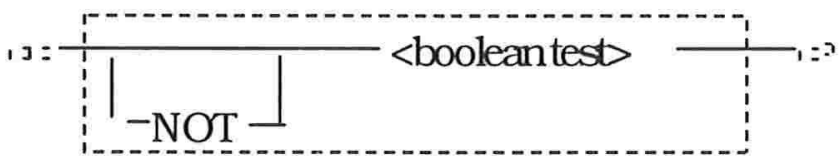

Booleantest

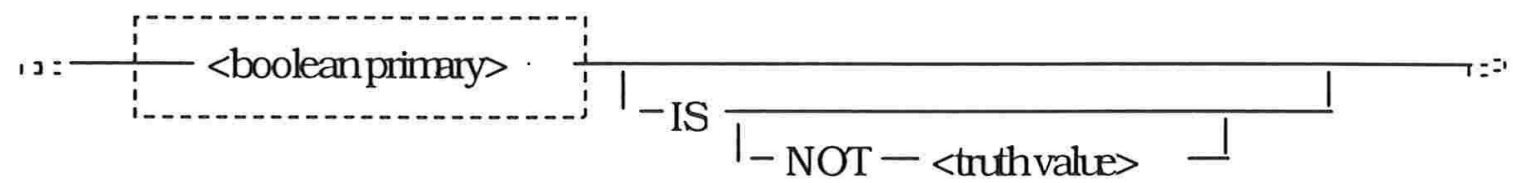

Boolean primary

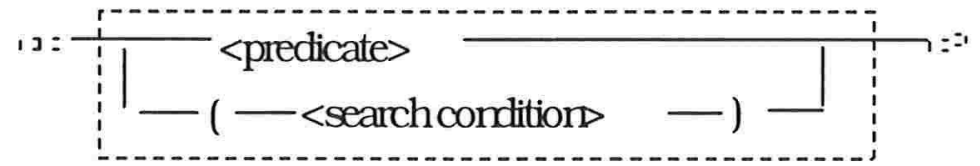


Predicate

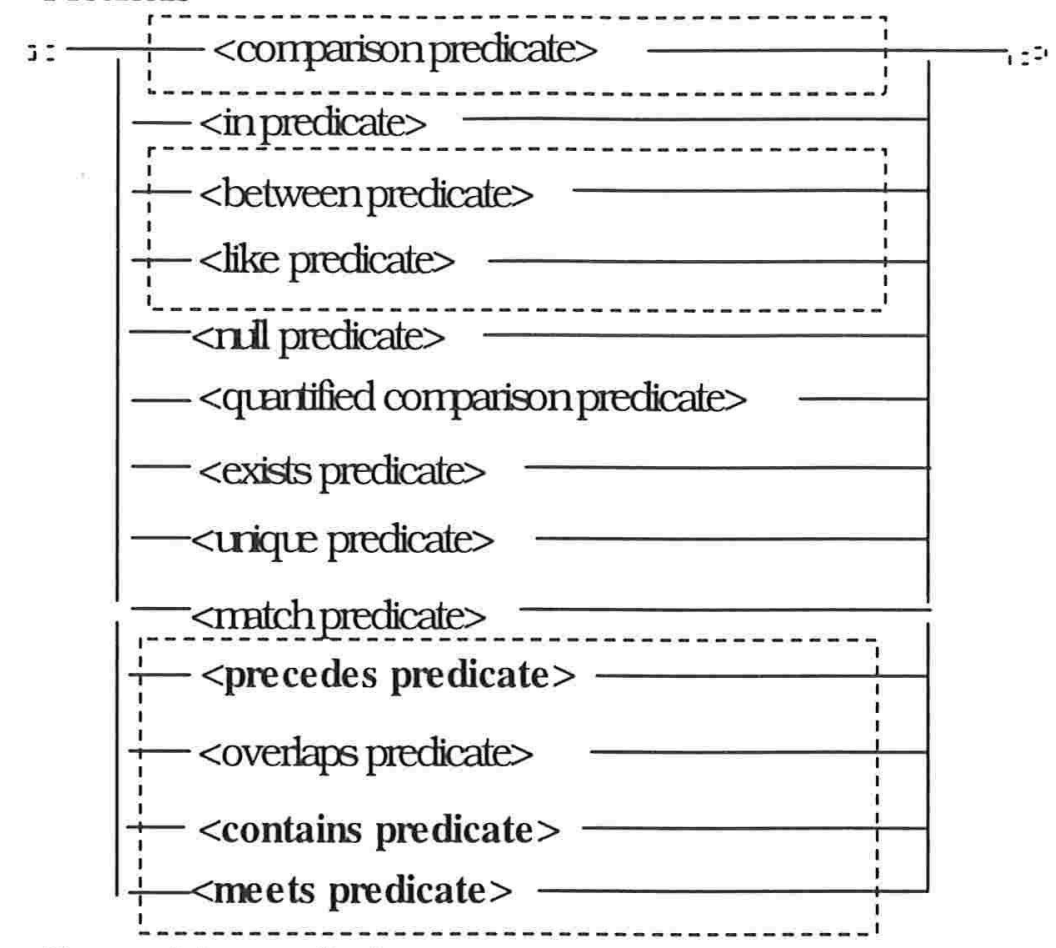

Comparisionpredicate

$\mathrm{s}=\frac{1}{1}<$ row value constuctor $>-<$ comp op $>-<$ row vahe constructor $>$

Comp op

$-!=-$
$-<-$
$->-$
$-<=\square$ 


\section{Row value constructor}

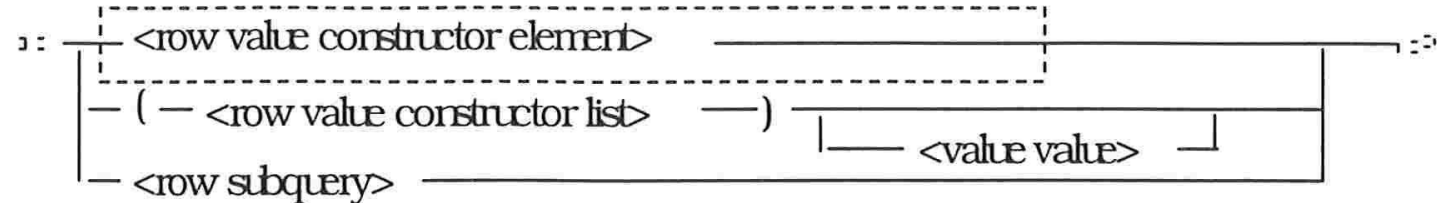

Row value constructor element

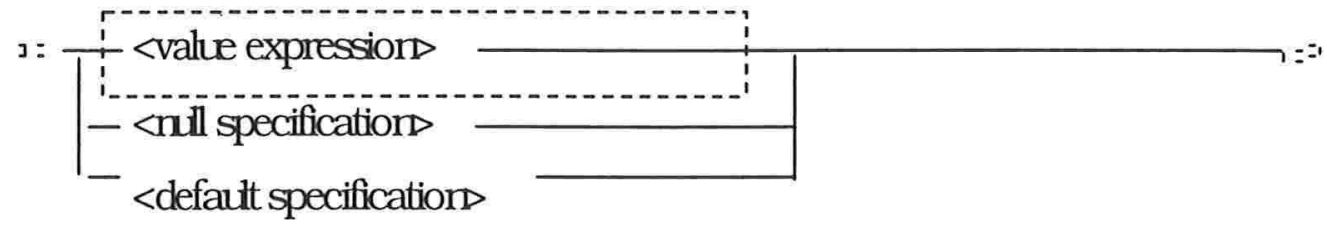

Overlaps predicate

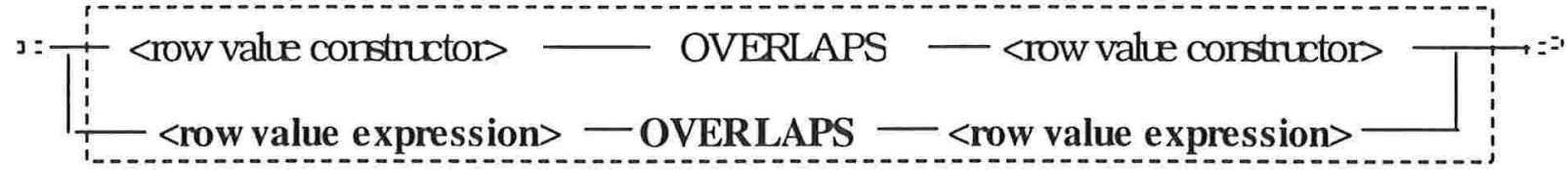

Precedes predicate

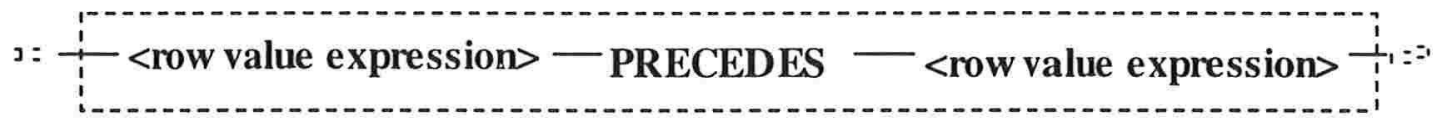

Meets predicate

$\mathrm{s}: \frac{1}{1}<$ row value expression $>$ MEETS $-<$ row value expression $>-$

Contains predicate

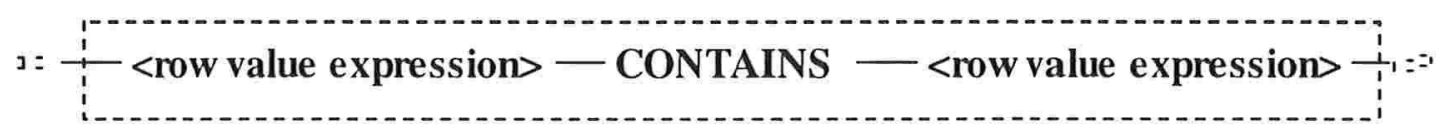


Table definitior

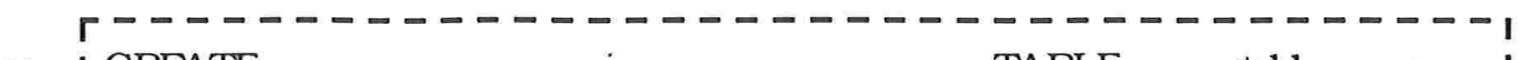

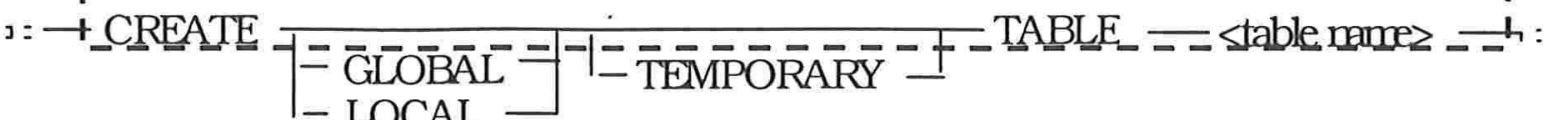

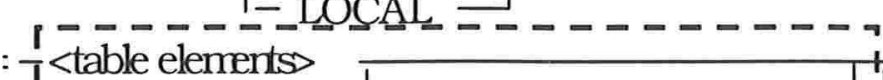

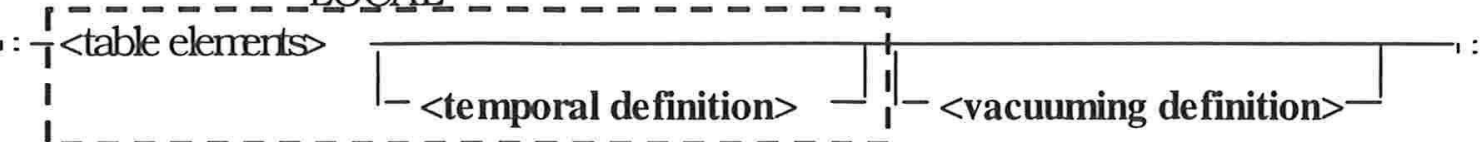

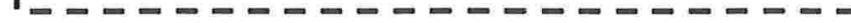

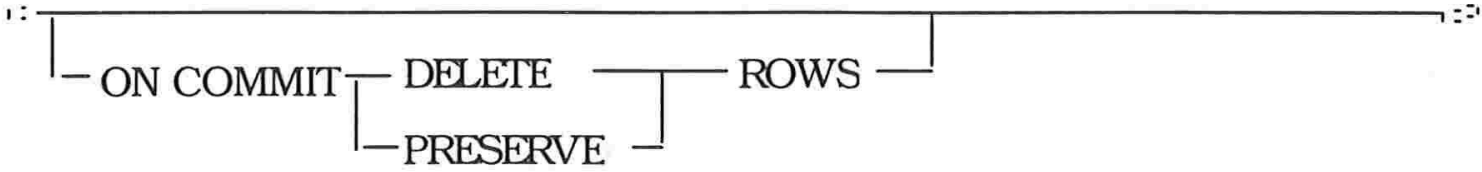

Temporal definition

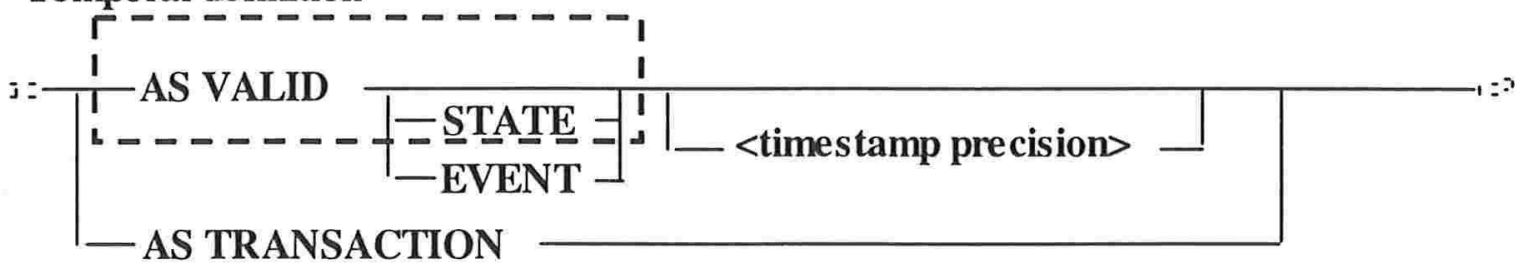

Vacuuming definition

$\mathrm{J}:-$ VACUUM $-<$ datetime value expression $>$

Insert columns and source

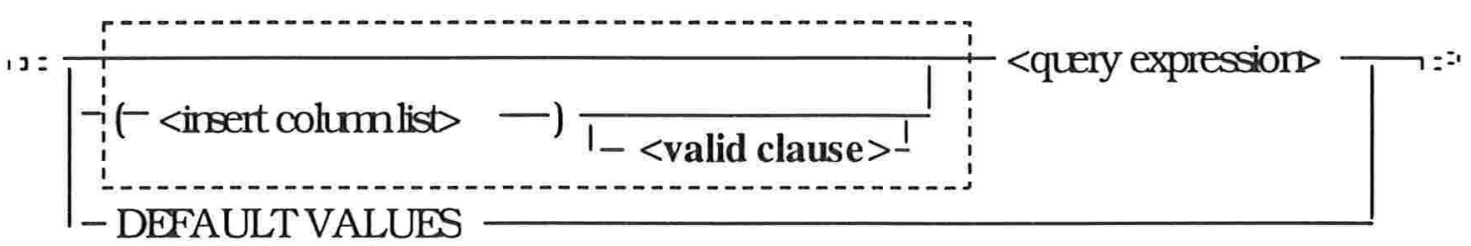

